Adaptação de stream de vídeo em veículos aéreos não tripulados

Thiago Henrique Martinelli 


\section{Adaptação de stream de vídeo em veículos aéreos não tripulados}

\section{Thiago Henrique Martinelli}

Orientador: Prof. Dr. Edson dos Santos Moreira

Dissertação apresentada ao Instituto de Ciências Matemáticas e de Computação - ICMC-USP, como parte dos requisitos para obtenção do título de Mestre em Ciências - Ciências de Computação e Matemática Computacional. EXEMPLAR DE DEFESA 
Ficha catalográfica elaborada pela Biblioteca Prof. Achille Bassi e Seção Técnica de Informática, ICMC/USP, com os dados fornecidos pelo(a) autor(a)

Henrique Martinelli, Thiago
Adaptação de stream de video em veículos aéreos não
tripulados / Thiago Henrique Martinelli; orientador
Edson dos Santos Moreira. -- São Carlos, 2012.
96 p.
Dissertação (Mestrado - Programa de Pós-Graduação en
Ciências de Computação e Matemática Computacional) --
Instituto de Ciências Matemáticas e de Computação,
Universidade de São Paulo, 2012.
1. adaptação de vídeo. 2. veículo aéreo não
tripulado. 3. vant. 4. uav. 5. h.264/avc. I. dos
Santos Moreira, Edson, orient. II. Título.




\section{Agradecimentos}

Agradeço, com muito amor, a meus pais que sempre me instruíram no caminho da honestidade, do respeito e da resiliência. Que sempre foram a voz de apoio na necessidade e o braço forte na dificuldade. E que me ensinaram o valor da luta e do trabalho.

Agradeço os meus amigos de trabalho que tornaram essa obra possível, que me instruíram no caminho das pedras e que sempre me dedicaram gratuitamente seu tempo me ensinando. Agradeço a vocês: Rigolin, Sadao, Tim e Mário.

Agradeço também ao meu orientador Edson dos Santos Moreira, pelas dicas e conselhos, pela orientação e experiência, que me ajudaram a finalizar este trabalho.

Agradeço a todos que me auxiliaram mesmo sem que eu soubesse e, por não saber, não posso citar seu nomes aqui. 


\section{Abstract}

Unmanned Aerial Vehicles (UAVs) are being increasingly used in several countries, both in the military and civilian areas. In this study we consider an UAV equipped with a camera, capturing video for a real-time transmission to a ground-base using wireless network. The problem is that it's not possible to ensure a continuous transmission rate, with stable bandwidth. That occurs due to factors like the speed of the aircraft, irregularities of terrain, or the weather (as storms, heat and fog, for instance, can interfere with RF transmission). Finally, the movements that the UAV can perform in flight (Roll, pitch and yaw) can impair link availability. Thus, it is necessary to perform an adaptation of video according to the available bandwidth. When the link quality is degraded, a reduction in the resolution of the video must be performed, avoiding interruption of the transmission. Additionally, adaptation must also provide that all the available bandwidth is used, avoiding sending the video with lower quality that would be possible for a given value bandwidth. In this work we propose a system which can vary the total amount of data being transmitted, by adjusting the compression parameters of the video. We manage to produce a system which uses the range from $8 \mathrm{Mbps}$ up to zero. We use the H.264/AVC Codec, with scalable video coding. 


\section{Resumo}

Veículos Aéreos não tripulados (VANTs) vêm sendo cada vez mais utilizados em diversos países, tanto na área militar como na civil. O cenário considerado nesse estudo é o de um VANT realizando captura de vídeo em tempo real, transmitindo-o a uma base terrestre por meio de rede sem fio. O problema consiste no fato de não ser possível garantir uma taxa de transmissão contínua, com banda estável. Isso ocorre devido a fatores como a velocidade da aeronave (da ordem centenas de $\mathrm{km} / \mathrm{h}$ ), irregularidades de terreno (impedindo a linha de visada do enlace de transmissão), ou do clima, como tempestades que podem interferir na transmissão da RF. Por fim, os movimentos que o VANT pode realizar no vôo (Rolagem, Arfagem ou Guinada) podem prejudicar a disponibilidade do link. Dessa forma, é necessário que seja realizada adaptação de vídeo de acordo com a banda disponivel. Assim, quando a qualidade do enlace for degradada, deverá ser realizada uma redução no tamanho do vídeo, evitando a interrupção na transmissão. Por outro lado, a adaptação também deverá fazer com que a banda disponível seja utilizada, evitando o envio de vídeos com qualidade inferior à que seria possivel para determinado valor de largura de banda. Nesse trabalho será considerada a faixa de valores de largura de banda de $8 \mathrm{Mbps}$ até zero. Para realizar a adaptação será utilizado o padrão H.264/AVC com codificação escalável. 


\section{Sumário}

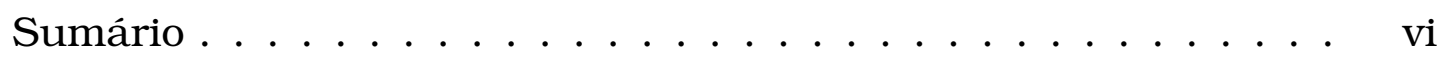

Lista de Figuras . . . . . . . . . . . . . . v viii

Lista de Tabelas . . . . . . . . . . . . . . . . ix

Lista de Abreviaturas . . . . . . . . . . . . . . . xii

1 Introdução 1

1.1 Contextualização . . . . . . . . . . . . . . . 1

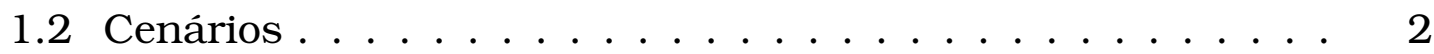

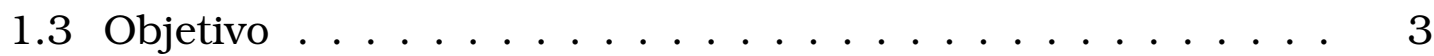

2 Codificação de Vídeo $\quad 9$

2.1 Espaços de Cores . . . . . . . . . . . . . . . . 9

2.1 .1 Espaço RGB . . . . . . . . . . . . . . . 10

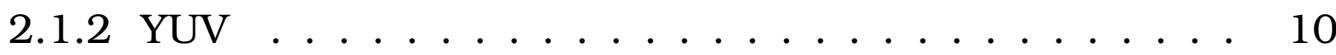

2.2 Técnicas de compressão de vídeo . . . . . . . . . . . . . 13

2.2.1 Técnicas de compressão sem perda . . . . . . . . . 13

2.2.2 Técnicas de compressão com perda . . . . . . . . 15

2.2 .3 Predição de Movimento . . . . . . . . . . . . . 17

2.3 Padrões de Codificação de Vídeo . . . . . . . . . . . . . . . 18

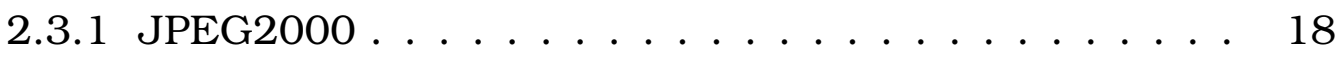


2.3.2 Padrão H.264/AVC . . . . . . . . . . . . . . . . . . 19

2.3.3 Comparação entre H.264/AVC e JPEG 2000 . . . . . . 20

2.3.4 Extensão Escalável do Padrão H.264/AVC . . . . . . . 24

$\begin{array}{lll}3 & \text { VANTS } & 31\end{array}$

3.1 Considerações Iniciais . . . . . . . . . . . . . . . . 31

3.1.1 Classificação de VANTs: . . . . . . . . . . . . . . . 31

3.1 .2 Missões e Tarefas . . . . . . . . . . . . . . . 33

3.1.3 Arquiteturas de Comunicação em VANTs . . . . . . . . 36

4 Desenvolvimento $\quad 39$

4.1 Testes de Compressão de Vídeo . . . . . . . . . . . . . . . . 39

4.1.1 Teste 1: Parâmetro de Quantização . . . . . . . . . . . 42

4.1.2 Teste 2: Variação do Group of Pictures . . . . . . . . . 44

4.1 .3 Teste 3: Resolução Espacial . . . . . . . . . . . . . 45

4.1.4 Teste 4: Combinação de Escalabilidade . . . . . . . . . 48

4.1 .5 Faixas de valores de bits . . . . . . . . . . 50

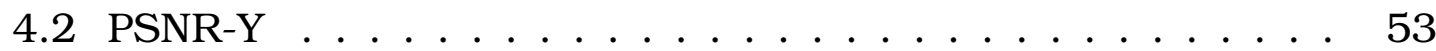

5 Conclusões e trabalhos futuros $\quad 57$

5.1 Considerações iniciais . . . . . . . . . . . . . . . 57

5.2 Considerações quanto à performance em tempo real . . . . . 58

5.3 Trabalhos Futuros . . . . . . . . . . . . . . . 61

A Apêndice A $\quad 69$

B Apêndice B $\quad 75$

B.1 Arquivos de configuração para os experimentos. . . . . . . 75

B.1.1 Teste 1. Parâmetro de quantização. . . . . . . . . . . 75

B.1.2 Teste 2. GOPs. . . . . . . . . . . . . . . . . . . 77

B.1.3 Teste 3. Predição Espacial. . . . . . . . . . . . . . . . . 82

B.1.4 Teste 4. Escalabilidade Combinada. . . . . . . . . . . 91 


\section{Lista de Figuras}

1.1 Vant Arara . . . . . . . . . . . . . . . . 2

1.2 Sistema de Adaptação de Vídeo de um VANT . . . . . . . . 4

1.3 Sequência de processamento do stream de vídeo. . . . . . . . 7

2.1 Relação $4: a: b \ldots \ldots \ldots \ldots 12$

2.2 Relação $4: 2: 2 \ldots \ldots \ldots \ldots$. . . . . . . . . . . . . . 12

2.3 Relação $4: 2: 0 \ldots \ldots \ldots \ldots$. . . . . . . . . . . . . . . 12

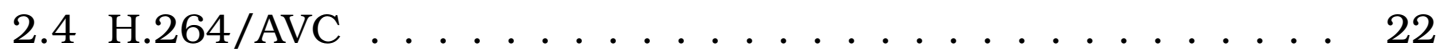

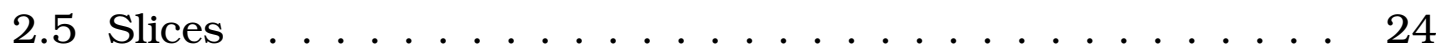

2.6 Três tipos de escalabilidade . . . . . . . . . . . 26

2.7 Escalabilidade Temporal . . . . . . . . . . . . . . 27

2.8 Group of Pictures . . . . . . . . . . . . . . . . 28

2.9 Escalabilidade Espacial . . . . . . . . . . . . . . . . 29

3.1 VANT Predator $\ldots \ldots \ldots \ldots \ldots \ldots \ldots \ldots \ldots$

3.2 VANT Draganflyer-x6 . . . . . . . . . . . . . 32

3.3 Arquiteturas de Comunicação em VANTs . . . . . . . . . . . 37

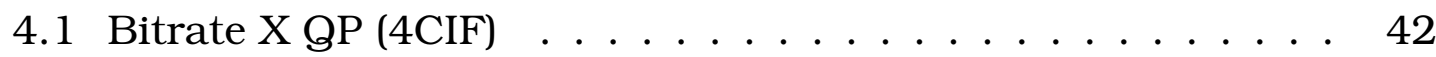

4.2 Bitrate X $\mathrm{QP}(\mathrm{CIF}) \ldots \ldots \ldots \ldots \ldots \ldots$

4.3 Bitrate X $\mathrm{GP}(\mathrm{GCIF}) \ldots \ldots \ldots \ldots$ 
4.4 Bitrate X GOP para vídeo 4CIF a 30 FPS . . . . . . . . . 44

4.5 Bitrate X Resolução Espacial. 4CIF X CIF X QCIF. 30 FPS. . 46

4.6 Bitrate X Resolução Espacial. 4CIF X CIF. 30 FPS. . . . . . . 46

4.7 Bitrate X Resolução Espacial. 4CIF X QCIF. 30 FPS. . . . . . 47

4.8 Bitrate X Resolução Espacial. CIF X QCIF. 30 FPS. . . . . . . 47

4.9 Bitrate X Camada . . . . . . . . . . . . . . . . . . 50

4.10 Bitrate X Framerate. Somente Q-CIF e CIF. . . . . . . . . 51

4.11 Bitrate X Framerate. Gráfico Completo. . . . . . . . . . . . 52

4.12 Bitrate X Framerate. Escala Logaritmica. Somente Q-CIF e

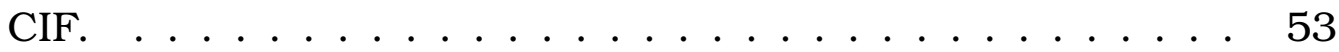

4.13 Bitrate X Framerate. Escala Logarítmica. Gráfico Completo. 54

A. 1 PSNR-Y X Framerate (4CIF, 30 FPS) $\ldots \ldots \ldots \ldots$

A.2 PSNR-Y X Resolução Espacial. 4CIF X CIF X QCIF. . . . . . . 70

A.3 PSNR-Y X Resolução Espacial. 4CIF X CIF. . . . . . . . . . 71

A.4 PSNR-Y X Resolução Espacial. 4CIF X QCIF. . . . . . . . . 71

A.5 PSNR-Y X Resolução Espacial. CIF X QCIF. . . . . . . . . . 72

A.6 PSNR-Y X LQP (4CIF, 30 FPS) $\ldots \ldots \ldots \ldots \ldots \ldots$

A.7 PSNR-Y X LQP (CIF, 30 FPS) $\ldots \ldots \ldots \ldots \ldots \ldots$

A.8 PSNR-Y X LQP (QCIF, 30 FPS) $\ldots \ldots \ldots \ldots \ldots$

A.9 PSNR-Y X Camada. Configuração do teste $4 . \ldots \ldots$. . . . 74 


\section{Lista de Tabelas}

4.1 Camada X Bit-rate(kbit/s) . . . . . . . . . . . 55

4.2 Bitrates suportados (kbit/s) . . . . . . . . . . 55 


\section{Lista de Abreviaturas}

VANT Veículo Aéreo não Tripulado

UAV Unmanned Aerial Vehicle

RPA Remotely Piloted Aircraft

RF Rádio Frequência

SVC Scalable Video Coding

SNR Signal-Noise Ratio

MPEG Moving Picture Experts Group

CGS Coarse Grain Scalability

FGS Fine Grain Scalability

ADM Armas de Destruição em Massa

ISR Inteligência, Monitoramento e Reconhecimento

VLO Very Low Observable

PDA Personal Digital Assistant 
BRSK Binary Phase Shift Keying

QAM Quadrature Amplitude Modulation

GPS Global Positioning System

HD High Definition

DCT Discrete Cosine Transform

GOP Group of Pictures

PSNR Peak Signal-to-Noise Ratio

ITU International Telecommunications Union

ISO International Organization for Standardization

HDTV High Definition Television

DSL Digital Subscriber Line

NAL Network Abstraction Layer

VCL Video Coding Layer

ISDN Integrated Services Digital Network 


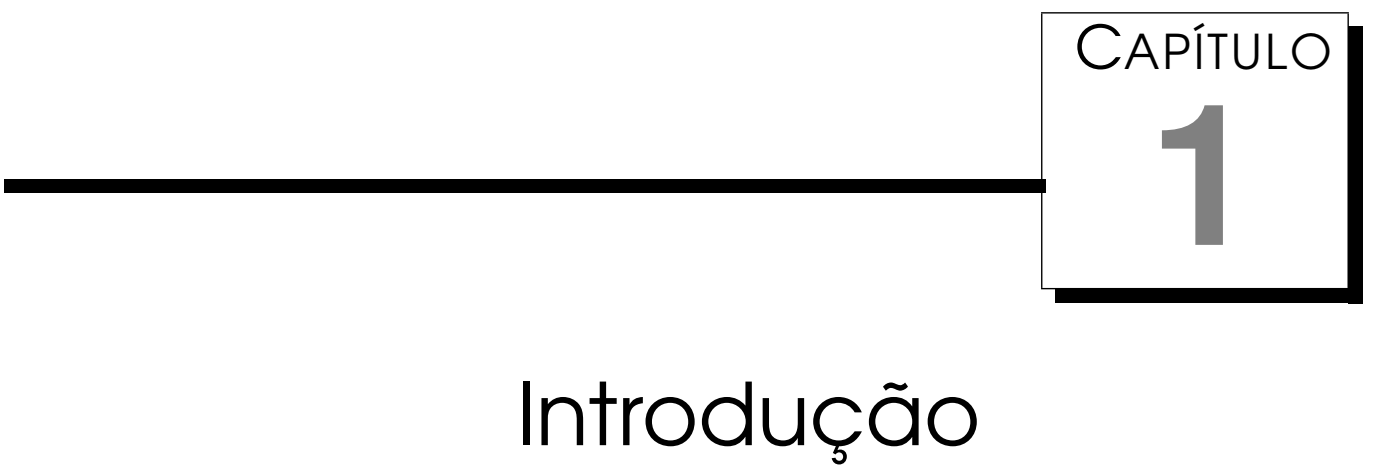

\subsection{Contextualização}

Nos últimos anos tem-se observado um constante acréscimo na utilização de Veículos Aéreos Não Tripulados - VANTs, assim como avanços tecnológicos relativos aos mesmos (Wagner, 2007) . Originalmente projetados para missões militares, esses veículos tiveram sua utilização ampliada também para fins civis. Um bom exemplo disso é seu emprego em aplicações agrícolas, sensoriamento ambiental (Trindade Jr et al., 2004) e monitoramento do trânsito de veículos. No campo militar, VANTs são úteis em operações táticas como monitoramento de fronteiras, coleta de informações de terreno ou de posicionamento de tropas, estabelecimento de comunicação, entre outros. Na agricultura, é possível efetuar a vigilância de propriedades rurais, identificar plantas nocivas e estimar com melhor precisão a produção. A figura 1.1 mostra o vant Arara. 


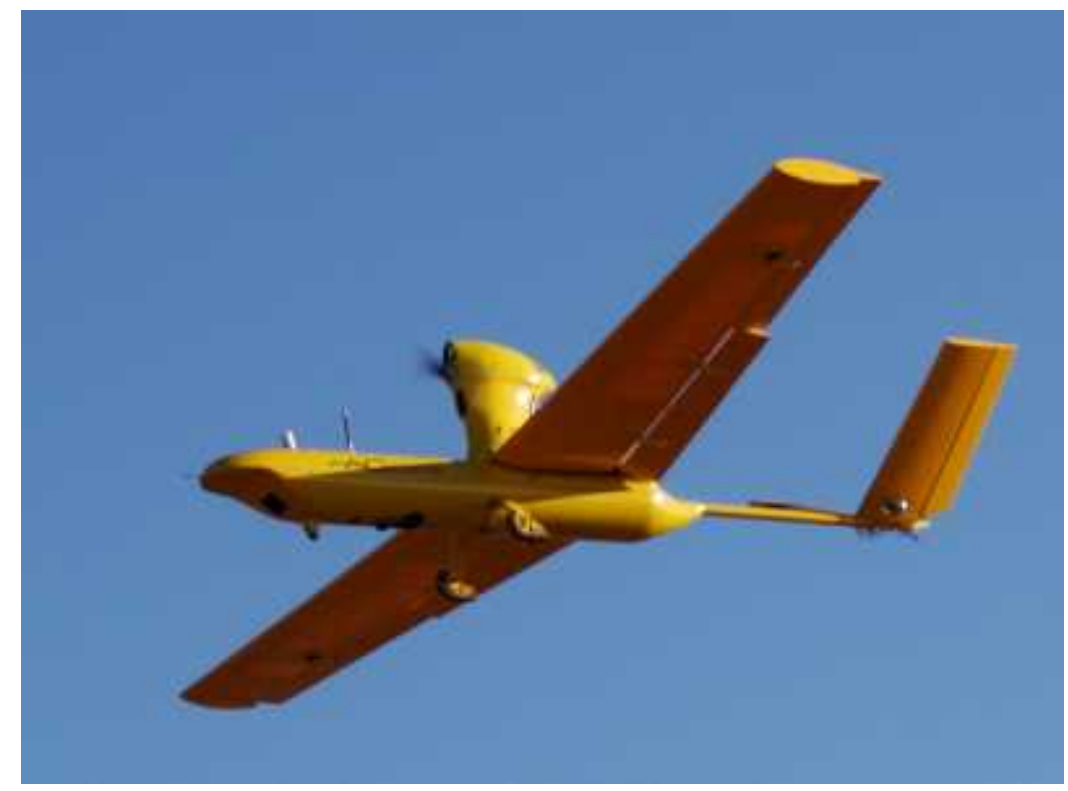

Figura 1.1: Vant Arara

\subsection{Cenários}

O cenário dessa pesquisa apresenta uma aeronave não tripulada realizando captura de vídeo em tempo real, o qual será transmitido a uma base terrestre por meio de uma rede sem fio, utilizando-se link unidirecional. Há requisitos de que o vídeo transmitido não sofra interrupções. Em aplicações críticas o estabelecimento do link de comunicação com a base enfrenta diversos obstáculos. Por exemplo, na área militar nem sempre as tropas se localizam em área adequada à operação da transmissão. Pode haver também interferências no sinal por vários condicionantes ambientais, a possibilidade de escuta inimiga, a identificação da presença dos VANTs por este, irregularidades do terreno, limitação do alcance do veículo, entre outros. Outra questão é quanto ao posicionamento da aeronave. Devido à utilização de antena unidirecional, uma inclinação da aeronave pode fazer com que a linha de comunicação fique obstruída pelo próprio VANT, ocasionando a perda temporária de comunicação. Dessa 
forma não é possível garantir uma taxa de dados para a transmissão de vídeo, ou seja, é implícita ao cenário a flutuação sistemática da largura de banda. Se o valor da banda disponível for menor que o da taxa requerida para transmitir o stream de vídeo, a transmissão será prejudicada, ocorrendo atrasos ou interrupções. Tendo isso em mente, surge a necessidade de uma adaptação dos dados capturados. Comprimindo o vídeo quando a banda disponível for reduzida.

\subsection{Objetivo}

O objetivo do presente trabalho é realizar uma pesquisa que proporcione dados relevantes à construção de um algoritmo de adaptação de vídeo de modo a garantir, para o cenário anteriormente explicitado, a transmissão de vídeo com o mínimo de interrupções. Essa adaptação ocorrerá de acordo com a banda disponível em cada momento, de forma que a taxa de transmissão necessária não ultrapasse a taxa disponível (evitando interrupções), mas que aproveite toda a banda (obtendo a máxima qualidade possivel). A redução do tamanho do stream de vídeo poderá levar a uma perda na qualidade deste, por isso também será realizado o estudo de diferentes métodos de compressão e a verificação da adequação a requisitos mínimos de qualidade.

É importante ressaltar que a presente pesquisa não se restringe a um modelo específico de aeronave, sistema, hardware ou implementação. O objeto VANT, nesse caso, constitui uma abstração de estudo. O objetivo é alimentar o algoritmo de adaptação, que poderá ser implementado em diferentes VANTs e sistemas. Dessa forma, o resultado final poderá ser escalado ou adaptado para diferentes VANTs, necessitando apenas de uma implementação específica.

A figura 1.2 ilustra o sistema de captação e de transmissão de vídeo de um VANT. A presente pesquisa irá concentrar-se principalmente no Módulo de Adaptação de Vídeo. 


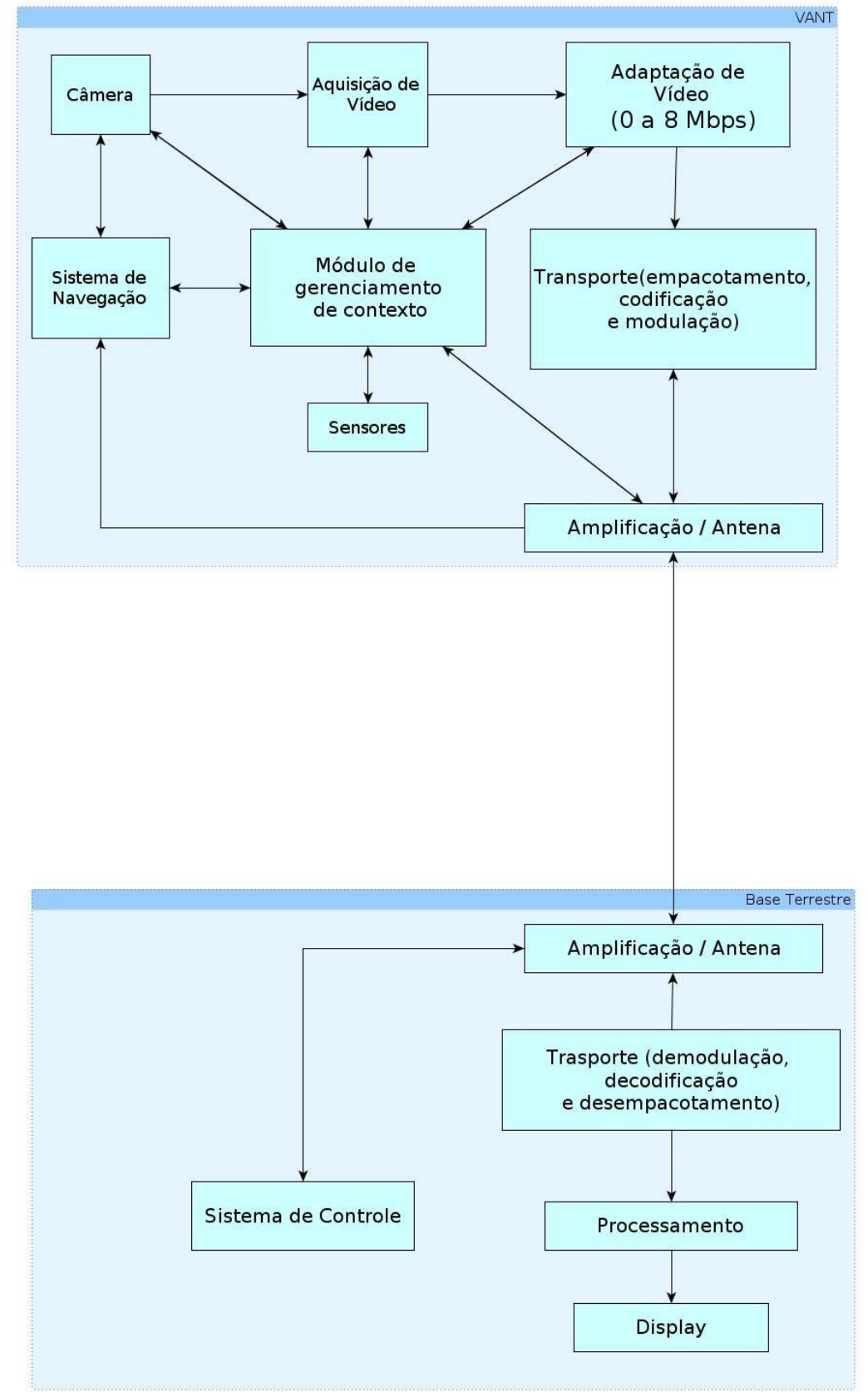

Figura 1.2: Sistema de Adaptação de Vídeo de um VANT 
Essa figura ilustra os módulos do sistema considerado para o estudo. Esse diagrama representa alguns dos subsistemas que constituem um VANT. A seguir serão explicados esses módulos:

- câmera: realiza a captura de fotos e vídeos.

- aquisição de vídeo: recebe e processa os dados fornecidos pela câmera.

- adaptação de vídeo: esse módulo é o núcleo da presente pesquisa, nele serão realizados todos os procedimentos de adaptação a serem utilizados. Como visto na figura, é considerada a necessidade de se adaptar vídeos para serem transmitidos com valores de largura de banda que variem desde 0 até $8 \mathrm{Mbps}$.

- transporte: Dois módulos análogos, sendo um situado na aeronave e outro na estação base. Preparam os dados para serem transmitidos. Realizam o empacotamento, aplicam os métodos de transporte e atuam na modulação do sinal

- amplificação/antena: Dois módulos análogos, sendo um situado na aeronave e outro na estação base. Constituem pontes de comunicação.

- processamento e display: realiza-se o processamento final e apresentação das imagens transmitidas pela aeronave.

- sistema de controle: esse módulo é responsável pelo envio de comandos de controle de navegação da base até o VANT.

- sistema de navegação: subsistema responsável por garantir auxílio à navegação remotamente controlada ou realizar navegação autônoma.

- sensores: diversos tipos de sensores captam informações do meio. 
- gerenciamento de contexto: Recebe informações de sensores, usuários e outros subsistemas e as processa e disponibiliza para outros módulos.

Tendo-se em vista esse cenário, busca-se construir um modelo de adaptação de vídeo que atenda aos requisitos explicitados. Um elemento disponível à adaptação do stream de vídeo é a utilização do Zoom da câmera, reduzindo-se a resolução tanto quanto possível. A ação da câmera seria disparada a partir de um sinal enviado pelo módulo de gerenciamento de contexto, com a informação a respeito do bitrate requerido em dado momento, a alteração do Zoom buscaria então ajustar os quadros a uma resolução compatível com o bitrate. A resolução de 352 X 288 é padronizada e utilizada amplamente, sendo também conhecida como CIF. Outra resolução conhecida é a de 704 X 576, quatro vezes superior à CIF, e por isso chamada de $4 \mathrm{CIF}$. Buscando-se um valor intermediário que combine as possibilidades de velocidade de processamento e percepção de detalhes, a resolução 4CIF mostra-se adequada.

Para a adaptação do vídeo, será realizada a interação do módulo de gerenciamento de contexto com a câmera e com o módulo de adaptação de vídeo. A primeira irá reduzir a resolução espacial a partir do máximo (HD, FullHD ou outro, dependendo da câmera) até 4CIF. E o módulo de adaptação irá realizar o processamento tendo como valor máximo de referência a resolução 4CIF, buscando adaptar os dados para o menor bitrate possível. A resolução temporal considerada será de 30 FPS. Essa taxa é maior que a utilizada em muitos filmes e na televisão, e é considerada satisfatória pra a percepção do movimento (Richardson, 2003). A figura 1.3 ilustra as etapas da adaptação do stream de vídeo.

Dessa forma, o presente trabalho irá focar na atuação do módulo de processamento de vídeo, buscando uma solução de processamento adequada para um vídeo em resolução $4 \mathrm{CIF}$ a 30 FPS. Para resoluções espaciais acima disso a adaptação será realizada pela interação entre o módulo 


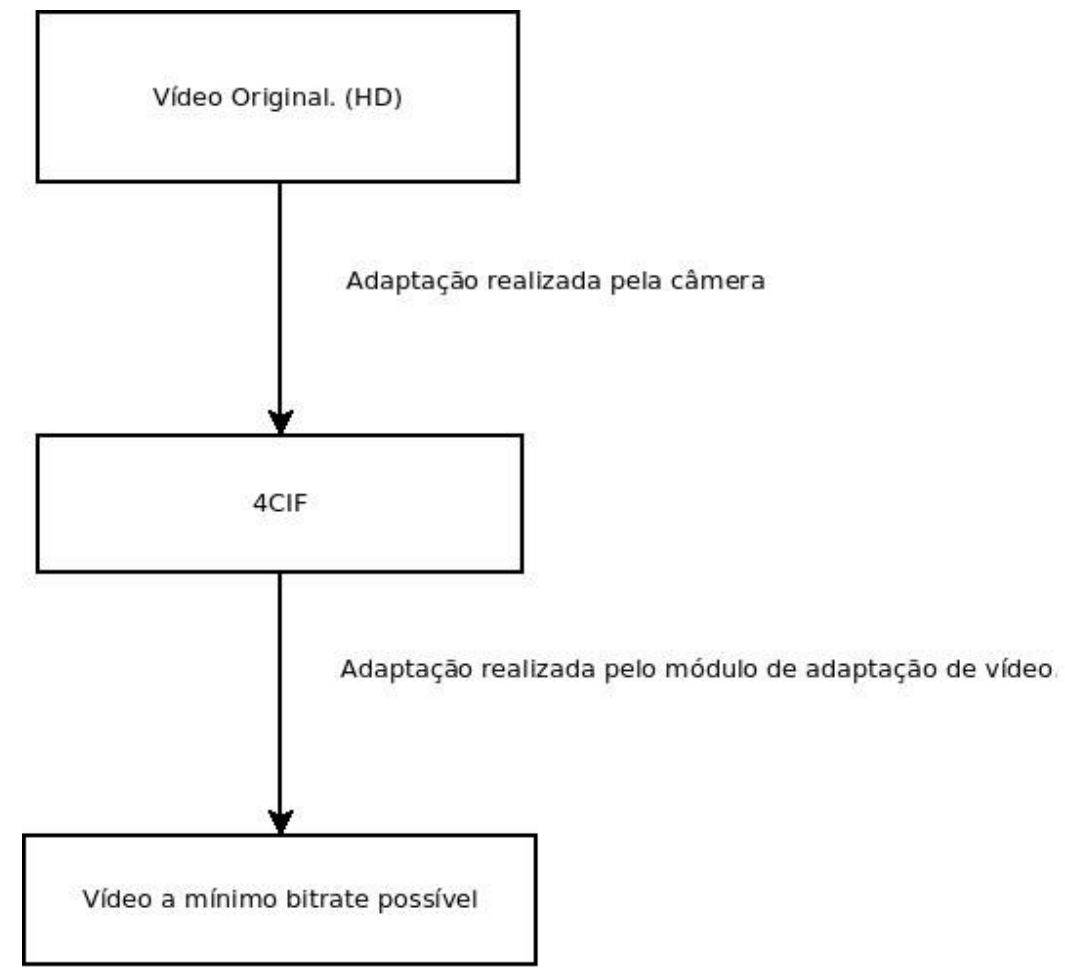

Figura 1.3: Sequência de processamento do stream de vídeo.

de gerenciamento de contexto e o controle da câmera. 


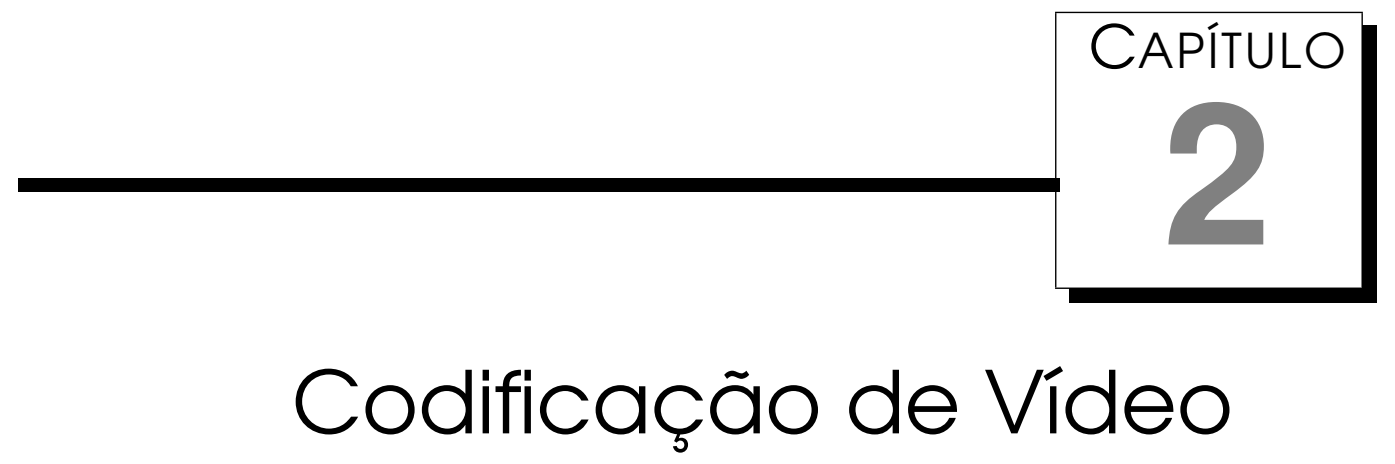

Nesse capítulo serão estudados os métodos de compressão de vídeo existentes, de forma a descobrir a melhor maneira de se adaptar o fluxo de dados. Na seção um será realizada uma introdução sobre formatos de vídeo e espaços de cores, o que é importante para se entender como se procede a compressão. Na seção dois são descritos diversos algoritmos de compressão de vídeo. Na seção três são analisados padrões de codificação. Finalmente, os conceitos estudados nesse capítulo servirão de base para o início dos testes práticos, nos quais serão realizadas comparações estatísticas entre diferentes abordagens de adaptação de vídeo. Esses testes serão descritos no capítulo 4 .

\subsection{Espaços de Cores}

Antes de descrever as metodologias de compressão de vídeo é importante definir os formatos "brutos" ou raw, pois isso é relevante para com- 
preender como o vídeo é armazenado inicialmente e de que forma o espaço ocupado (na memória) é reduzido na compressão.

\subsubsection{Espaço RGB}

RGB é abreviatura do sistema de cores formado por vermelho, Verde e Azul (em inglês Red, Green, Blue: RGB). Esse modelo de cores baseia-se na teoria da visão tricromática, de Young-Helmholtz (Trussell et al., 2005), e no triângulo de cores de Maxwell (Trussell et al., 2005).

Nesse modelo, as cores vermelho, verde e azul são combinadas de várias maneiras para reproduzir as demais. Em termos computacionais, cada um dos três componentes possui um número específico de bits, que combinados formam cada pixel. Em sistemas truecolor, por exemplo, cada componente possui 8 bits, totalizando 24 bits para cada pixel, dessa forma, cada um pode assumir 256 valores, totalizando $256^{3}$ cores diferentes (16.777.216).

\subsubsection{YUV}

No sistema YUV ou YCrCb cada pixel é representado por três componentes, um chamado luminância ou luma $(\mathrm{Y})$, que define os tons de cinza, ou brilho, e dois componentes (U e V), que definem as cores, chamados componentes de crominância ou croma. Os termos YUV, Y'UV, YCbCr, YPbPr são muitas vezes utilizados para representar o mesmo formato. Historicamente, as designações YUV e Y'UV eram utilizadas para codificações analógicas em sistema televisivos, enquanto $\mathrm{YCbCr}$ era usado para codificação digital (Apostolopoulos, 2005). Atualmente o termo YUV é utilizado na computação para descrever formatos codificados com $\mathrm{YCbCr}$, portanto, no presente trabalho será utilizado somente o termo YUV.

Esse sistema apresenta vantagens em relação ao RGB: em primeiro lugar, apresenta um funcionamento mais semelhante à visão humana, a qual também processa separadamente brilho e cores (Apostolopoulos, 
2005), além disso, devido ao fato de luz e cores serem transmitidas em canais separados, no caso de receptores monocromáticos, basta simplesmente descartar os componente $\mathrm{U}$ e $\mathrm{V}$, economizando recursos de transmissão.

Outra vantagem desse formato é que é possível descartar uma parte dos dados para reduzir a banda necessária. Isso é possível devido ao fato de o olho humano possuir menos sensibilidade à cor que à luz. Dessa forma as informações de crominância são reduzidas por meio de sampleamento.

\section{Sampleamento}

A imagem YUV é codificada no formato J:a:b. Esse formato define que a imagem é dividida em grupos com duas linhas de pixels, e a largura dessas linhas é determinada pela variável J. Na prática, é sempre utilizada a forma 4:a:b, ou seja, grupos de duas linhas com 4 pixels cada, (figura 2.1). A variável "a" indica quantos pixels na primeira linha possuem componentes croma, enquanto a variável "b" indica quantos pixels na segunda linha recebem esses componentes. Dessa forma, uma imagem em formato não comprimido, apresenta o formato 4:4:4, o que significa que todos os pixels possuem componentes de crominância. Nada foi dito a respeito do luma porque essa componente não é descartada no sampleamento, e portanto não é incluída na representação J:a:b. Formatos comuns são 4:2:2 e 4:2:0. No 4:2:2, há dois valores de croma para cada linha, ou seja, cada dois pixels devem dividir um componente croma, adquirindo ambos esse mesmo valor (figura 2.2). Na relação 4:2:0 há um croma para cada dois pixels na primeira linha e na segunda não há croma algum, dessa forma, cada pixel da segunda linha assume o mesmo valor de croma que o pixel imediatamente acima (figura 2.3). Diversas técnicas de compressão de vídeo trabalham com o formato yuv devido a essa possibilidade de separar os componentes, o que torna o processamento dos 
dados mais eficiente (Richardson, 2003). Dessa forma, os experimentos realizados no presente trabalho terão como input vídeos construídos no formato YUV.

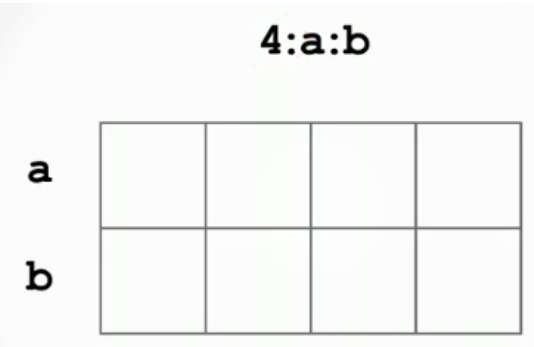

Figura 2.1: Relação 4:a:b

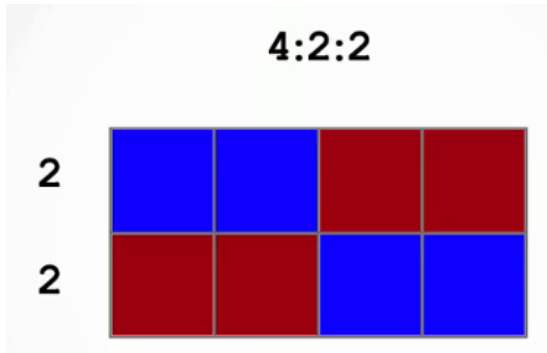

Figura 2.2: Relação 4:2:2

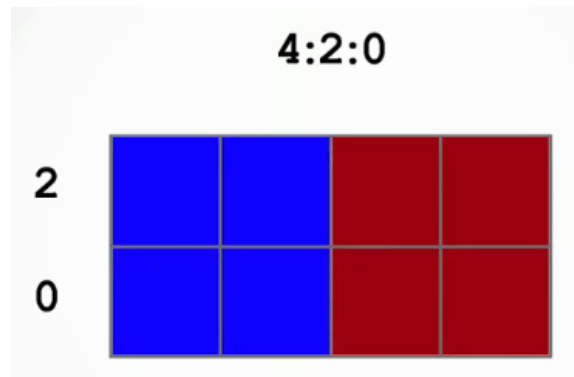

Figura 2.3: Relação 4:2:0 


\subsection{Técnicas de compressão de vídeo}

\subsection{Técnicas de compressão sem perda}

Nas técnicas de compressão sem perda são realizados dois procedimentos: primeiramente o conjunto de dados é analisado, gerando-se um modelo estatístico e identificando-se a redundância, e em seguida o modelo gerado irá guiar a geração de símbolos de forma a eliminar a redundância encontrada. Existem dois tipos de modelos estatísticos: estáticos e dinâmicos (também chamados de adaptativos). O tipo estático é o mais simples e requer menos recursos computacionais. Nesta modalidade é gerado um único modelo que descreverá os dados a serem analisados, o qual é enviado juntamente com o código gerado ou então é utilizado um modelo genérico sem se analisar a amostra específica de dados a serem comprimidos. No modelo dinâmico, inicia-se com um modelo básico, o qual é alterado conforme são analisados os dados do stream de vídeo. Dessa forma, pode-se adaptar conjuntos de dados que possuem sessões com diferentes distribuições de probabilidades. As técnicas sem perda mais utilizadas são: codificação por entropia e run-length.

\section{Codificação por entropia}

Este tipo de codificação é baseado na atribuição de códigos de tamanho variável, de maneira que símbolos ou conjuntos com maior probabilidade de ocorrência recebam códigos com menos bits. Supõe-se aqui que alguns símbolos irão ocorrer com maior frequência que outros, de forma que a atribuição de códigos menores para os símbolos com maior frequência irá ocasionar uma quantidade menor de bytes. Na construção dos códigos deve-se ater para que nenhum seja prefixo de outro, possibilitando distingui-los sem demarcar o início e fim de cada um. 
Tenha-se como exemplo a cadeia de letras "AAAAAAABBCDE". A maneira mais direta de codificá-la seria definir um tamanho fixo de bits como, por exemplo: $\mathrm{A}=000, \mathrm{~B}=001 \mathrm{C}=010, \mathrm{D}=011 \mathrm{e} \mathrm{E}=100$, usando 36 bits para armazenar a cadeia escolhida. Porém é possível comprimir este código utilizando codificação por entropia: como o símbolo A tem uma maior probabilidade atribuímos a este um código binário de menor tamanho; podemos, por exemplo, definir $\mathrm{A}=1, \mathrm{~B}=01 \mathrm{C}=001$ e $\mathrm{D}=0001$ $\mathrm{E}=0000$, lembrando que é imprescindível, para podermos decodificar a sequência que será gerada, que nenhum código seja prefixo de outro. Utilizando esta codificação usaríamos apenas 21 bits para codificar a cadeia escolhida, comprimindo os dados. É interessante observar que o processo de compressão dos dados, quando inadequado para o conjunto em que é utilizado, pode gerar um código que ocupa mais bits que o original (Bovik, 2009).

Run-length

Essa técnica é utilizada quando se tem um código que apresenta símbolos com uma alta taxa de repetições consecutivas. Para determinados símbolos escreve-se apenas o número de vezes que este se repete.

Como exemplo considere-se novamente a cadeia "AAAAAAABBCDE", que poderia ser codificada como "7A2B1C1D1E", se definíssemos que todo símbolo deveria ser especificado através do número de repetições, ou como "7ABBCDE", se definíssemos que a especificação por número de repetições devesse ocorrer apenas para a letra A. É necessário observar que essa técnica só será eficiente se aplicada a conjuntos de dados com características conhecidas, pois pode, quando aplicada em conjuntos inadequados, aumentar consideravelmente o número de bits necessários para a representação da informação. Por exemplo, a cadeia "ABCDEFG"poderia se tornar "1A1B1C1D1E1F1G", duplicando o número de bits necessários (Bovik, 2009). 


\subsubsection{Técnicas de compressão com perda}

O processamento dos algoritmos de compressão com perda é divididos em duas etapas. Primeiramente, é aplicado aos dados originais um procedimento que altera a representação da informação, gerando perdas limitadas. Essa alteração apenas elimina a redundância subjetiva para aumentar a redundância estatística, sem necessariamente mudar a quantidade de bytes necessária para armazenar a informação. A essa etapa segue-se então a aplicação de uma técnica de compressão sem perda. Note-se então que o procedimento da primeira etapa visa principalmente aumentar a redundância estatística, melhorando assim a eficiência da subsequente compressão sem perda. Os procedimentos de compressão com perda podem ser divididos em dois tipos: baseados em transformadas e preditivos.

Algoritmos com perda baseados em transformadas

Esses algoritmos utilizam operações matemáticas para transformar a representação da informação, de forma a aumentar a redundância estatística, reduzindo a redundância subjetiva. Há dois tipos de algoritmos nessa classificação: transformada discreta do cosseno e redução do espaço de cor.

\section{Transformada Discreta do Cosseno}

Esse tipo de transformada é baseado no fato de a visão humana perceber melhor elementos com frequências espaciais mais baixas, ou seja, imagens com padrões mais homogêneos (Bovik, 2009). Imagine-se como exemplo um tabuleiro de xadrez. Nesse caso, quanto maior a frequência espacial (menores os quadrados), mais difícil será ao olho humano distinguir as formas. Dessa maneira, para uma determinada imagem, quanto maior a frequência espacial, maior a possibilidade de se alterar 
o padrão de visualização com menos prejuízo à qualidade percebida, ou seja, a alta frequência espacial pode ser considerada uma redundância subjetiva a ser aproveitada em compressões de imagens. A informação sobre componentes de frequência espacial não é facilmente percebida na representação de imagens como matriz de pixels. Por isso é necessário aplicar uma transformação que altere o domínio da representação para o domínio da frequência. Para isso, é utilizada a transformada discreta do cosseno (DCT - do Inglês Discrete Cosine Transform). Essa transformada é utilizada de forma a expressar uma quantidade finita de pontos discretos em termos de uma soma de cossenos de diferentes amplitudes e frequências, de forma a resultar em uma função no domínio da frequência. Ao ser aplicada a uma matriz de pixels o resultado é uma matriz de intensidade de frequências espaciais, de maneira a se poder identificar facilmente, após a transformação, a intensidade, para cada cor do modelo RGB, de cada componente de frequência. O uso da DCT nos algoritmos de compressão apresenta baixa complexidade computacional, pois essa transformada pode ser implementada como uma operação de matrizes.

Redução do espaço de cor

Esse tipo de técnica baseia-se no fato de a visão humana ter maior sensibilidade à intensidade luminosa que à cor (Bovik, 2009). Dessa forma, a intensidade de cor pode ser considerada redundância subjetiva. Os pixels podem ser transformados do modelo RGB para o modelo YUV, de modo que cada ponto será representado não mais com três componentes de cor mas sim com duas componentes de cor e uma de luminosidade.

Dessa forma, é possível se aproveitar a redundância subjetiva da informação de cor, produzindo imagens com resolução menor. Por exemplo, uma imagem 40x40 pode ser expressa como duas matrizes 20x20 de intensidade de cor e uma matriz 40x40 de intensidade de luz. 
Algoritmos com perda baseados em predição

Nesse tipo de algoritmo, seleciona-se um grupo de informações do stream original, codificando-se apenas estas e não cada pixel do conjunto de dados. Essas informações serão utilizadas para uma predição da imagem original, codificando-se apenas esses dados preditivos e não toda a imagem.

\section{Predição Espacial}

Nesse método, também conhecido como predição intra-frame, o conjunto de informações capturadas irá consistir em um subconjunto dos pixels que representam a imagem. Dessa forma, realiza-se a codificação apenas de uma parte dos pixels, e o restante terá seus valores calculados por meio de alguma função de interpolação. Para isso, os algoritmos de predição espacial partem do princípio de que pixels próximos tendem a ter valores próximos. Assim o erro de previsão será baixo quando a imagem contiver variações suaves de cor, e alto quando houver variações bruscas. Como serão levadas em consideração apenas informações espaciais (valores de cada pixel) é possível aplicar essa predição de maneira independente em cada quadro do vídeo. Dessa forma, o processamento exato de um quadro não será necessário para garantir a decodificação do próximo.

\subsubsection{Predição de Movimento}

Também chamada de predição inter-frame, essa técnica parte do princípio de que cada quadro será similar ao quadro que o antecede, ou seja, a semelhança entre os frames será inversamente proporcional ao tempo entre eles. Para realizar a predição é utilizada a técnica de compensação de movimento, que consiste em expressar um frame como um deslocamento dos elementos do frame antecessor. Por exemplo, considere-se um 
carro em movimento. Supondo-se o fundo da cena estático, cada frame irá diferir do seu antecessor apenas pela posição do carro.

Para a realização da compensação de movimento é necessária a estimativa de movimento, que consiste em identificar regiões similares em dois quadros distintos (o quadro de referência e o quadro a ser estimado) e calcular adequadamente o vetor de movimento para essas regiões. Esse vetor irá expressar a translação a ser feita na imagem de referência de forma que essa fique na posição correta relativa à imagem estimada.

\subsection{Padrões de Codificação de Vídeo}

Pode-se citar quatro padrões como representantes da geração atual de padrões de codificação de vídeo (Bovik, 2009): WMV9 / VC-1, Audio Video Standard (AVS) , H.264 / MPEG-4 part 10 Advanced Video Coding (AVC) e JPEG2000.

O padrão WMV9 surgiu como um padrão proprietário fornecido pela Microsoft. Apresenta diversas restrições relativas a direitos autorais, não é distribuído gratuitamente e sua aplicação é relativamente limitada.

O padrão AVS foi desenvolvido pelo governo Chinês para tornar os produtos deste país independentes de patentes estrangeiras, porém a sua documentação encontra-se em chinês, constituindo uma barreira linguística que limita sua aplicação fora da área de origem.

Os padrões JPEG2000 e H.264/AVC são mais interessantes à presente pesquisa e serão descritos a seguir.

\subsection{JPEG2000}

JPEG2000 foi criado pela Joint Photographic Experts Group, no ano 2000, visando superar o padrão anterior, chamado JPEG. A principal vantagem desse protocolo em relação ao JPEG não é sua maior taxa de compressão (que supera modestamente o padrão anterior, cerca de $20 \%$ ), 
mas sim a sua flexibilidade. Os dados gerados após a compressão são de natureza escalável, o que significa que a taxa de bits pode ser truncada em algum ponto intermediário, exibindo-se uma imagem a uma resolução menor, ou SNR menor. No entanto, essa escalabilidade provoca um aumento da complexidade dos codificadores e decodificadores. Existem ainda outros protocolos relacionados ao JPEG2000, como o JPIP, publicado como ISO 15444-9. Esse protocolo possibilita que, caso alguma imagem seja demasiado extensa, apenas algumas regiões selecionadas sejam transmitidas, reduzindo a banda necessária. É importante salientar que, por tratar-se apenas de compressão de imagem, O JPEG 2000 não proporciona compressão Inter-Frame.

\subsubsection{Padrão H.264/AVC}

O padrão H.264/MPEG-4 part 10 AVC, foi resultado de uma parceria entre a International Telecommunication Union (ITU) e International Organization for Standardization (ISO). O desenvolvimento durou quatro anos e a primeira versão foi aprovada em 2003. A partir de agora será utilizado nesse texto apenas o termo H.264/AVC para designar esse padrão.

O objetivo do desenvolvimento do H.264/AVC foi criar um padrão capaz de prover boa qualidade de vídeo a taxas de bit menores que os padrões anteriores, mas sem um acréscimo na complexidade do projeto a ponto de tornar a implementação do algoritmo inviável. Outro objetivo era proporcionar flexibilidade suficiente de forma a permitir a utilização do H.264/AVC em uma vasta gama de aplicações, dentre as quais pode-se citar (Wiegand et al., 2003):

- Broadcast por cabo, satélite, cabo de modem, DSL (do inglês, Digital Subscriber Line)

- Armazenamento interativo ou serial em dispositivos óticos ou magnéticos, DVD, etc. 
- Serviços de conversação através de ISDN (do inglês, Integrated Services Digital Network), Ethernet, LAN, DSL, dispositivos móveis e sem fio, modems, etc. Ou combinações desses.

- Vídeo sob demanda ou serviços de multimídia através de ISDN, cabo de modem, DSL, LAN, redes sem fio, etc.

- Serviços mensageiros multimídia (MMS-do inglês, Multimedia messaging service) através de ISDN, DSL, ethernet, LAN. dispositivos móveis e sem fio,etc.

Além disso, novas aplicações deverão ser desenvolvidas utilizando redes existentes ou a serem criadas. Isso levanta a questão a respeito de como prover compatibilidade e eficiência em relação a essa gama de aplicações e redes.

Ao contrário do JPEG 2000, o H.264/AVC realiza predição inter-frame, ou seja, leva em consideração a interação entre os quadros de forma a melhorar a performance da compressão e a qualidade final do vídeo. Em outras palavras pode-se dizer que o H.264 é de fato um protocolo de compressão de vídeo enquanto o JPEG 2000 trata apenas da compressão de imagens.

\subsubsection{Comparação entre H.264/AVC e JPEG 2000}

Agora será feito um estudo comparativo entre esses dois protocolos de forma a escolher o mais adequado a esse trabalho. Em primeiro lugar, a presença de predição inter-frame no H.264/AVC já indica uma vantagem desse protocolo. Adicionalmente, é interessante conhecer a eficiência de cada um no tocante à compressão intra-frame. Para isso foram analisados diversos estudos realizando testes comparativos entre o JPEG2000 e o H.264/AVC Intra-frame. O trabalho de Camperi e Picco (2008) aponta o H.264/AVC como tendo melhor desempenho. Já os estudos de Tran (2009) e Ouaret (2009) revelam um desempenho similar dos dois codecs. 
Outros estudos concluem que o H.264 é mais eficiente, exceto em resoluções muito altas (HD, Full HD), utilizadas em cinema e televisão digital (Shi et al., 2009), (Marpe et al., 2007). Além do mais, o H.264 é aconselhado em cenários com bit-rate escasso (Wright, 2008).

Em vista dessa informações, aliadas ao fato de somente o codec H.264/AVC possuir predição inter-frame. Este foi o padrão escolhido para o presente trabalho. Dessa forma, este será mais detalhadamente descrito a seguir.

\section{Características Técnicas do H.264/AVC}

Para atenter à demanda por flexibilidade e adaptabilidade, o padrão H.264/AVC apresenta duas camadas. A primeira é a camada de dados, conhecida como VCL (do inglês, Video Coding Layer) e foi desenvolvida para representar adequadamente o conteúdo do vídeo. A segunda é a camada de rede, conhecida como NAL (do inglês, Network Abstraction Layer), que adapta a representação VCL do vídeo e provê informação de cabeçalho que possa ser lida por uma variedade de dispositivos de armazenamento e camadas de transporte. A figura 2.4 exibe um diagrama com um esquema básico da estrutura do encoder H.264/AVC, mostrando como se relacionam essas duas camadas.

$N A L$

A camada NAL foi projetada para prover flexibilidade de rede, de forma a possibilitar customizações simples e efetivas do uso do VCL para uma variedade de sistemas. Essa camada facilita a tarefa de mapear os dados dos VCL para as camadas de transporte. Seu projeto antecipa uma variedade de mapeamentos necessários para a compatibilidade com diferentes aplicações.

Alguns conceitos chave dessa camada são: Unidades NAL, stream de bytes, definições de parâmetros e unidades de acesso. Unidades NAL são pacotes entre os quais são divididos os dados do vídeo codificado. Cada 


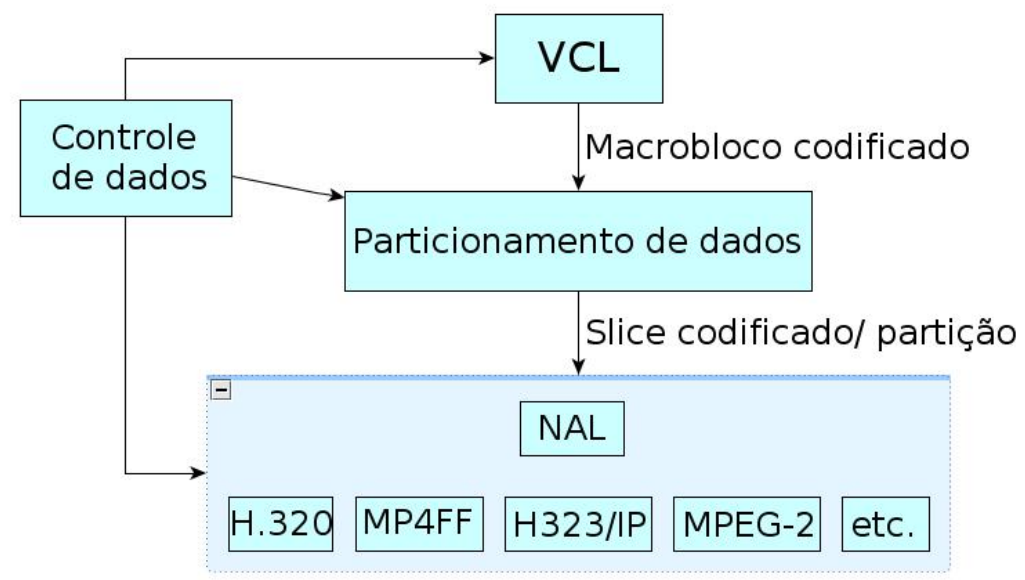

Figura 2.4: H.264/AVC

um desses pacotes possui um número inteiro de bytes (Wiegand et al., 2003). O primeiro byte de cada unidade NAL tem função de cabeçalho e contém uma indicação do tipo de dados presentes na unidade. Os demais bytes contêm os dados em si. Em relação ao sistema de transporte utilizado para transmitir as unidades NAL, este pode ser de dois tipos: orientado a pacotes ou orientado a stream de bits. Em sistemas de transporte orientados a pacotes a própria especificação das unidades NAL é suficiente para uma transmissão eficiente de dados. Em sistemas orientados a stream de bits, por outro lado, faz-se necessário anexar bytes além da especificação da NAL. Nesses sistemas, uma unidade deve ser inteira ou parcialmente entregue na forma de um stream de bytes ou bits de maneira que a localização dos limites de cada unidade NAL possa ser identificada em padrões dentro do próprio código transmitido. Para que essa identificação seja possivel o padrão H.264/AVC especifica a utilização, em cada unidade NAL, de um prefixo composto por três bytes. 
VCL

Os padrões anteriores ao H.264/AVC aplicavam o que se conhece por abordagem de codificação híbrida de vídeo baseada em blocos (Wiegand et al., 2003). Nessa abordagem, cada quadro é representado em unidades na forma de blocos. O algoritmo de codificação é basicamente uma combinação de predição inter-frame (de forma a explorar redundâncias estatísticas temporais) e aplicação de transformadas (de forma a codificar a redundância espacial) (Wiegand et al., 2003).

O VCL não apresenta um elemento de codificação que proporcione aumento significativo na taxa de compressão. Na realidade, o aumento em eficiência proporcionado por esse método é obtido por meio do somatório de uma variedade de pequenas melhorias. As principais técnicas utilizadas no VCL são: slices, predição intra-frame e predição inter-frame. Essas duas últimas já foram detalhadas na seção de algoritmos de compressão com perda. A explicação referente aos slices será dada a seguir.

\section{A. Slices}

Versões anteriores ao H..264/AVC utilizavam o conceito de macroblocos, em que cada frame é dividido entre quadrados de 8X8 ou 16X16 pixels (Wiegand et al., 2003). O padrão atual, além dessa abordagem, apresenta também o agrupamento dos blocos em slices. Um slice representa uma região contígua do frame que pode ser codificada de maneira independente, ou seja, sem a codificação dos outros slices. Dessa forma, uma imagem será composta por um conjunto de slices, como é ilustrado na figura 2.5.

Cada slice pode possuir uma designação específica de acordo com o tipo de codificação:

- slice I: todos os macroblocos são codificados utilizando predição intraframe. 


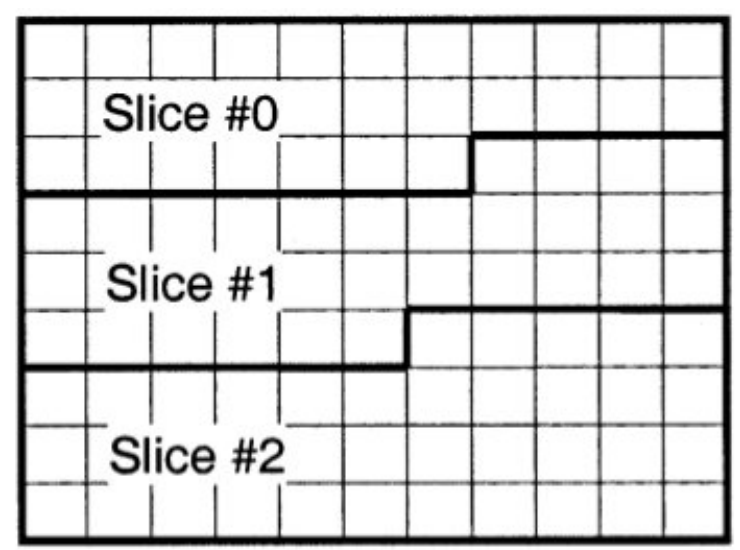

Figura 2.5: Slices

- slice P: além da codificação referente a um slice I, essa categoria apresenta também codificação inter-frame com apenas um quadro como referência para estimação de movimento.

- slice B: além da codificação referente a um slice P, essa categoria apresenta também codificação inter-frame com dois quadros de referência para estimação de movimento.

- slice SP: do inglês, switching $P$, é codificado de forma a possibilitar a troca entre figuras pré-codificadas.

- slice SI: do inglês, switching I, permite existência de uma correlação exata em um macrobloco de um slice SP para fins de acesso randômico e recuperação.

Dentre os tipos citados, apenas os dois últimos constituem inovações apresentadas pelo padrão H.264/AVC.

\subsubsection{Extensão Escalável do Padrão H.264/AVC}

Por muitos anos, a escalabilidade foi o objetivo das tecnologias de compressão de vídeo. No entanto as extensões escaláveis do MPEG-2 nunca 
obtiveram aceitação suficiente devido a grandes perdas na compressão, se comparadas a versões não escaláveis. Isso mudou com a padronização H.264/MPEG-4 Scalable Video Coding (SVC) (Amon et al., 2008).

Em um vídeo escalável, partes do conteúdo original podem ser destacadas, de forma que cada sub-stream resultante forma um novo conteúdo decodificável. Dessa forma, o vídeo será dividido em diversas camadas. A camada primária será uma representação equivalente do stream de vídeo, mas com a redução de alguma característica, como resolução temporal ou espacial. As camadas adicionais serão bit-streams decodificáveis que farão com que seja agregada essa característica cada vez mais. Dessa forma, ao se baixar todas as sub-streams, será obtido o vídeo em sua qualidade máxima. Porém, se houver limitações na qualidade da conexão, poderão ser carregadas apenas algumas camadas, podendo-se, dessa forma, apresentar o vídeo com uma qualidade inferior.

São especificadas três diferentes técnicas de codificação: escalabilidade espacial, escalabilidade temporal e escalabilidade SNR (Razão SinalRuído - Do Inglês, Signal-Noise Ratio), esta última também conhecida como escalabilidade de qualidade (Horn and Girod, 1997). Pode-se ver na figura 2.6 exemplos dos três tipos de mídia escalável.

\section{Escalabilidade Temporal}

Na escalabilidade temporal, o vídeo é particionado em uma camada temporal base e camadas adicionais. A camada base apresentará o vídeo a uma resolução temporal mínima. Conforme forem adicionadas mais camadas, poderá ser exibido um vídeo com resolução temporal cada vez maior, até a resolução máxima do vídeo completo. Considere-se que cada camada seja representada por um índice, de zero a $\mathrm{X}$, sendo $\mathrm{X}$ o índice da última camada a ser adicionada. Então para uma dada camada com índice $\mathrm{Y}$, o Bit-Stream obtido ao se remover todas as unidades de acesso das camadas com índice $Z>Y$ constituirá um bit-stream válido para o de- 
Escalabilidade Temporal

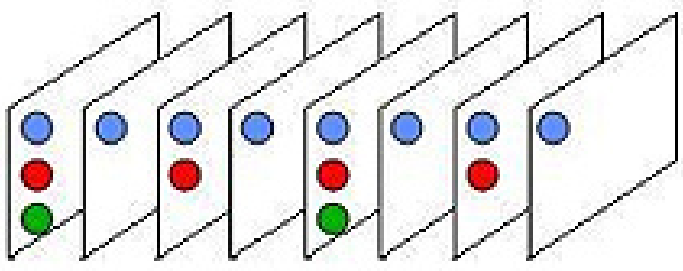

Escalabilidade Espacial
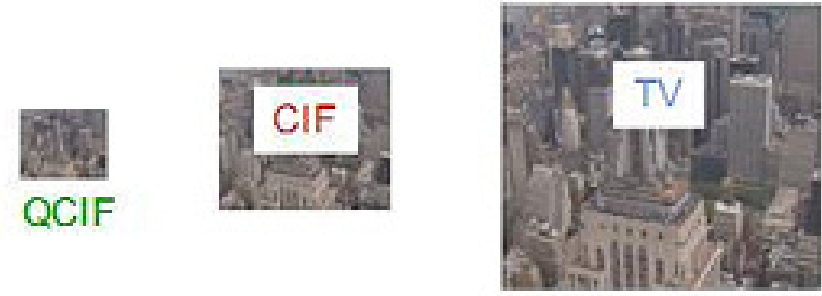

\section{Escalabilidade de Qualidade}
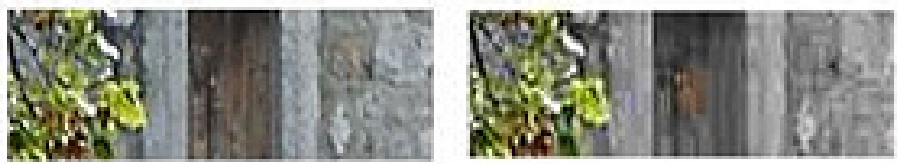

Figura 2.6: Três tipos de escalabilidade

codificador. Na figura 2.7 pode-se observar um exemplo de como funciona esse tipo de processamento.

Em codificadores híbridos, a escalabilidade temporal geralmente pode ser obtida restringindo-se a predição de movimento a figuras de referência com uma camada temporal com identificador menor que o da camada da figura a ser prevista (o identificador da camada é um número inteiro que identifica a ordem na qual esta é transmitida, de forma que camadas com identificador maior sempre são transmitidas depois). Isso garante que os dados necessários à predição estarão presentes, pois a figura de referência é codificada e transmitida antes da figura a ser prevista. O H.264/AVC apresenta, quando comparado a padrões anteriores, uma grande flexibilidade a escalabilidade temporal. Isso ocorre devido a seu controle de memória de figuras de referência, o qual permite a codificação de sequên- 


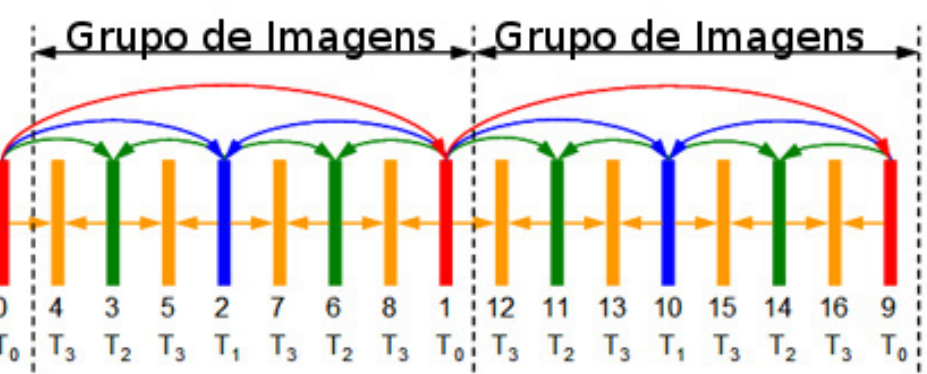

(a)

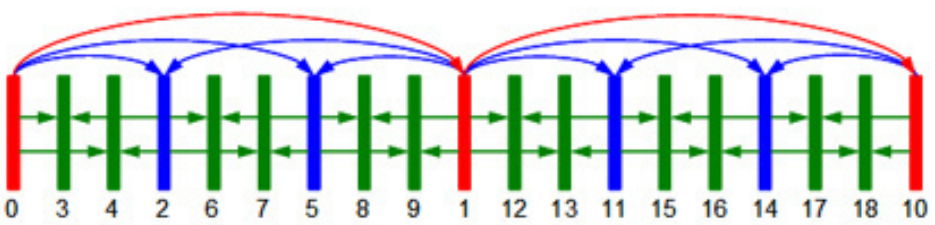

(b)
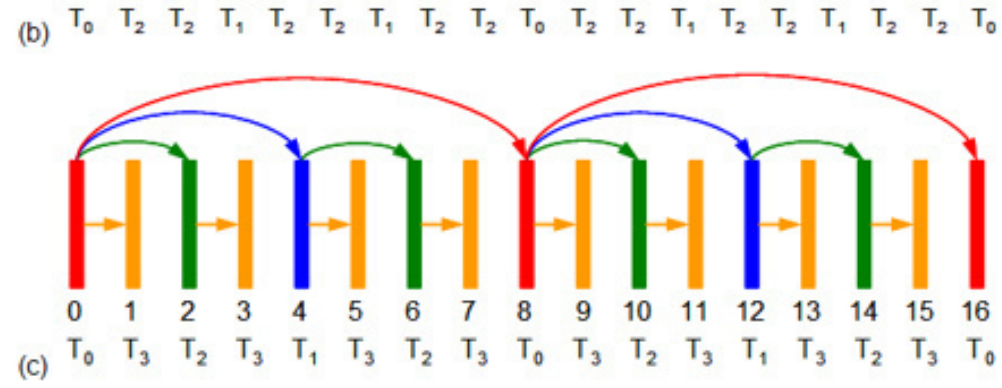

Figura 2.7: Escalabilidade Temporal

cias de figuras com dependências temporais arbitrárias. Além disso, não foi necessário realizar mudanças no projeto do H.264/AVC para que esse suportasse uma quantidade razoável de camadas temporais.

O padrão H.264/AVC utiliza o conceito de figuras de referências múltiplas, ou seja, na utilização de algoritmos de predição é possível se utilizar mais de uma figura de referência, incluindo figuras pertencentes à mesma camada temporal que a figura a ser prevista. Esse conceito fornece ao H.264/AVC considerável compatibilidade com algoritmos de escalabilidade temporal. Além disso, para a extensão escalável é definido o conceito de GOP (do inglês, Group of Pictures), que especifica o número de quadros contíguos até que se tenha um quadro codificado de maneira independente, ou seja, o conjunto de quadros existentes entre dois quadros da 
camada base, adicionados ao próximo frame da camada base. Essa idéia é ilustrada na figura 2.8 .

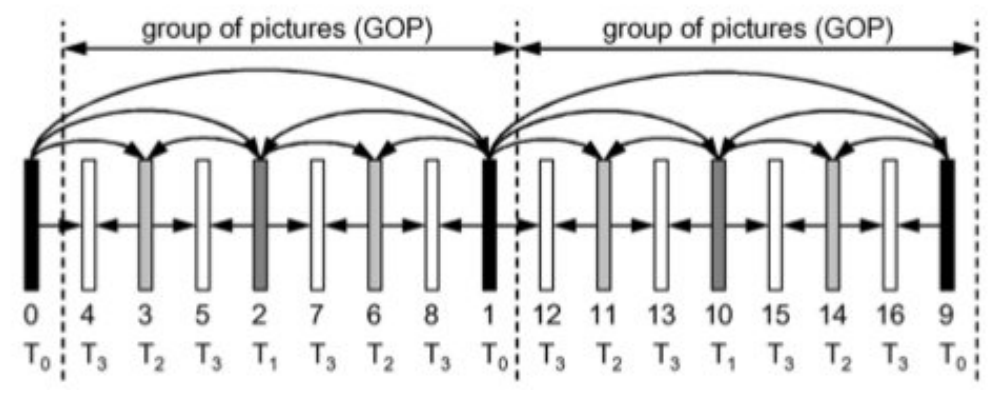

Figura 2.8: Group of Pictures

\section{Escalabilidade Espacial}

Para a escalabilidade espacial o padrão SVC segue a abordagem de codificação multi-camadas, tambem utilizada no MPEG-2 Video/H.262, H.263 e no MPEG-4 Visual (Amon et al., 2008). Cada camada corresponde a uma resolução espacial e é nomeada com um identificador de dependência, sendo zero para a primeira, aumentando em uma unidade para cada camada adicional. A primeira camada apresenta o vídeo a uma resolução espacial mínima e conforme forem decodificadas camadas adicionais, haverá um acréscimo progressivo desta. Vemos um exemplo na figura 2.9 .

\section{Escalabilidade de Qualidade}

$\mathrm{Na}$ escalabilidade de qualidade, também conhecida como escalabilidade SNR (Do Inglês, Signal to Noise Ratio) são apresentadas opções de diversas qualidades de imagem. Para isso aplica-se o processo de refinamento de coeficientes QP (Do Inglês Quantization Parameter), ou parâmetros de quantização. Uma camada base irá possuir os coeficientes mínimos necessários, ou coeficientes primários, e cada camada adicional irá 


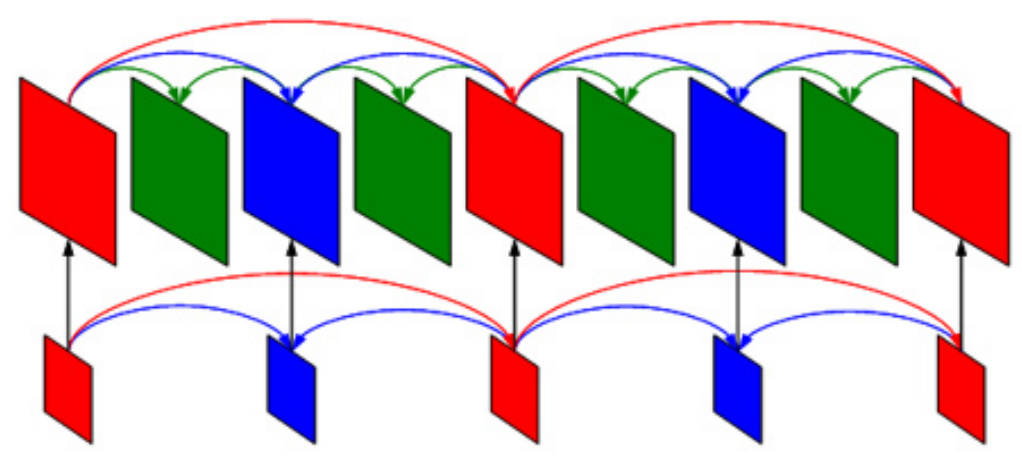

Figura 2.9: Escalabilidade Espacial

incrementar o refinamento dos coeficientes (Horn and Girod, 1997). Há dois tipos de escalabilidade SNR. A CGS (Escalabilidade Granular Grosseira - Do Inglês, Coarse Grain Scalability ) e MGS (Escalabilidade Granular Média - Do Inglês, Medium Grain Scalability ).

29 


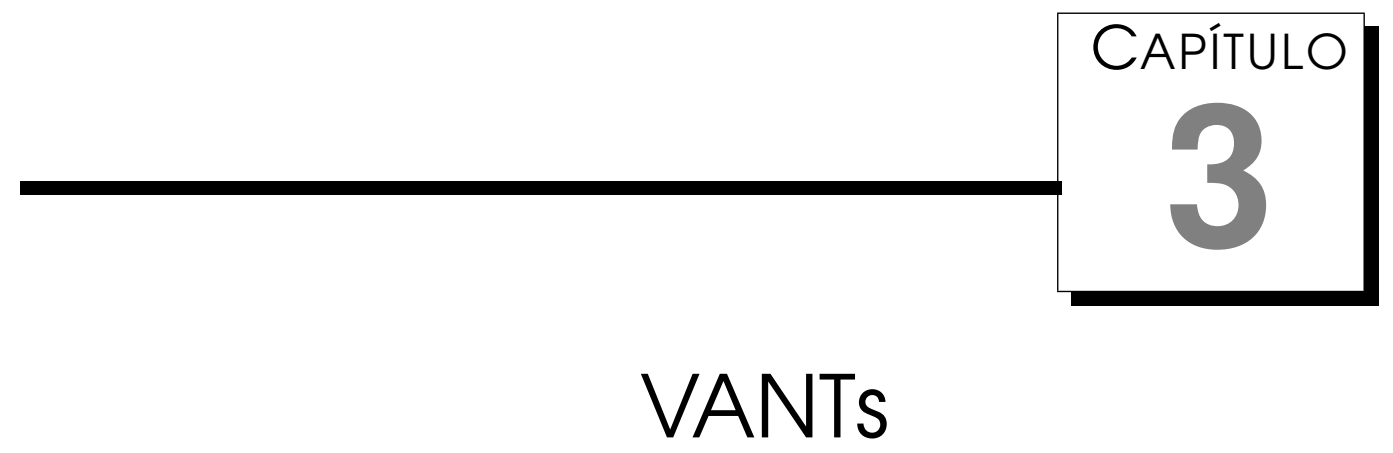

\section{1 Considerações Iniciais}

O objetivo desse capítulo é realizar uma revisão conceitual a respeito de veículos aéreos não tripulados (VANTs), sua importância, tipos existentes, diferentes utilizações, etc.

VANT é definido como veículo aéreo motorizado que não carrega operador humano, utiliza forças aerodinâmicas para prover sustentação, pode voar de forma autômata ou controlada remotamente e pode carregar uma carga paga. As figuras 3.1 e 3.2 mostram exemplos de VANTs.

\subsubsection{Classificação de VANTs:}

Para melhor estudo e organização dos projetos de VANTs, estes são classificados em seis categorias principais, de acordo com a força aérea americana (FAA 2005): 


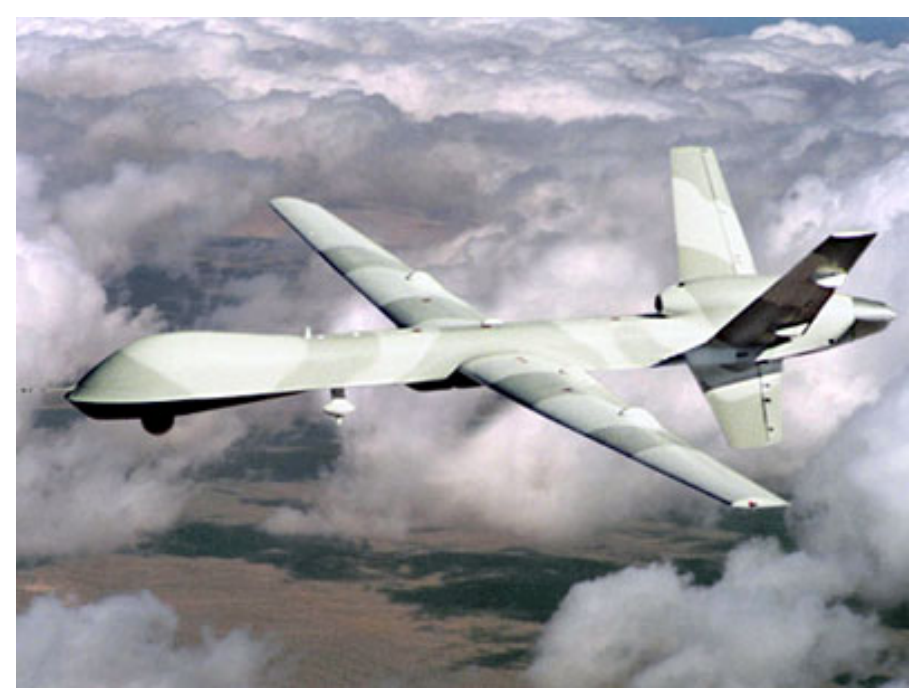

Figura 3.1: VANT Predator

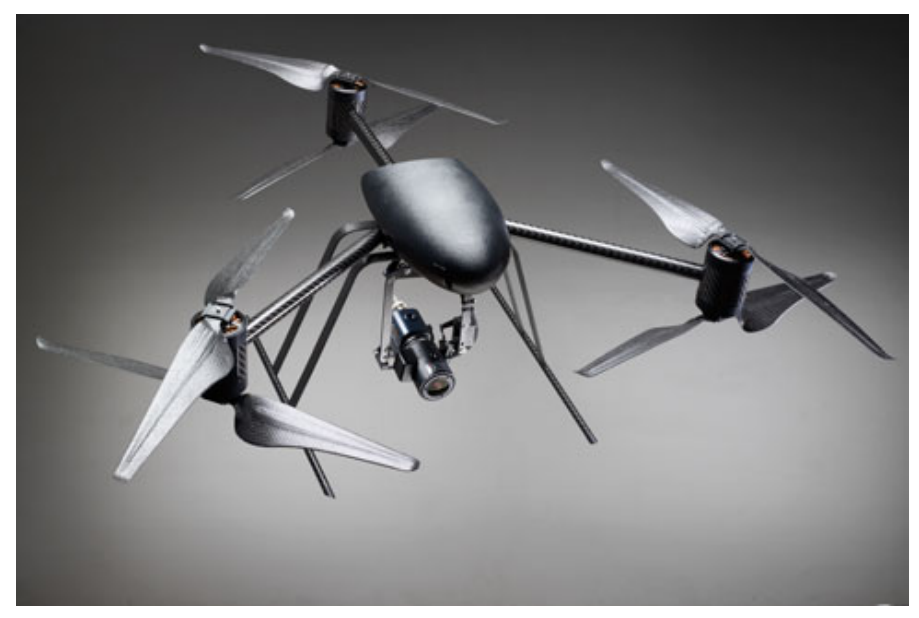

Figura 3.2: VANT Draganflyer-x6

- alvo e distração: Esse tipo de aeronave pode ser utilizado como alvo em treinos da artilharia do próprio exército que o utiliza, assim como para servir de distração ou isca para exércitos inimigos (aqui já se observa uma evidente vantagem da aeronave não ser tripulada).

- reconhecimento: este tipo de VANT é utilizado em missões de vigi- 
lância e reconhecimento de áreas, as quais podem estar localizadas em cenário hostil, justificando a vantagem da aeronave não ser tripulada, não arriscando vidas na missão.

- combate: aeronaves utilizadas diretamente em combate.

- logística: utilizadas para missões de transporte de carga e materiais.

- pesquisa e desenvolvimento: aeronaves experimentais utilizadas para auxiliar o desenvolvimento de novas tecnologias.

- civil: não são utilizados em missões militares, mas para outras como monitoramento de plantações, rios, etc.

Os VANTs possuem diversos sistemas automáticos que assistem o vôo e o controle por um ser humano, realizando automaticamente uma série de tarefas, como estabilização da aeronave ou execução de rotas prédefinidas. Os primeiros VANTs a serem desenvolvidos não possuíam esse grau de autonomia e são simplesmente controlados pelo operador via rádio. Essas aeronaves são comumente chamadas de drones.

\section{1.2 Missões e Tarefas}

Ao se avaliar a eficiência de um VANT para o sucesso de uma missão é necessário se considerar diversos fatores, como características da plataforma, graus de autonomia no controle de voo, confiabilidade, integração de sistemas e fatores humanos. A operação de uma aeronave não tripulada pode apresentar uma diversidade de cenários. A seguir serão descritas algumas das principais operações executadas por VANTs, classificadas pela força aérea americana (FAA 2005):

Defesa contra armas de destruição em massa: Uma das missões mais críticas é encontrar e destruir armas de destruição em massa. Conceitos operacionais desse tipo de missão incluem o uso de VANTs no papel 
de auxiliar a descoberta de posse, manufatura, armazenamento e movimentação de armas nucleares, químicas ou biológicas por forças inimigas. Nesse caso os VANTs complementam outras forças, com sua vantagem em poder se aproximar das forças adversárias sem risco de danos humanos.

Nesse contexto, o VANT destrói a Arma em questão sem dispersar material perigoso ou nocivo. O ataque é realizado por um VANT duplamente equipado (Sensores Multi-Espectrais e Armas) ou por um VANT de vigilância acompanhado de outro que carregue as armas.

Defesa contra mísseis de cruzeiro: $O$ papel do controle aeroespacial é reforçado pela participação dos VANTs em missões de defesa aérea. Essas aeronaves, com sua capacidade de vigilância, reconhecimento e ataque, podem ampliar fortemente os sistemas tripulados nas missões de defesa contra mísseis de cruzeiro. Esses VANTs poderão realizar o tipo de missão em questão eficientemente e sem atrasos, com alta capacidade de penetração em território inimigo, e cobertura de diferentes altitudes que favorecem geometricamente a interceptação de mísseis. O desenvolvimento futuro de VANTs altamente difíceis de observar (VLO - Do inglês Very Low Observable) e capazes de viajar a grandes altitudes deve ampliar ainda mais os recursos desse tipo de missão.

Ataque a alvo fixo: Em missões militares pode ser requerido de um VANT o ataque a um importante alvo estratégico fixo no espaço. São fornecidas ao sistema da aeronave informações como localização, tipo de alvo, e efeito desejado. Uma missão de ataque a um alvo fixo irá determinar os eixos e táticas para otimizar a aquisição do alvo, efeitos das armas, efeitos colaterais, etc.

Supressão de Defesas Aéreas Inimigas: VANTs podem detectar sistemas de defesa aérea e transmitir dados de localização para a base de aeronaves aliadas, de forma a desenvolver um sistema de ataque. Dessa forma, poderão ampliar a força total de seus aliados, através da coleta de dados sobre aeronaves adversárias.

Inteligência / Vigilância / Reconhecimento: Nesse tipo de missão 
são utilizadas as capacidades do VANT de penetrar em território hostil ou perigoso sem oferecer risco a vidas humanas, dessa forma podem ser capturados dados visuais em forma de vídeos ou fotos. No cenário militar isso constitui um fator preponderante de inteligência, e deve ser aliado a uma baixa visibilidade do VANT, de forma que esse não seja percebido facilmente por forças adversárias. Esse tipo de missão também possui aplicabilidade em cenários não militares (como, por exemplo, observação de áreas controladas por facções criminosas, monitoração de florestas e desmatamento e vigilância de plantações e fazendas). Esse tipo de missão é o de maior importância para o presente trabalho.

Pode-se observar que para todos os tipos de missões citados, é importante a utilização de captura de vídeo. A seguir serão apenas citadas outras categorias de missões classificadas pela FAA:

- ataque a alvo em movimento

- jamming

- comunicações, apoio à navegação

- combate ar-ar

- defesa da base

- ataque estratégico

- controle espacial

- operações especiais

- negação de área

- descontaminação

- busca e salvamento em combate 
- abastecimento

- transporte de carga

- aumento de GPS

- guerra de informação

- assistência humanitária

Em todas essas operações, a realização da captura e transmissão de stream de vídeo até a base é, no mínimo, desejável para o sucesso da missão. De fato, independentemente da operação realizada, a captura de imagens realizada pela câmera pode sempre assistir o controle da aeronave, sua navegação, orientação, localização e retorno (feedback) para um eventual piloto em solo. Isso justifica a importância dada a esse subsistema.

\subsubsection{Arquiteturas de Comunicação em VANTs}

Há quatro arquiteturas básicas de comunicação em VANTS: Link Direto, Satélite, Celular e Redes Mesh (Frew and Brown, 2009). Na transmissão por Link direto a aeronave se comunica diretamente com a torre através de antenas direcionais (as quais possibilitam maior alcance de sinal) e transmissores de alta potência.

$\mathrm{Na}$ arquitetura em Mesh, as aeronaves estabelecem links entre si de forma que o envio de dados até a base pode ser assistido por outro VANT que, estando convenientemente localizado, funciona como retransmissor de dados. Sendo assim é possível ter um maior alcance da transmissão. Este modelo pode possuir características de auto-organização e auto-configuração da rede, as quais possibilitam às aeronaves uma maior liberdade de trajeto. Além disso, essa arquitetura pode ser utilizada em redundância com um dos outros três modelos de comunicação. 
Na comunicação Celular são utilizadas torres do sistema telefônico de aparelhos celulares, as quais recebem os sinais advindos dos VANTs. Nessa arquitetura, várias estações podem prover redundância de cobertura em determinada área. Isso possibilita uma maior confiabilidade na entrega de pacotes. A desvantagem desse tipo de transmissão é o alto custo de instalação.

$\mathrm{Na}$ comunicação por satélites, estes constituem o principal ponto de transmissão de sinal com o VANT. Possui a vantagem de fornecer uma vasta área de cobertura devido à presença do satélite. Sua desvantagem é a necessidade de grandes dimensões para a antena do VANT, o que pode vir a sobrecarregar a aeronave. Essas configurações são mostradas na figura 3.3.

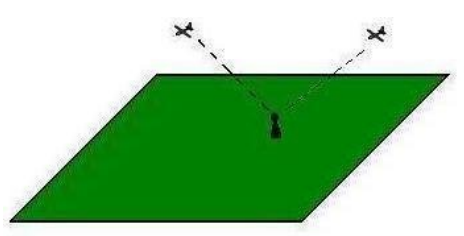

Direta

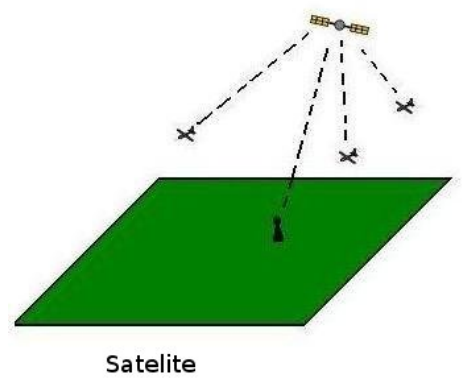

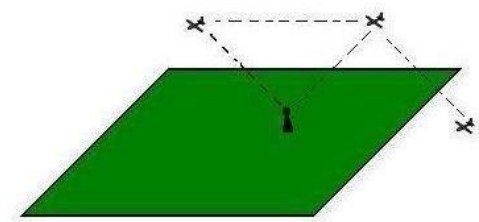

Mesh

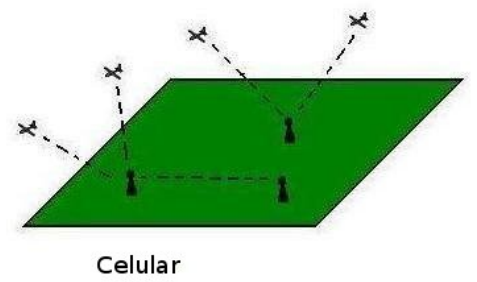

Figura 3.3: Arquiteturas de Comunicação em VANTs

Para o presente trabalho, é considerado um VANT utilizando link direto. Pois é o tipo mais comumente utilizado e sua relação eficiência/custo é relativamente melhor quando comparado às demais arquiteturas. Além disso, paralelamente à presente pesquisa, vêm sendo realizados traba- 
lhos no desenvolvimento de um link direcional com requisitos de potência e eficiência para a utilização no cenário de aeronaves não tripuladas. 


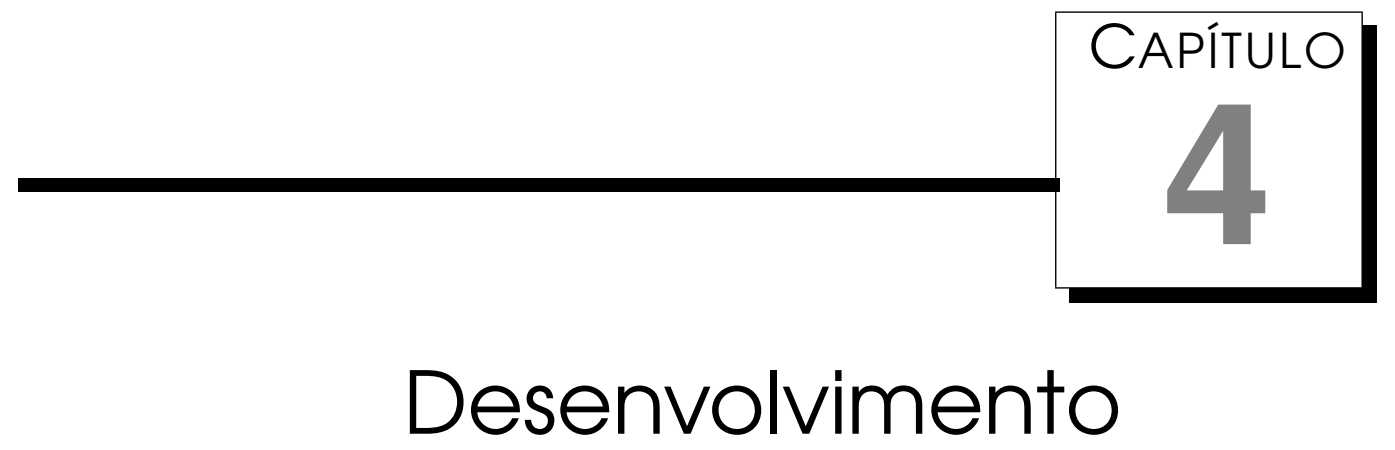

\subsection{Testes de Compressão de Vídeo}

Conforme estudado, o padrão H.264/AVC apresenta diversas vantagens, além de ser um padrão aberto. Adicionalmente, a utilização de escalabidade permite degradação suave e gradativa dos dados, sendo vantajosa para a aplicação em um cenário de transmissão em tempo real. Por esses motivos, foi escolhido o padrão H.264/AVC com escalabilidade para a realização dos testes. Estes serão feitos, variando-se a maneira de se comprimir o stream de vídeo e analisando-se os resultados: a taxa de bits por segundo e a qualidade.

A seguir serão descritos os testes realizados para se determinar a resposta dos algoritmos de compressão de vídeo em diferentes situações. Para todos os experimentos foi utilizada a extensão escalável do padrão H.264/AVC. A implementação utilizada foi o programa chamado Joint Scalable Video Model (JSVM), essa escolha se justifica por tratar-se de 
uma implementação open source cuja performance e documentação possuem qualidade aceitável.

Como input para os testes foi escolhido um vídeo yuv. Trata-se de um formato bruto, ou não compactado, em que as informações da imagem são fornecidas diretamente pixel por pixel. O vídeo escolhido é chamado CITY, na resolução espacial 704 X 576, comumente abreviada como 4CIF. O framerate escolhido foi de 30 quadros por segundo. Essas resoluções se revelam como suficientes para o olho humano realizar percepção de movimento de forma funcional (Richardson, 2003). É importante salientar que o arquivo yuv de entrada está na forma 4:4:4, ou seja, não sampleado.

$\mathrm{O}$ vídeo CITY foi escolhido primeiramente por tratar-se da vista aérea de uma cidade, ou seja, encaixa-se exatamente no cenário de estudo. Além disso é fornecido gratuitamente, e especificamente para finalidades científicas, já foi utilizado em diversos trabalhos (Ouaret and Dufaux, 2009), (Azad et al., 2010), (Wang et al., 2009), e suas especificações são fornecidas. Para todos os testes envolvendo camadas temporais foi utilizada variação diádica, ou seja, cada camada temporal tem o dobro de quadros em relação à camada imediatamente inferior. A taxa de FPS base para os testes é de 30, mas também foram realizados testes em vídeos com 15 FPS. No primeiro caso os números de FPS para variação diádica seriam $30,15,7.5,3.75$ e 1.875 .

Como indicador objetivo da qualidade do vídeo será utilizada uma medida logarítmica conhecida como Peak Signal-to-Noise Ratio (PSNR). Essa medida é amplamente utilizada como indicador de qualidade de faixas de vídeo (Ouaret and Dufaux, 2009), (Azad et al., 2010), (Wang et al., 2009), (Bovik, 2009). O PSNR é calculado a partir do erro quadrado médio dos pixels de cada frame, quando decodificado, em relação aos pixels do vídeo original.

A fórmula do PSNR é dada por:

$$
P S N R=20 \log \left(M A X_{i} / \sqrt{M S E}\right)
$$


Onde MSE é o erro quadrado médio de um frame e MAX é o máximo valor de um pixel. Subjetivamente, pode-se considerar que um valor de PSNR maior que 50 corresponde a uma imagem de boa qualidade e um valor inferior a 25 a uma imagem com qualidade ruim (Bovik, 2009).

Devido à maior sensibilidade do olho humano à luminância (Richardson, 2003) o PSNR medido será o referente à componente luma do yuv, ou seja, a componente Y. Dessa forma a qualidade será indicada pela sigla PSNR-Y ou apenas PSNR.

Os testes reslizados são:

- Parâmetro de quantização: Esse parâmetro é relacionado à qualidade e bitrate do vídeo. Nesse experimento busca-se o valor desse fator que proporcione a melhor combinação entre estes valores.

- Variação de Group of Pictures: Para descobrir a influência deste parâmetro na eficiência compressiva.

- Resolução espacial: Verifica se é mais vantajoso utilizar duas ou três camadas espaciais

- Escalabilidade combinada. Neste último teste, serão reunidos os resultados colhidos para construir uma configuração de vídeo escalável e verificar se atende aos requisitos da proposta de trabalho.

Em todos os experimentos, os dados de saída coletados serão:

- Gualidade do vídeo, medida a partir do PSNR.

- Taxa de Bits por segundo requerida.

A seguir são listados os parâmetros de configuração dos testes, alguns dos quais já foram citados mas serão repetidos para maior clareza:

- Máquina: : Intel(R) Core(TM) i3 CPU M 370 @ 2.40GHz 4GB RAM. 
- Sistema Operacional: Linux Ubuntu 10.04

- Software: JSVM 9.15.

- Bitrate do vídeo original:

- 4CIF: $17,4 \mathrm{Mbps}=139200 \mathrm{kbit} / \mathrm{s}$

- $\mathrm{CIF}: 4,35 \mathrm{Mbps}=34800 \mathrm{kbit} / \mathrm{s}$

- QCIF: $1,09 \mathrm{Mbps}=8720 \mathrm{kbit} / \mathrm{s}$

\subsubsection{Teste 1: Parâmetro de Quantização}

O parâmetro de Quantização (QP, do Inglês Quantization Parameter) está diretamente ligado à relação sinal ruído esperada na codificação. Da perspectiva da codificação escalável, esse parâmetro varia de acordo com a camada SNR do stream processado. Nesse teste foi realizada a codificação para diferentes valores de parâmetro de quantização. O resultados são apresentados nas figuras 4.1 a 4.3.

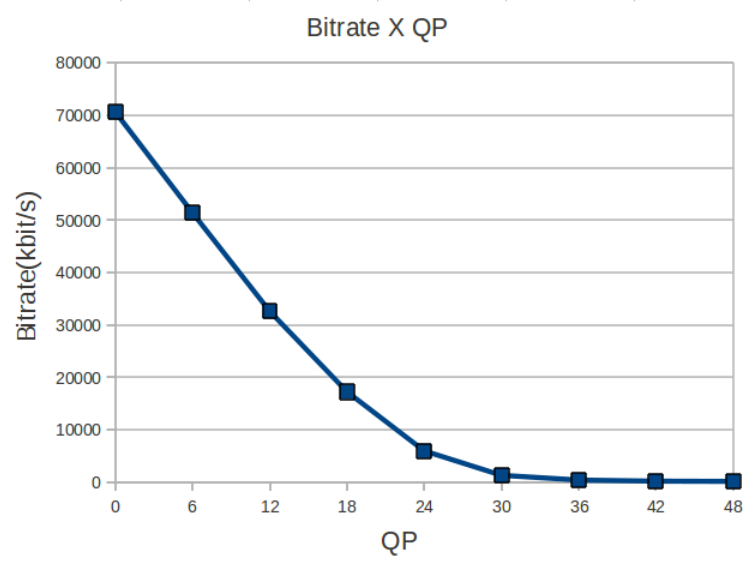

Figura 4.1: Bitrate X QP. 4CIF. 


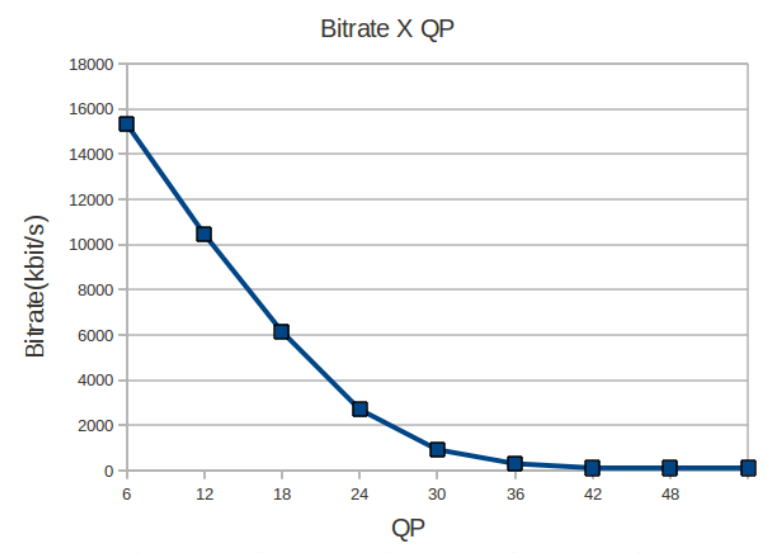

Figura 4.2: Bitrate X QP. CIF.

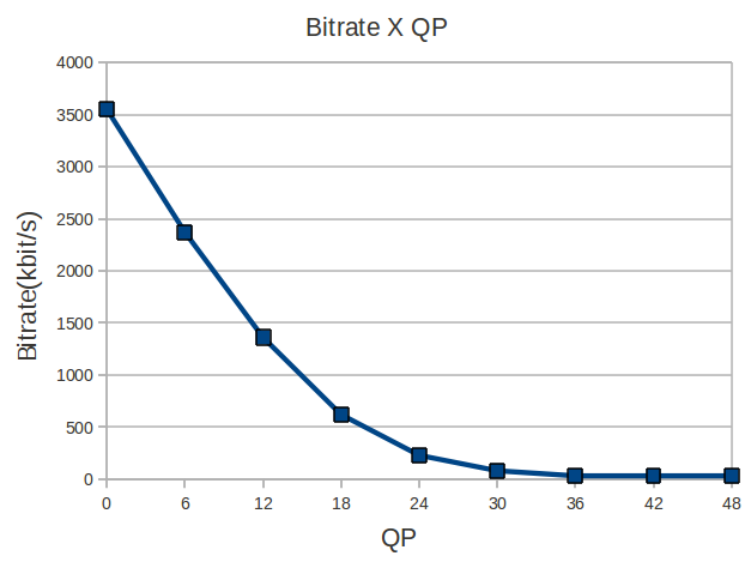

Figura 4.3: Bitrate X QP. QCIF.

\section{Análise}

A partir desses experimentos pode-se observar que:

As medidas de bitrate caem sensivelmente para valores de $\mathrm{QP}$ a partir de 24 e mais ainda para valores a partir de 30. Observa-se valores relativamente altos quando o QP é menor que 20. Os dados dos gráficos permitem concluir que a codificação mais apropriada deve ter 
um valor de QP maior que 24. As figuras A.6 a A.8, no apêndice A, mostram que o PSNR-Y está abaixo do aceitável para vídeos $4 \mathrm{CIF}$ codificados com QP maior que 36. Por isso os valores finais de parâmetro de quantização serão entre 24 e 36.

\section{1.2 Teste 2: Variação do Group of Pictures}

Nesse teste, será variado o GOP do vídeo. Lembrando que este especifica o número de frames entre dois quadros consecutivos da camada base, mais um. Por exemplo para um GOP de 16 e uma taxa de quadros por segundo de 30 FPS, a camada base teria 30/16 FPS, igual a 1,875 e as camadas seguintes teriam 3,75, 7,5, 15 e 30 FPS. A figura 4.4 apresenta a resposta de bitrates.

Análise

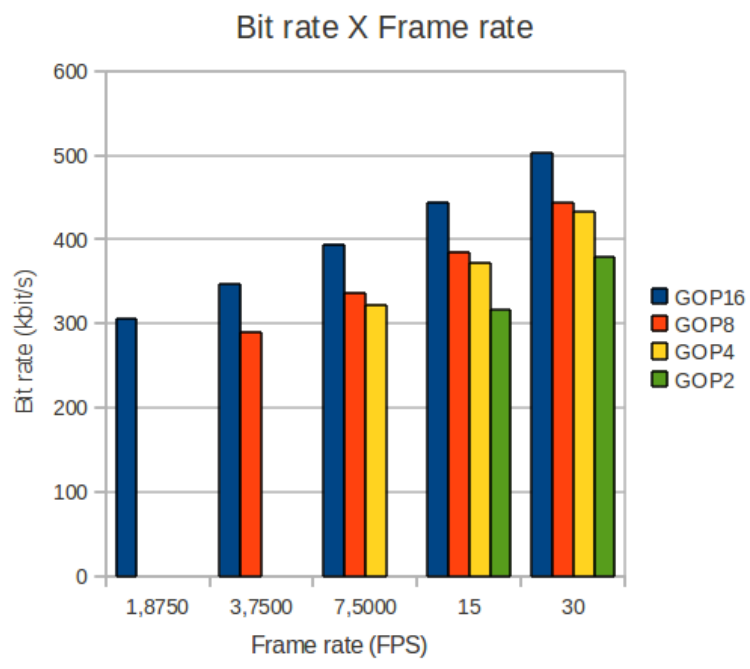

Figura 4.4: Bitrate X GOP para vídeo 4CIF a 30 FPS 
Análise

Observa-se no gráfico que, com o aumento da taxa de quadros por segundo, ocorre um suave acréscimo do bitrate do vídeo. Esse acréscimo é proporcionalmente menor em relação à diferença de FPS. Observese que quando o FPS dobra o bitrate aumenta em torno de $20 \%$. Esse dado justifica a aplicação, sempre que possível, de resoluções temporais mais elevadas, devido à melhor relação bitrate/FPS.

A segunda conclusão é que para valores mais elevados de GOP, o bitrate aumenta. Novamente, esse acréscimo é relativamente baixo (variou de $10 \%$ a $30 \%$ ). Isso leva a duas escolhas possiveis para a configuração final. Utilizando-se um valor baixo de GOP teria-se menores bitrates para altas taxas de FPS. Em compensação, valores altos de GOP possibilitam a escolha de menores resoluções temporais e consequentemente menores bitrates. A última opção apresenta uma configuração final com mais opções de FPS e bitrate, além de uma menor taxa de bits mínima, o que denota um maior alcance adaptativo. Para o prosseguimento dos testes e a construção da adaptação final apresentada no teste 5, será escolhida a representação com mais opções, ou seja, com GOP 16.

\subsubsection{Teste 3: Resolução Espacial}

No terceiro teste foi observada a variação da resposta para diferentes resoluções espaciais. Foi medido o bitrate para vídeos com diferentes camadas espaciais correspondentes a todas as permutações entre 4CIF CIF e QCIF, ou seja, 4CIF,CIF; 4CIF, QCIF; CIF, QCIF; e $4 \mathrm{CIF}, \mathrm{CIF}, \mathrm{QCIF}$. Os resultados são apresentados nas figuras de 4.5 a 4.8 . 


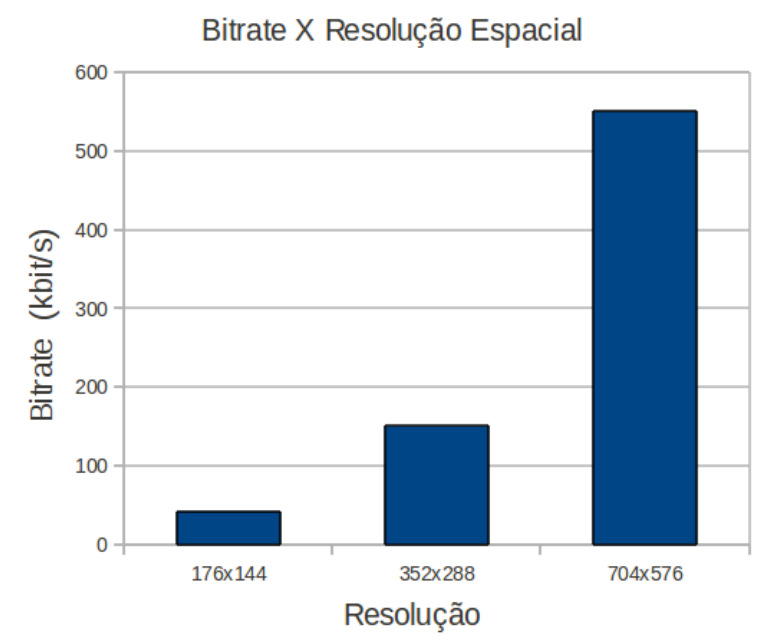

Figura 4.5: Bitrate X Resolução Espacial. 4CIF X CIF X QCIF. 30 FPS.

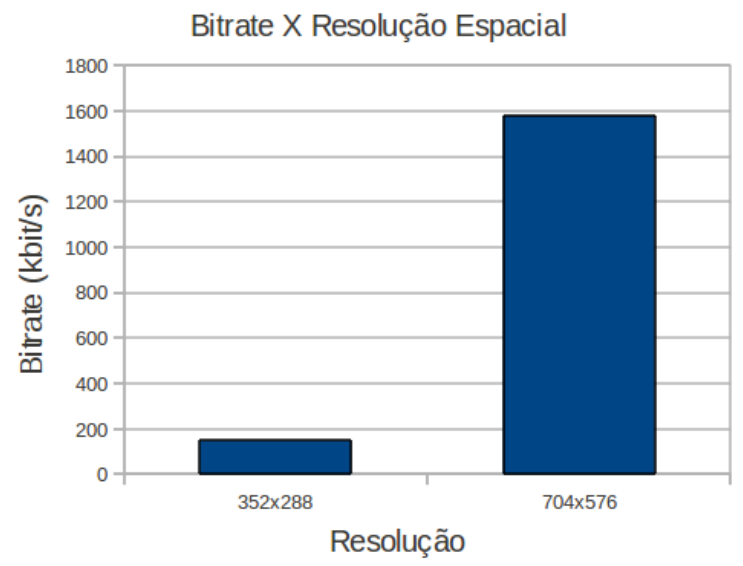

Figura 4.6: Bitrate X Resolução Espacial. 4CIF X CIF. 30 FPS.

\section{Análise}

A partir desse experimento observou-se: O valor de bitrate das camadas intemediárias não se alterou com a mudança de codificação, porém o valor máximo de bitrate apresentou diferentes valores, sendo 


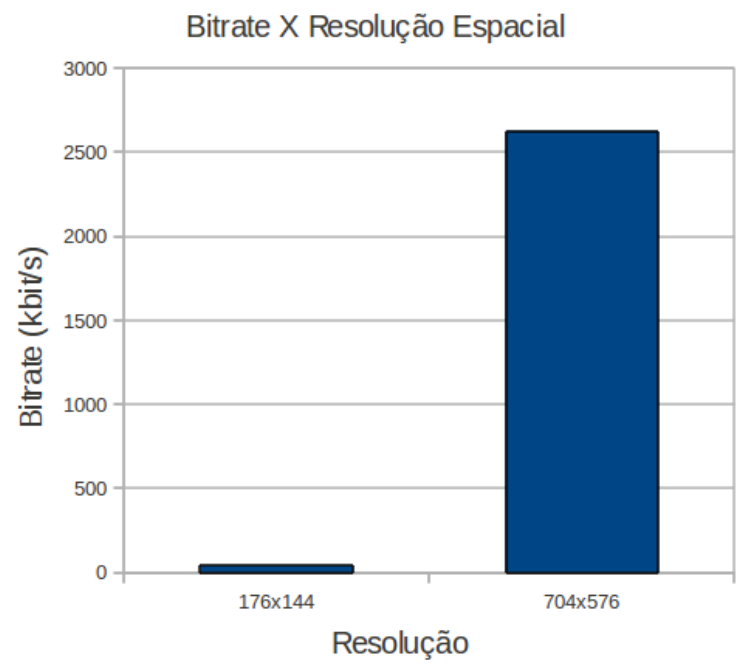

Figura 4.7: Bitrate X Resolução Espacial. 4CIF X QCIF. 30 FPS.

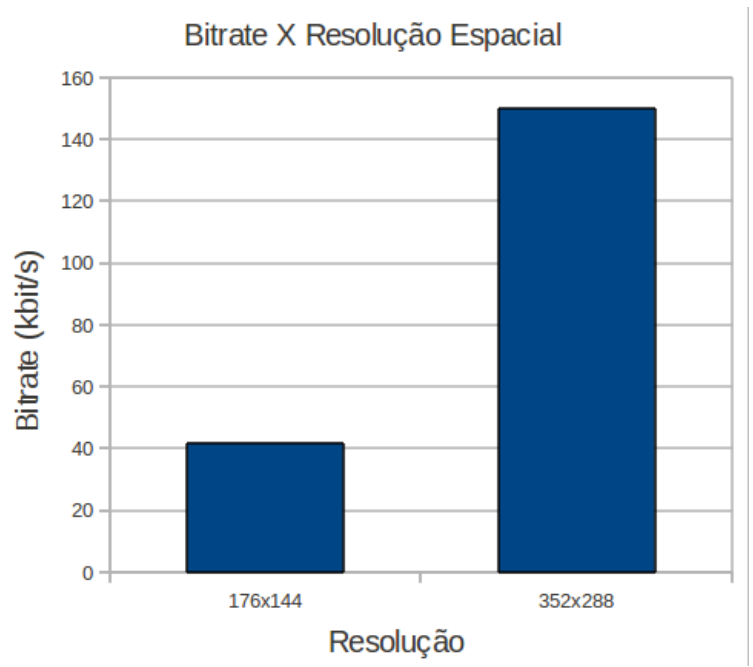

Figura 4.8: Bitrate X Resolução Espacial. CIF X QCIF. 30 FPS.

o menor para codificação com três camadas espaciais. Talvez isso seja devido ao fato de a predição entre camadas ser mais eficiente quando há mais destas disponíveis, ou quando a camada inferior tem 
resolução mais próxima da camada que utiliza os dados da predição. Esse experimento leva a concluir que a melhor resposta em termos de codificação espacial, nesse contexto, é para um stream com três camadas.

\subsubsection{Teste 4: Combinação de Escalabilidade}

Nesse teste foram utilizados os três tipos de escalabilidade (espacial, temporal e snr) combinadas, medindo-se o resultado para cada configuração. Esse teste final reúne as informações obtidas nos experimentos anteriores de forma a construir uma configuração de adaptação otimizada. Dessa forma, foram escolhidos os seguintes parâmetros: GOP de 16, de forma a proporcionar mais camadas temporais ; Três camadas espaciais que, conforme o teste dois, proporcionaram resultados adequados; e parâmetros de quantização de entre 28 e 36 . A configuração final estabeleceu-se então em:

- Quatro camadas temporais com resolução espacial QCIF: 1,87, 3,75, 7,5 e 15 FPS. Com parâmetro de quantização de 32 .

- Quatro camadas temporais análogas às anteriores em resolução espacial QCIF. Com parâmetro de quantização de 28.

- Cinco camadas temporais com resolução espacial CIF, com parâmetro de quantização de 34 .

- Cinco camadas temporais com resolução espacial CIF, com parâmetro de quantização de 28.

- Cinco camadas temporais com resolução espacial 4CIF, com parâmetro de quantização de 34 .

- Cinco camadas temporais com resolução espacial 4CIF, com parâmetro de quantização de 28 . 
Dessa forma a configuração final terá: Cinco camadas temporais; três espaciais e duas de qualidade, resultando em um stream escalável com 28 camadas.

A figura 4.11 mostra a variação do bitrate para cada resolução espacial em função da taxa de quadros por segundo. A figura 4.10 apresenta as mesmas informações, mas somente para para as resoluções Q-CIF e CIF, para fim de uma melhor visualização do gráfico. A figura 4.9 mostra o bitrate exigido para cada camada. Note-se que na figura 4.11 aparece mais de uma curva para a mesma resolução espacial, isso é devido à divisão de uma camada espacial em duas ou mais camadas SNR. As figuras 4.12 e 4.13 mostram os mesmos resultados em escala logarítmica

\section{Análise}

O último teste combinou os resultados adquiridos em todos os anteriores, a fim de proporcionar uma configuração escolhendo as variáveis de entrada mais adequadas de acordo com resultados predecessores. Observando-se os gráficos das figuras 4.9 a 4.11 nota-se que o bitrate passa a aumentar mais acentuadamente a partir da camada 17. Nesse ponto há o câmbio entre a resolução QCIF e CIF. Dessa forma, conclui-se que em situações de escassez de banda a utilização da resolução QCIF proporcionará uma substancial economia desse recurso. Aliada a essa observação, nota-se no gráfico da figura 4.11 que, quando se muda de camada espacial ou camada SNR, o impacto no bitrate é mais acentuado que quando se troca de camada temporal. Conclui-se então que a escalabilidade temporal é a de menor influência na alteração da largura de banda necessária. 


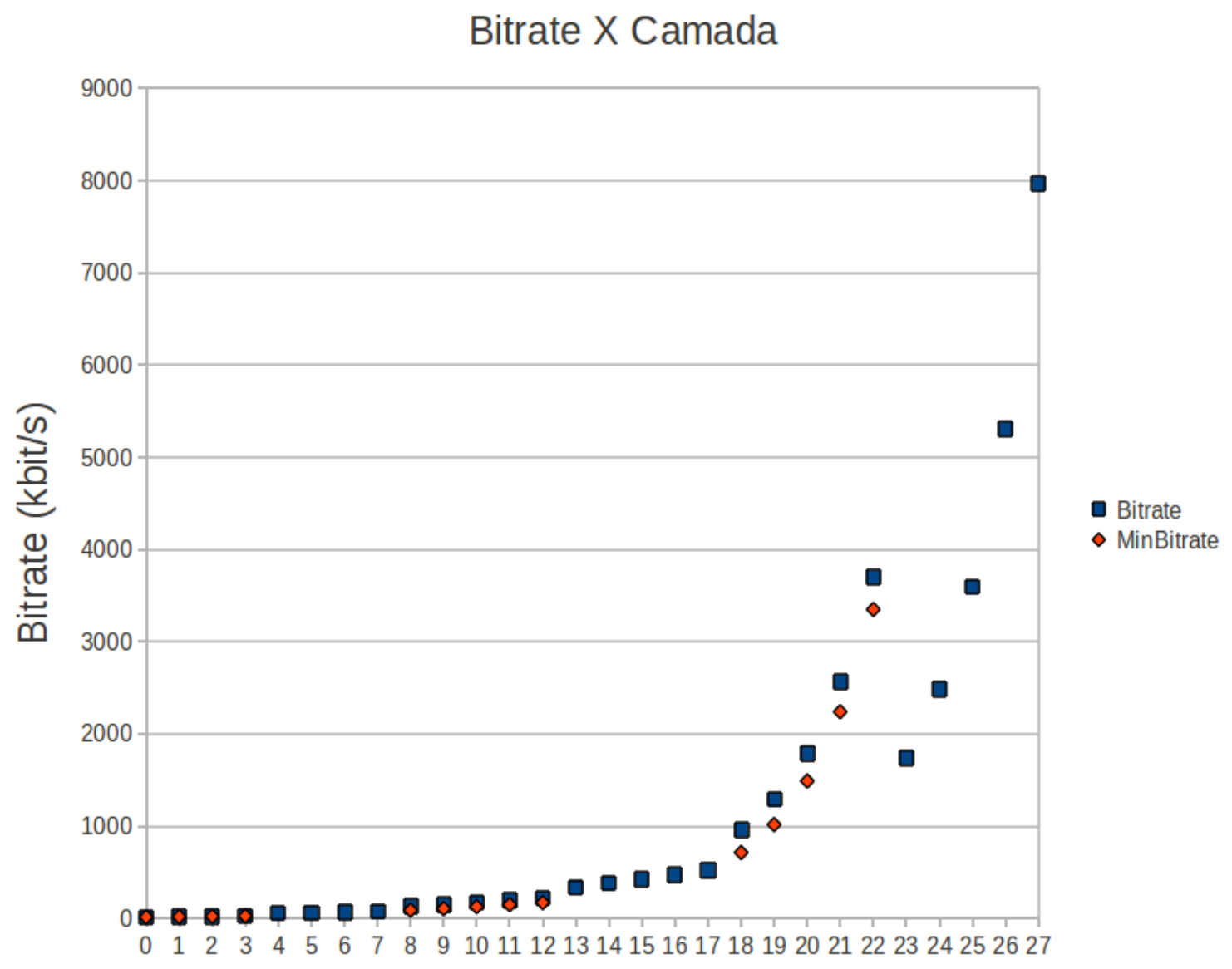

Camada

Figura 4.9: Bitrate X Camada

\section{1.5 Faixas de valores de bits}

Enfim, para guiar um algoritmo de adaptação de vídeo, possui-se agora as informações necessárias explicitando, para um stream de vídeo, faixas de bitrate e configurações de adaptação para cada uma dessas faixas. A tabela 4.1 exibe os mesmos dados da figura 4.9. A tabela 4.2 exibe grupos de faixas de bitrates para cada resolução 


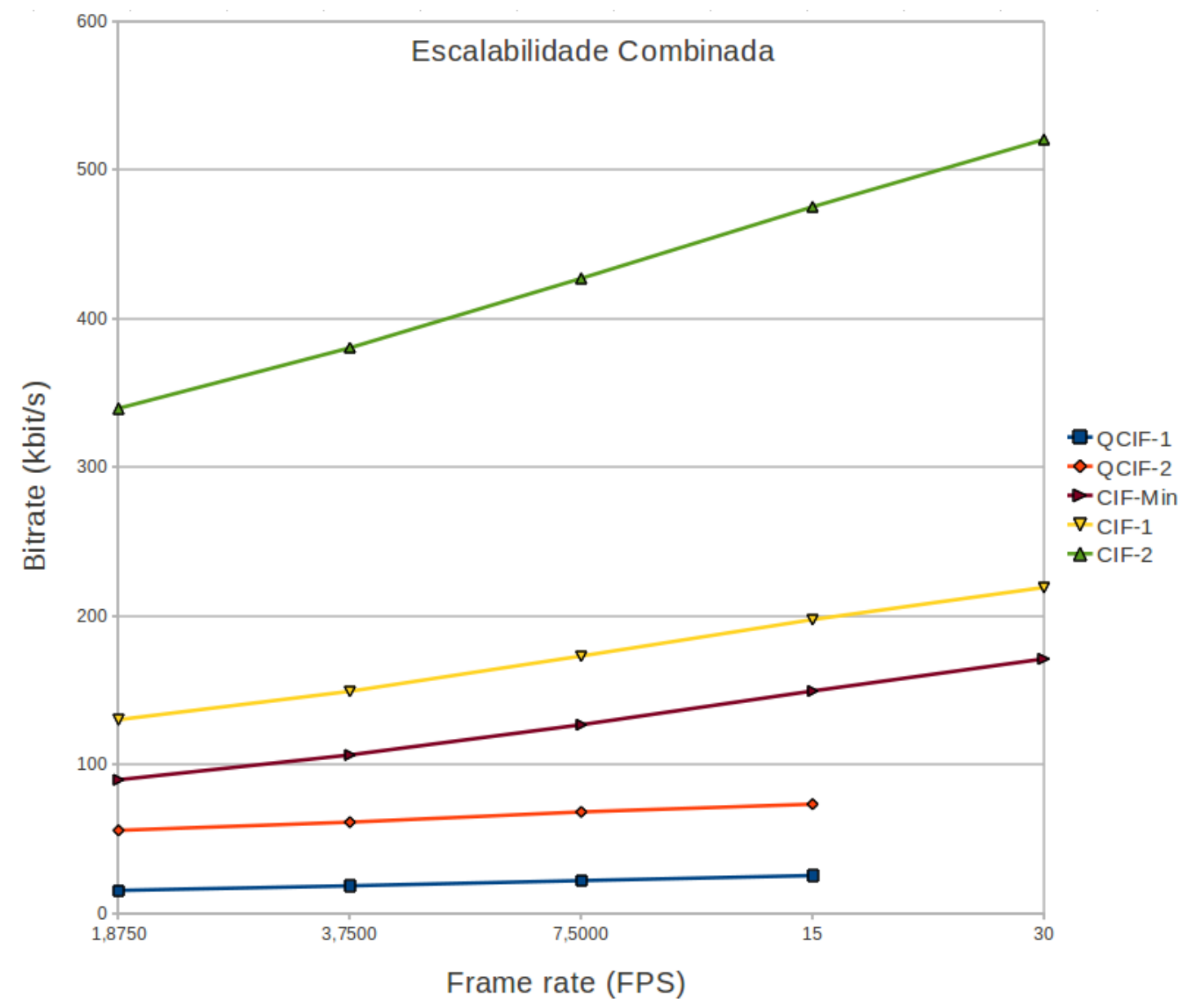

Figura 4.10: Bitrate X Framerate. Somente Q-CIF e CIF.

temporal e espacial. Com os resultados dos experimentos foi possível estabelecer valores de bitrate de 7968 a $16 \mathrm{kbps}$. Dessa forma, em um VANT em missão, quando o módulo de gerenciamento de contexto aferir uma dada largura de banda disponível, o módulo de adaptação de vídeo irá processar essa informação e comparar com os valores da tabela, chegando a uma determinada faixa de bitrate $\mathrm{e}$ uma respectiva combinação de resolução espacial $\mathrm{X}$ taxa de quadros por segundo X qualidade. O módulo de adaptação irá então descartar 


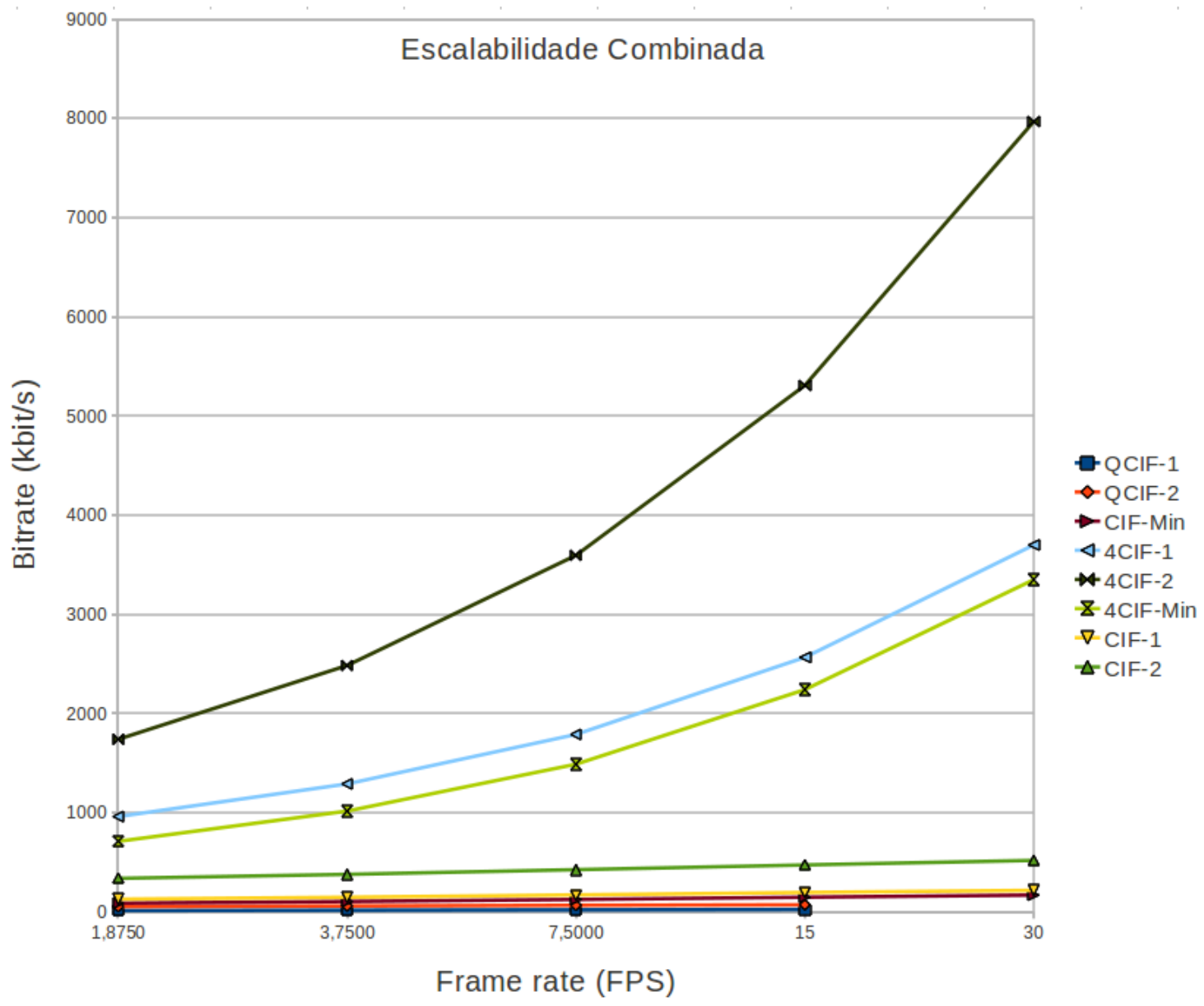

Figura 4.11: Bitrate X Framerate. Gráfico Completo.

as camadas em excesso e transmitir um stream com bitrate inferior ao disponível, dessa forma serão evitadas interrupções na apresentação. O mais importante é que, com os resultados desse experimento será possivel construir uma faixa de valores de bitrate, cada um associado a uma codificação, essa faixa servirá como guia do algoritmo de adaptação vídeo para este conhecer que codificação utilizar para cada bitrate necessário. 


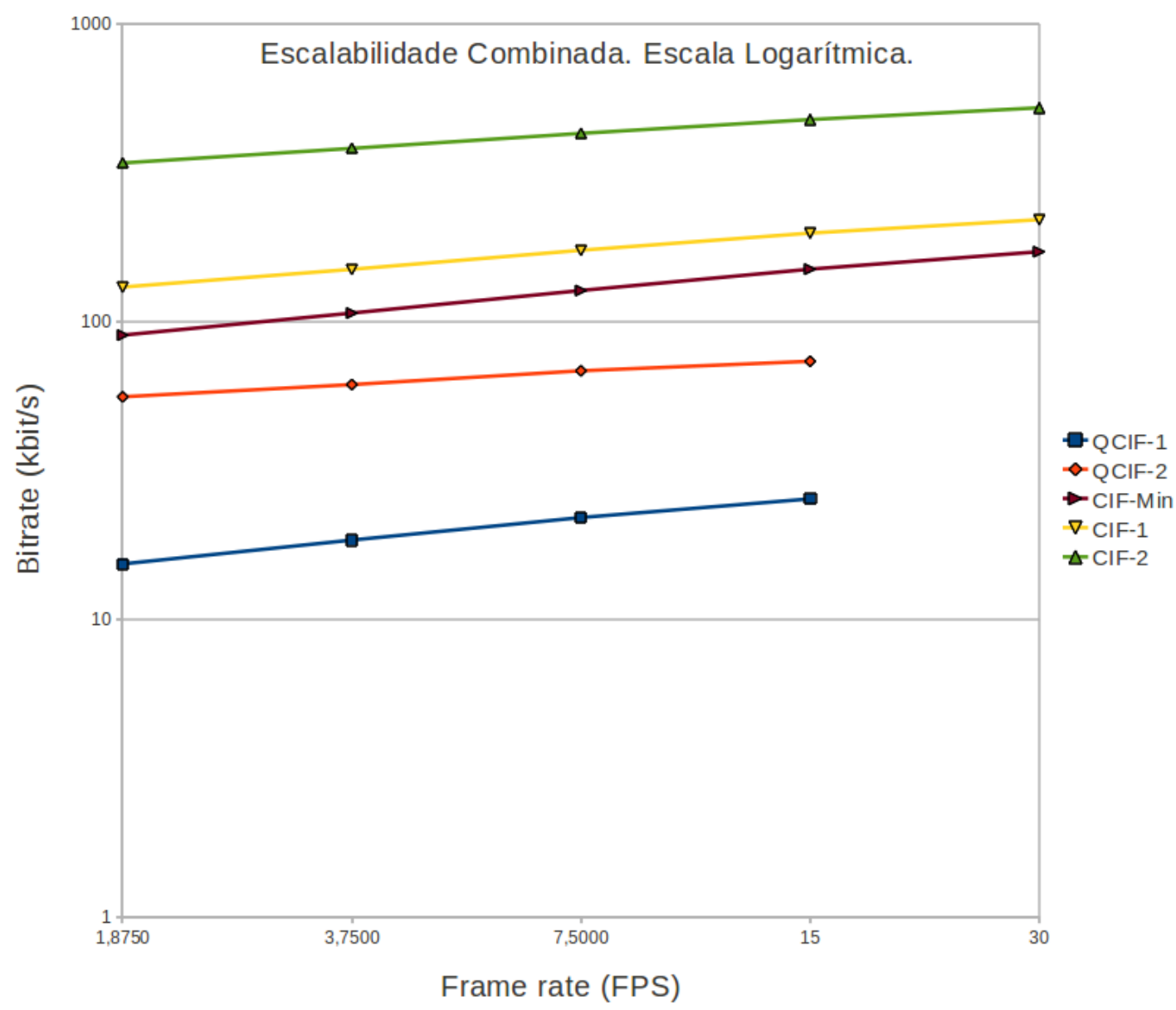

Figura 4.12: Bitrate X Framerate. Escala Logarítmica. Somente Q-CIF e CIF.

\subsection{PSNR-Y}

Os gráficos presentes no apêndice A mostram todas as saídas para PSNR-Y. De todas as informações contidas nesses gráficos, é suficiente observar que todos os valores de PSNR-Y estão acima de 30, exceto no teste da figura A.6 em que essa variável assume valores menores que 30 para vídeos em 4CIF, quando o gP é maior que 36. 


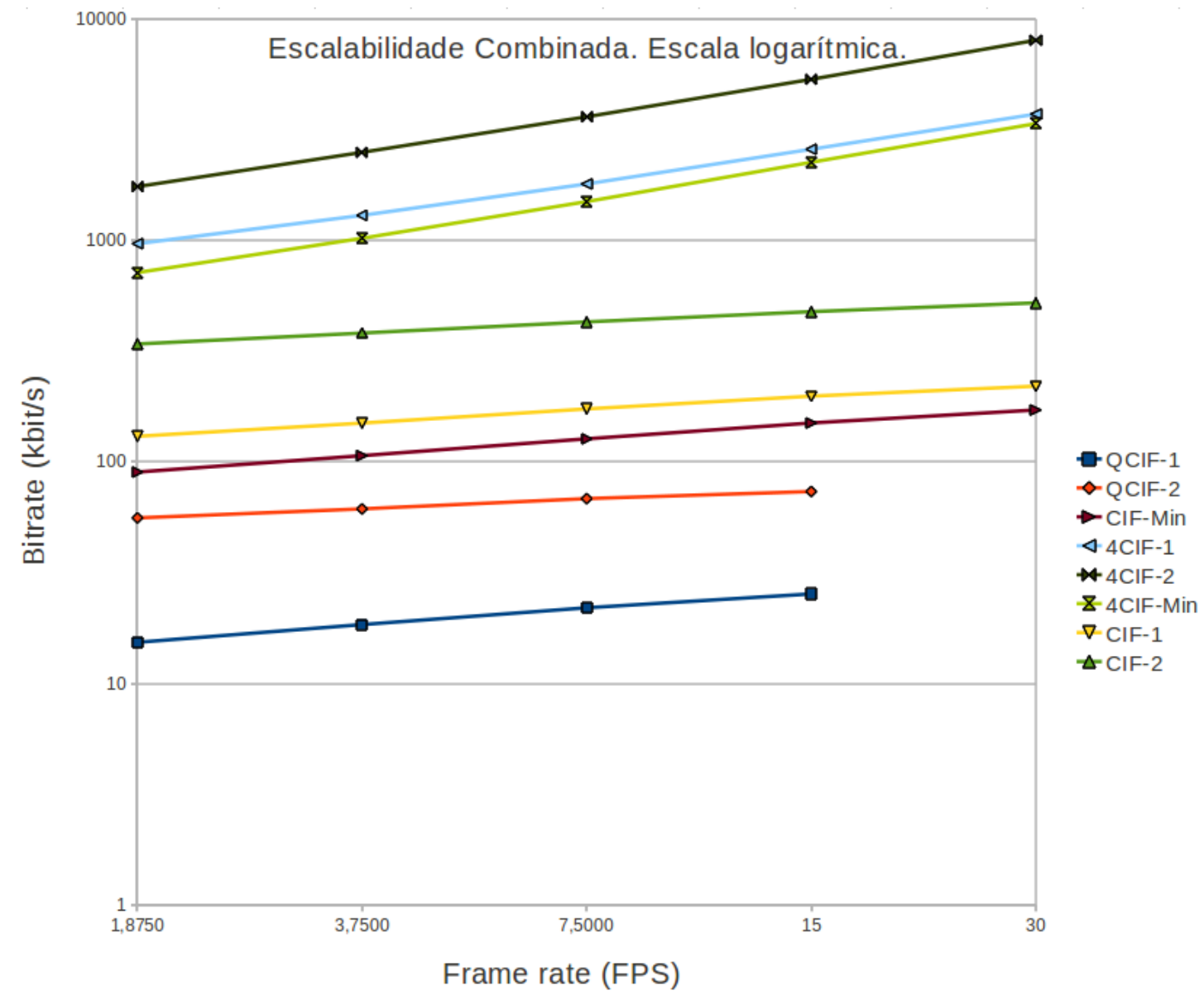

Figura 4.13: Bitrate X Framerate. Escala Logarítmica. Gráfico Completo.

Isso significa que todas as configurações de adaptação testadas, exceto essa última, são aceitáveis. 
Tabela 4.1: Camada X Bit-rate(kbit/s)

\begin{tabular}{|c|c|c|}
\hline \hline camada & bit-rate(kbit/s) & min bit-rate (kbit/s) \\
\hline 0 & 15,3 & - \\
\hline 1 & 18,4 & - \\
\hline 2 & 21,9 & - \\
\hline 3 & 25,3 & - \\
\hline 4 & 55,7 & - \\
\hline 5 & 61,2 & - \\
\hline 6 & 68,1 & - \\
\hline 7 & 73,3 & - \\
\hline 8 & 130,1 & 89,7 \\
\hline 9 & 149,2 & 106,4 \\
\hline 10 & 172,9 & 126,7 \\
\hline 11 & 197,7 & 149,4 \\
\hline 12 & 219 & 171 \\
\hline 13 & 339,4 & - \\
\hline 14 & 380,1 & - \\
\hline 15 & 426,8 & - \\
\hline 16 & 474,9 & - \\
\hline 17 & 520,2 & - \\
\hline 18 & 962,4 & 712,7 \\
\hline 19 & 1291,3 & 1017,6 \\
\hline 20 & 1790 & 1489,9 \\
\hline 22 & 3699 & 3349,8 \\
\hline 23 & 1741 & - \\
\hline 24 & 2485 & - \\
\hline 25 & 3595 & - \\
\hline 26 & 5307 & - \\
\hline 27 & 7967 & - \\
\hline & & \\
\hline
\end{tabular}

Tabela 4.2: Bitrates suportados (kbit/s)

\begin{tabular}{|c|c|c|c|c|c|}
\hline \hline & 1,875 & 3,75 & 7,5 & 15 & 30 \\
\hline BCIF & $16-56$ & $19-62$ & $22-69$ & $26-74$ & - \\
CIF & $90-340$ & $107-381$ & $173-427$ & $150-475$ & $171-521$ \\
$4 \mathrm{CIF}$ & $713-1741$ & $1018-2485$ & $1790-3595$ & $2242-5307$ & $3350-7967$ \\
\hline
\end{tabular}




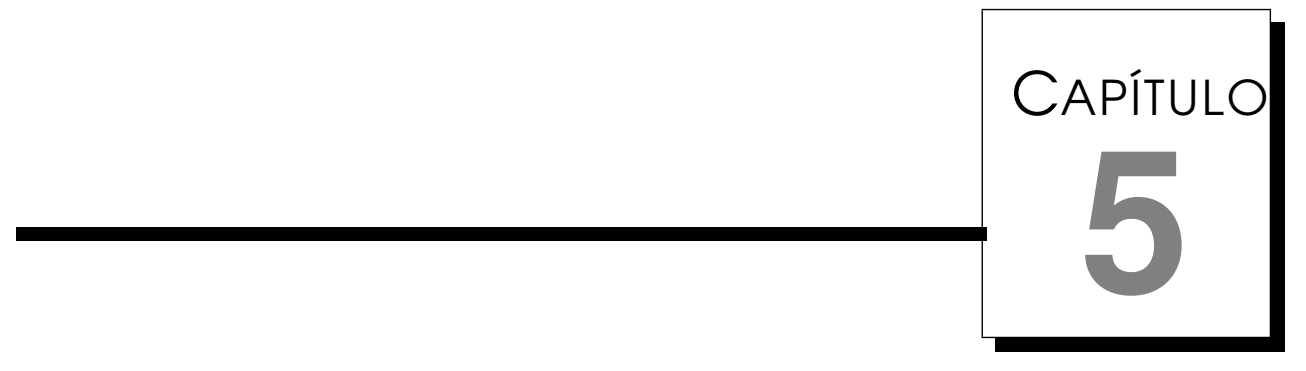

\section{Conclusões e trabalhos futuros}

\subsection{Considerações iniciais}

No presente trabalho foram realizadas pesquisas e experimentos para possibilitar a adaptação de vídeo em um VANT. Os estudos em adaptação de vídeo apontaram o codec H.264/AVC como o mais apropriado disponível. O JPEG2000 também possui atrativos mas estudos comparativos mostraram o H.264/AVC como mais indicado para o contexto deste trabalho. Adicionalmente, a utilização de vídeo escalável foi diferencial para tornar esse trabalho possível. A vantagem desse tipo de codificação possibilita aprimorar a adaptação de vídeo, uma vez que é realizada uma única codificação independente da largura de banda e só depois da aferição dessa última, é executada, não uma nova codificação, mas simplesmente o descarte 
de uma ou mais camadas. Testes do Codec JSVM buscaram identicar uma configuração apropriada do stream de vídeo. Chegou-se a valores de parâmetro de quantização entre 24 e 36 como mais adequados à compressão. No tocante à variável Group of Pictures, escolheu-se um GOP de 16 pois é o que oferece mais opções de escalabilidade. Em relação às camadas temporais, estas são diretamente proporcionais ao GOP, então a escolha do GOP de 16 já definiu a escolha de cinco camadas espacias de 1,875, 3,75, 7,5, 15 e 30 FPS. As camadas espaciais adotadas eram a princípio, em três resoluções conhecidas: QCIF, CIF e 4CIF, e os experimentos confirmaram a adequação dessas camadas. Finalmente foi construído o bitstream escalável final com 28 camadas, variando entre valores de bitrate de 16 até 7967 kbps. Foram medidos valores de PSNR para os testes e em quase a totalidade foram valores aceitáveis. O mais importante é que para a configuração final o PSNR foi aceitável, de forma que os resultados dos testes continuam válidos. Uma consideração importante é a respeito da possibilidade de implementar a compressão em questão em um cenário de vídeo em tempo real. Essa não é uma tarefa trivial. Para assegurar essa possibilidade e, dessa forma, validar os resultados obtidos, foi realizada uma revisão sistemática de artigos a respeito da implemtentação de compressão com H.264/AVC em tempo real. Os resultados são mostrados na seção seguinte:

\subsection{Considerações quanto à performance em tempo real}

Os testes realizados permitem definir o comportamento do módulo de adaptação de vídeo de um VANT de acordo com a taxa de bits necessária. No entanto, para a realização desse processamento, o módulo deve ter a capacidade de processar o stream em tempo 
real. O equipamento disponível para os experimentos não é suficiente para realizar o processamento nessa velocidade, e para isso seria necessário um hardware superior. Buscando analisar a viabilidade da implementação da compressão de vídeo em tempo real, nesse capítulo é realizada uma revisão sistemática sobre a tecnologia e conhecimento existentes nesse quesito. Foram analisados 25 trabalhos, dentre os quais: quinze afirmam a possibilidade dessa compressão, sendo sete considerando a utilização de vídeo escalável e oito considerando apenas o H.264/AVC sem escalabilidade; três consideram já implementada a compressão H.264/AVC, três apenas citam essa compressão e quatro apresentam soluções alternativas ao H.264 para o processamento em tempo real.

Dentre os trabalhos que afirmam a possibilidade de se utilizar H.264 em tempo real, cinco propuseram arquiteturas de hardware de forma a alcançar a eficiência proposta, e três propuseram novos algoritmos. Além desses trabalhos foram analisados 12 manuais de codecs disponíveis no mercado, dentre os quais: nove realizam adaptação em tempo real apenas com H.264/AVC, três afirmam realizar compressão H.264/AVC com escalabilidade e dentre esses últimos apenas um não processa em tempo real. Em virtude das informações colhidas nessa revisão, é possivel assegurar a possibilidade da implementação do processamento de vídeo com H.264/AVC com escalabilidade em um sistema operando em tempo real. As referências dos artigos pesquisados são:

- Yang et al. (2012)

- Wien et al. (2007)

- Zhang et al. (2010)

- Doukas et al. (2007)

- Käs and Nicolas (2009) 
- Stefan Karapetkov (2011)

- Ha et al. (2005)

- Wang et al. (2005)

- da Fonseca et al. (2010)

- Moorthy (2008)

- Su et al. (2007)

- OZBEK and TUNALI (2005)

- Alvarez et al. (2005)

- Kannangara (2006)

- Hannuksela (2009)

- Salem et al. (2009)

- Schwarz et al. (2007)

- Johanson (2003)

- Fowler et al. (1995)

- Igolgi Solutions (2010)

- Belyaev et al. (2010)

- Mrak et al. (2002)

- Sun et al. (2007)

- Zhang and Guanjun (2006)

- Wattson (2010)

A seguir são citados os codecs pesquisados:

- PCI e DVR - Wavestore.

- Vanguard Software Solutions H.264 encoder

- TVS Challenger HDE-2000 HD1080P MPEG-4 AVC ENCODER 
- SkyVision DS-4200 Series DVR cards

- Video Surveillance TruVision Digital Recorder

- Traficon - VIP - IP Encoder

- UltraView Encoder 10

- TruVision DVR 60, Scalable H.264 24-Ch. hybrid recorder

- ICRealtime Digital Video Compression Card

- Telairity BE7110 SD H264

- Allitwares.com 8 Ports Audio/Video DVR Card

- GE- TS -VID -Mp4

\subsection{Trabalhos Futuros}

Os resultados deste estudo funcionam como entrada para um algoritmo de adaptação de vídeo de um VANT. Buscou-se nesse trabalho assegurar a possibilidade da implementação dos resultados, assim como a utilização do codec mais apropriado disponível, obtendo informações atualizadas. Para o futuro, uma continuação desse trabalho seria possibilitar a compressão usando a extensão escalável do H.264/AVC em tempo real, para isso pode ser elaborada uma nova arquitetura de hardware ou buscar a solução através de algoritmos inovadores. Outro trabalho futuro é a elaboração do funcionamento do módulo de contexto, de forma a otimizar a adaptação de vídeo provendo informações contextuais adquiridas através dos sensores do VANT ou calculadas no próprio módulo. 


\section{Referências Bibliográficas}

(2005). The u.s. air force remotely piloted aircraft and unmanned aerial vehicle strategic vision. 31,33

(2010). The Case for Software Solutions for Real Time Video Applications. 60

Alvarez, M., Salami, E., Ramirez, A., and Valero, M. (2005). A performance characterization of high definition digital video decoding using h.264/avc. In Workload Characterization Symposium, 2005. Proceedings of the IEEE International, pages 24-33. 60

Amon, P., Li, H., Hutter, A., Renzi, D., and Battista, S. (2008). Scalable video coding and transcoding. In Automation, Quality and Testing, Robotics, 2008. AQTR 2008. IEEE International Conference on. 25,28

Apostolopoulos, J. G. (2005). Video compression: Principles, practice, and standards. Streaming Media Systems Group. 10

Azad, S., Song, W., and Tjondronegoro, D. (2010). Bitrate modeling of scalable videos using quantization parameter, frame rate and spa- 
tial resolution. In Acoustics Speech and Signal Processing (ICASSP), 2010 IEEE International Conference on, pages 2334-2337. 40

Belyaev, E., Sukhov, T., and Kai, L. (2010). Scalable video coding based on three-dimensional discrete pseudo cosine transform. In Balandin, S., Dunaytsev, R., and Koucheryavy, Y., editors, Smart Spaces and Next Generation Wired/Wireless Networking, volume 6294 of Lecture Notes in Computer Science, pages 448-459. Springer Berlin / Heidelberg. 10.1007/978-3-642-14891-0_39. 60

Bovik, A. (2009). The essential guide to video processing. Elsevier Science Publishers B. V. 14, 15, 16, 18, 40, 41

Camperi, G. and Picco, V. (2008). H.264/avc intra coding and jpeg 2000 comparison. 20

da Fonseca, T., de Queiroz, R., and Mukherjee, D. (2010). Complexity-scalable h.264/avc in an ipp-based video encoder. In Image Processing (ICIP), 2010 17th IEEE International Conference on, pages 2885-2888. 60

Doukas, C., Pliakas, T., and Maglogiannis, I. (2007). Advanced scalable medical video transmission based on h.264 temporal and spatial compression. In AFRICON 2007, pages 1-4. 59

Fowler, J. J., Adkins, K., Bibyk, S., and Ahalt, S. (1995). Real-time video compression using differential vector quantization. Circuits and Systems for Video Technology, IEEE Transactions on, 5(1):1424. 60

Frew, E. W. and Brown, T. X. (2009). Networking issues for small unmanned aircraft systems. J. Intell. Robotics Syst., 54:21-37. 36

Ha, V., Shim, W.-S., and Kim, J.-W. (2005). Real-time mpeg-4 avc/h.264 cabac entropy coder. In Consumer Electronics, 2005. 
ICCE. 2005 Digest of Technical Papers. International Conference on, pages 255-256. 60

Hannuksela, M. M. (2009). Error-Resilient Communication Using the H.264/AVC Video Coding Standard. PhD thesis, Tampere University of Technology. 60

Horn, U. and Girod, B. (1997). Scalable video transmission for the internet. Comput. Netw. ISDN Syst., 29:1833-1842. 25, 29

Johanson, M. (2003). A scalable video compression algorithm for real-time internet applications. In Video/Image Processing and Multimedia Communications, 2003. 4th EURASIP Conference focused on, volume 1, pages 329-334 vol.1. 60

Kannangara, C. S. (2006). Complexity management of h.264/avc video compression. Master's thesis, Robert Gordon University. 60

Käs, C. and Nicolas, H. (2009). Compressed domain indexing of scalable h.264/svc streams. Image Commun., 24(6):484-498. 59

Marpe, D., George, V., Cycon, H. L., and Barthel, K. U. (2007). Performance evaluation of motion-jpeg2000 in comparison with h.264/avc operated in pure intra coding mode. Image Commun. 21

Moorthy, T. (2008). Scalable fpga hardware acceleration for h.264 motion estimation. Master's thesis, Ryerson University. 60

Mrak, M., Grgic, M., and Grgic, S. (2002). Scalable video coding in network applications. In Video/Image Processing and Multimedia Communications 4th EURASIP-IEEE Region 8 International Symposium on VIPromCom, pages 205-211. 60

Ouaret, M. and Dufaux, F. (2009). On comparing jpeg2000 and intraframe avc. Image Processing, IET. 20, 40 
OZBEK, N. and TUNALI, T. (2005). A survey on the h.264/avc standard. Image Processing, IET. 60

Richardson, I. E. G. (2003). H.264 and MPEG-4 Video Compression. Video Coding for Next-generation Multimedia . 6, 12, 40, 41

Salem, O., Carminati, L., Senoussaoui, A., Renan, E., Bacquet, A.-S., Corlay, P., Coudoux, F.-X., Deknudt, C., Gazalet, M., Gharbi, M., Zwingelstein-Colin, M., Guarisco, M., Rabah, H., Berviller, Y., and Weber, S. (2009). Toscane: Towards scalable audiovisual communication networks. In Information Infrastructure Symposium, 2009. GIIS '09. Global, pages 1-6. 60

Schwarz, H., Marpe, D., and Wiegand, T. (2007). Overview of the scalable video coding extension of the h.264/avc standard. Circuits and Systems for Video Technology, IEEE Transactions on, 17(9):11031120. 60

Shi, B., Liu, L., and Xu, C. (2009). Comparison between jpeg2000 and h.264 for digital cinema. Image Commun. 21

Stefan Karapetkov (2011). H.264 high profile: The next big thing in visual communications. Polycon. 60

Su, L., Lu, Y., Wu, F., Li, S., and Gao, W. (2007). Real-time video coding under power constraint based on h.264 codec. IEEE. 60

Sun, H., Vetro, A., and Xin, J. (2007). An overview of scalable video streaming. Wireless Communications and Mobile Computing, 7(2):159-172. 60

Tran, T. D., Liu, L., and Topiwala, P. (2009). Performance comparison of leading image codecs: H.264/avc intra, jpeg2000, and microsoft hd photo. Image Commun. 20 
Trindade Jr, O., Jorge, L. A., and Aguiar, J. (2004). Field of dreams - using uavs for precision farming. Unmanned Systems Magazine. 1

Trussell, H., Saber, E., and Vrhel, M. (2005). Color image processing [basics and special issue overview]. Signal Processing Magazine, IEEE, 22(1):14-22. 10

Wagner, B. (2007). Civilian market for unmanned aircraft struggles to take flight. National Defense Magazine. 1

Wang, S.-Z., Lin, T.-A., Liu, T.-M., and Lee, C.-Y. (2005). A new motion compensation design for h.264/avc decoder. In Circuits and Systems, 2005. ISCAS 2005. IEEE International Symposium on, pages 4558-4561 Vol. 5. 60

Wang, Y., Ma, Z., and Ou, Y.-F. (2009). Modeling rate and perceptual quality of scalable video as functions of quantization and frame rate and its application in scalable video adaptation. In Packet Video Workshop, 2009. PV 2009. 17th International, pages 1-9. 40

Wattson, C. (2010). Scalable video coding integrates video and voice. Vidyo. 60

Wiegand, T., Sullivan, G., Bjontegaard, G., and Luthra, A. (2003). Overview of the h.264/avc video coding standard. Circuits and Systems for Video Technology, IEEE Transactions on, 13(7):560-576. $19,22,23$

Wien, M., Cazoulat, R., Graffunder, A., Hutter, A., and Amon, P. (2007). Real-time system for adaptive video streaming based on svc. Circuits and Systems for Video Technology, IEEE Transactions on, 17(9): 1227-1237. 59 
Wright, C. (2008). A comparison of mpeg4 (h.264) and jpeg2000. video compressionand decompression algorithms. Image Processing, IET. 21

Yang, J., Sun, Y., Wu, Y., and Sun, S. (2012). Joint h.264/scalable video coding-multiple input multiple output rate control for wireless video applications. Image Processing, IET, 6(1):43-52. 59

Zhang and Guanjun (2006). Robust scalable video compression using multiple description coding. Master's thesis, University of Notre Dame. 60

Zhang, H., Zheng, Y., Khojastepour, M., and Rangarajan, S. (2010). Cross-layer optimization for streaming scalable video over fading wireless networks. Selected Areas in Communications, IEEE Journal on, 28(3):344-353. 59 


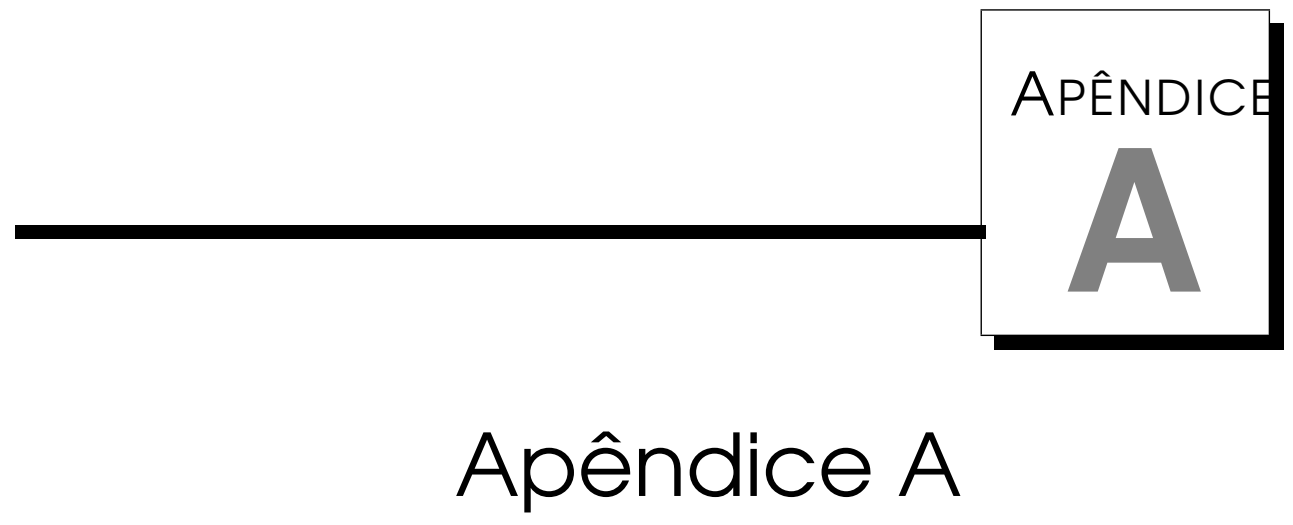

Valores medidos de PSNR-Y.

Aqui constam os valores objetivos de qualidade medidos para todos os experimentos realizados. Esses valores são expressos pelo PSNRY do vídeo. Optou-se por mostrá-los no apêndice pois para validar os experimentos basta que cumpram um requisito mínimo aceitável, ao contrário dos valores de bitrates em que variações menores importam e a análise deve ser mais detalhada. Observe-se que a maioria dos experimentos obtiveram valores de PSNR-Y aceitáveis. A única excessão foi para o experimento de vídeo $4 \mathrm{CIF}$ com parâmetro de quantização maior que 36. Por isso, essa configuração foi descartada na construção do algoritmo final, conforme é explicado no capítulo referente ao desenvolvimento do trabalho. 


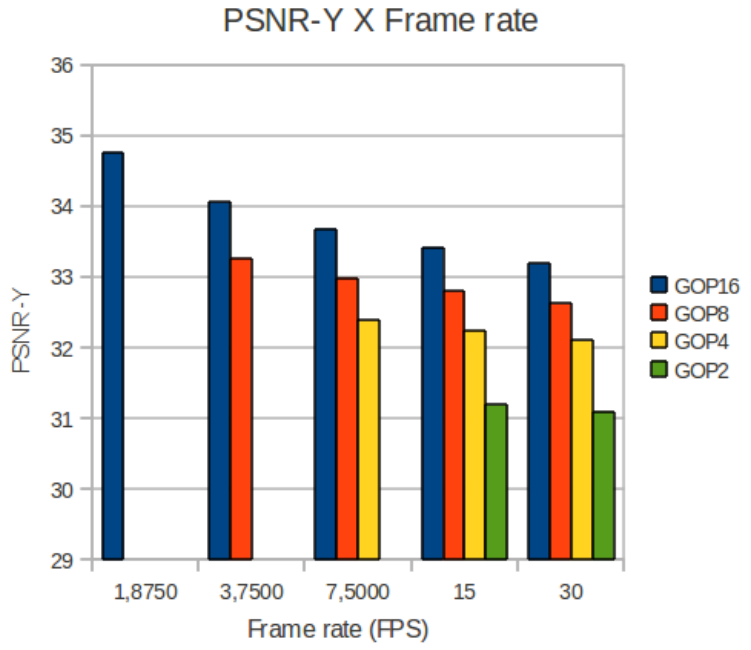

Figura A.1: PSNR-Y x Framerate (4CIF, 30 FPS)

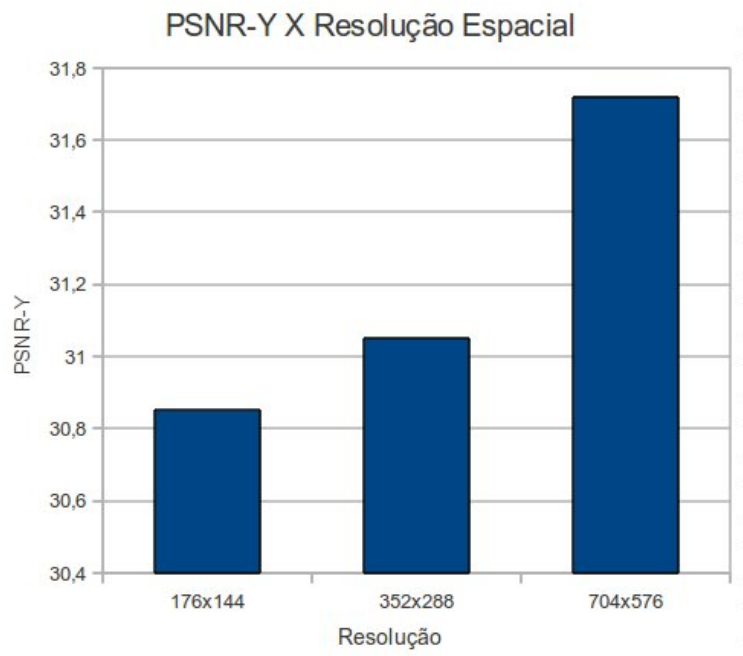

Figura A.2: PSNR-Y X Resolução Espacial. 4CIF X CIF X QCIF. 


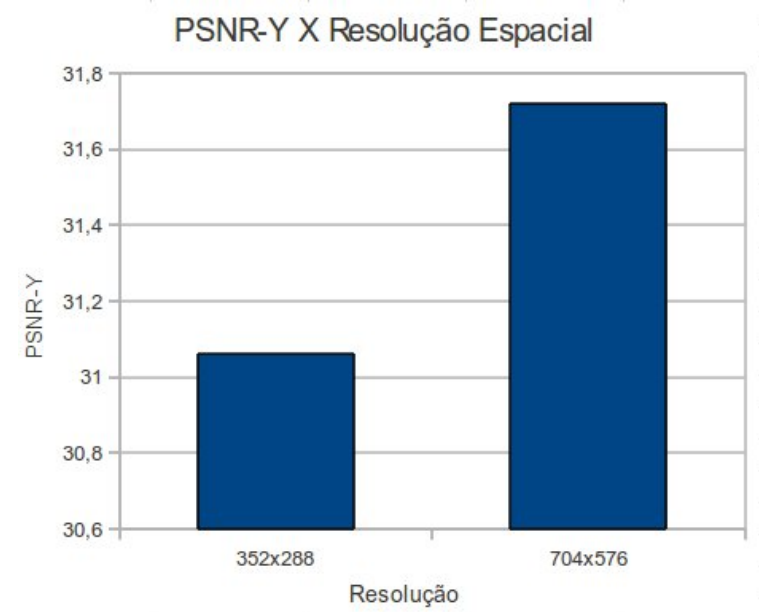

Figura A.3: PSNR-Y X Resolução Espacial. 4CIF X CIF.

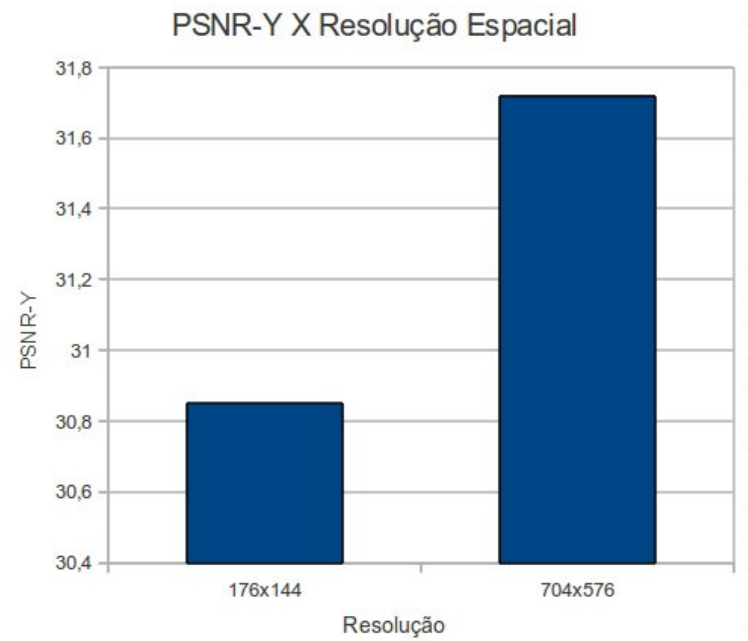

Figura A.4: PSNR-Y X Resolução Espacial. 4CIF X QCIF. 


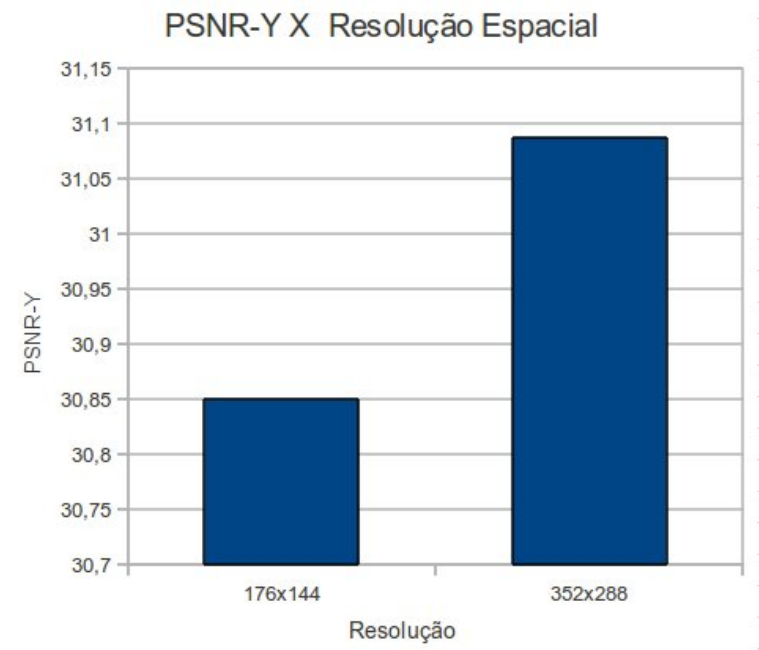

Figura A.5: PSNR-Y X Resolução Espacial. CIF X QCIF.

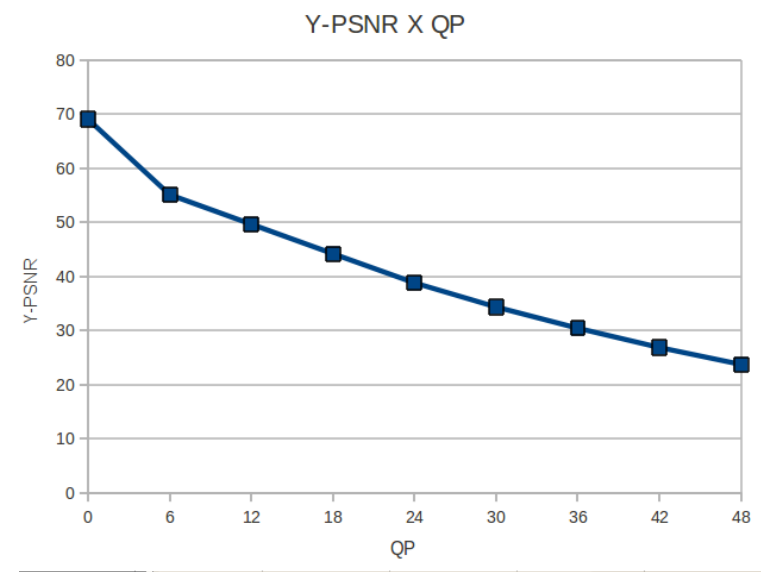

Figura A.6: PSNR-Y X QP (4CIF, 30 FPS) 


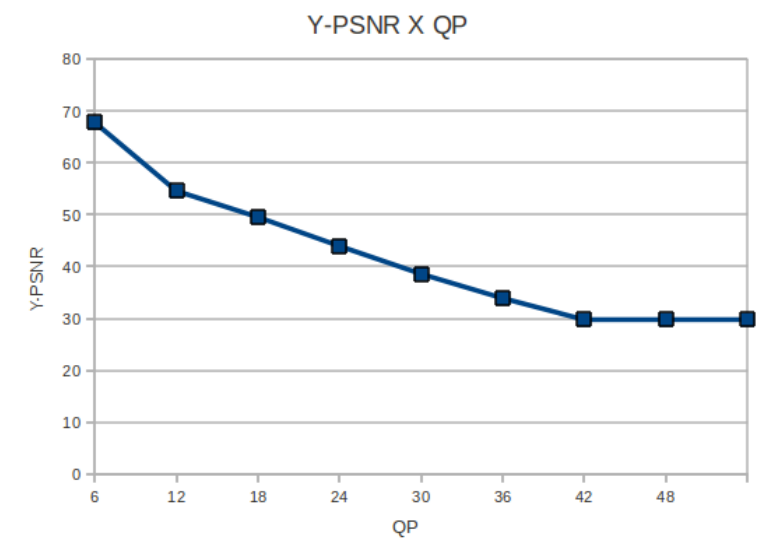

Figura A.7: PSNR-Y X QP (CIF, 30 FPS)

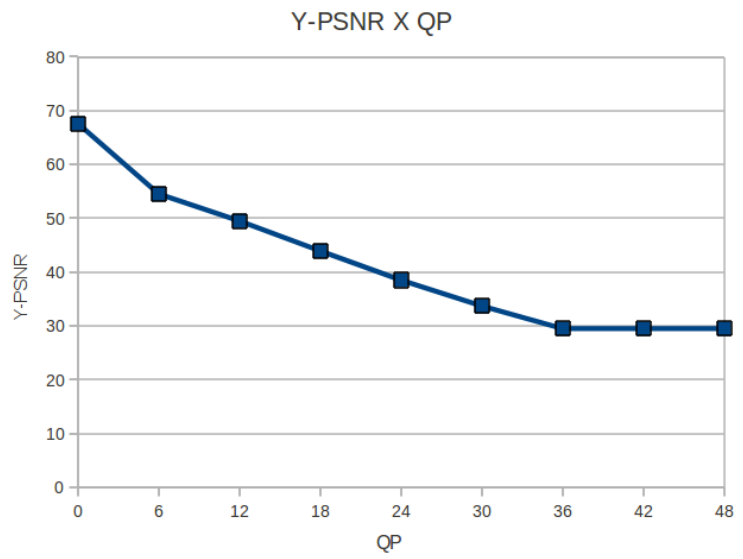

Figura A.8: PSNR-Y X QP (QCIF, 30 FPS) 


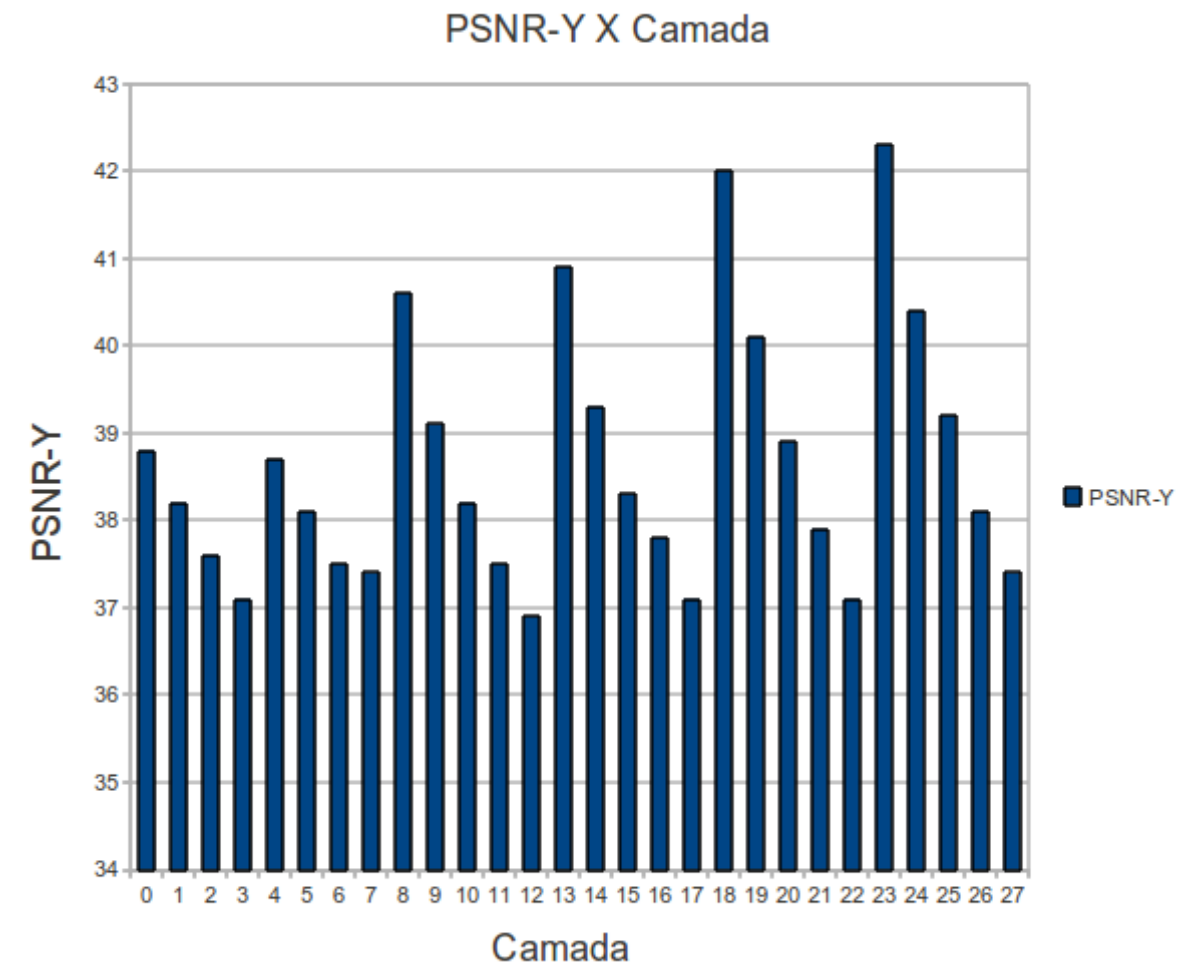

Figura A.9: PSNR-Y X Camada. Configuração do teste 4. 


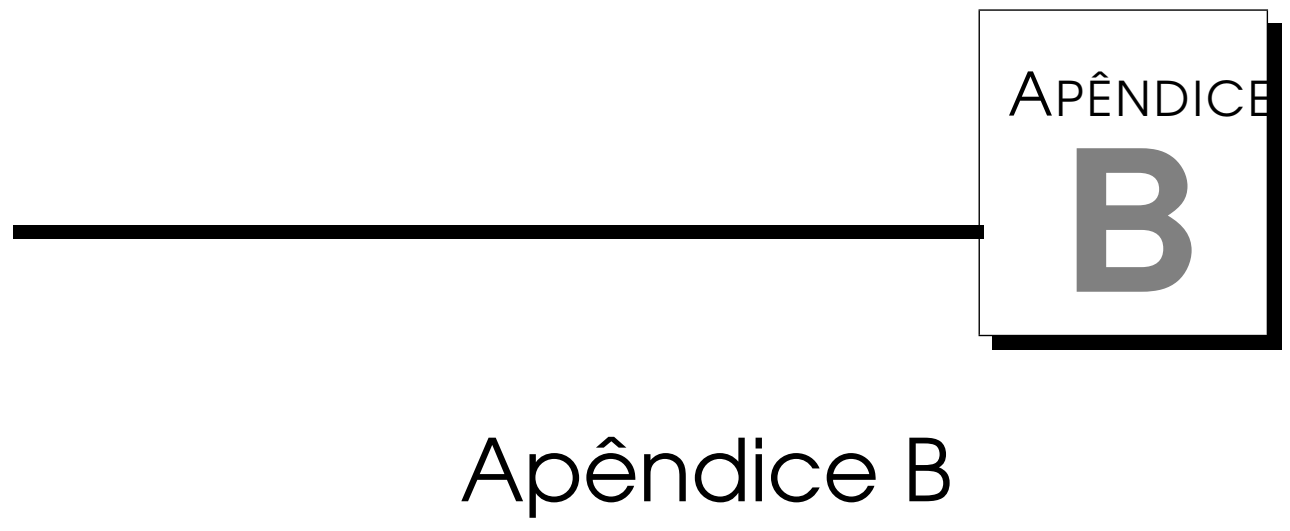

B. 1 Arquivos de configuração para os experimentos.

B. 1.1 Teste 1. Parâmetro de quantização.

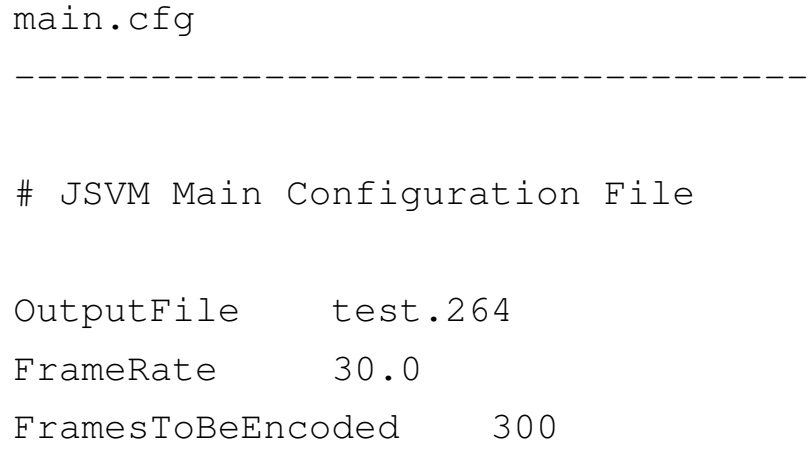




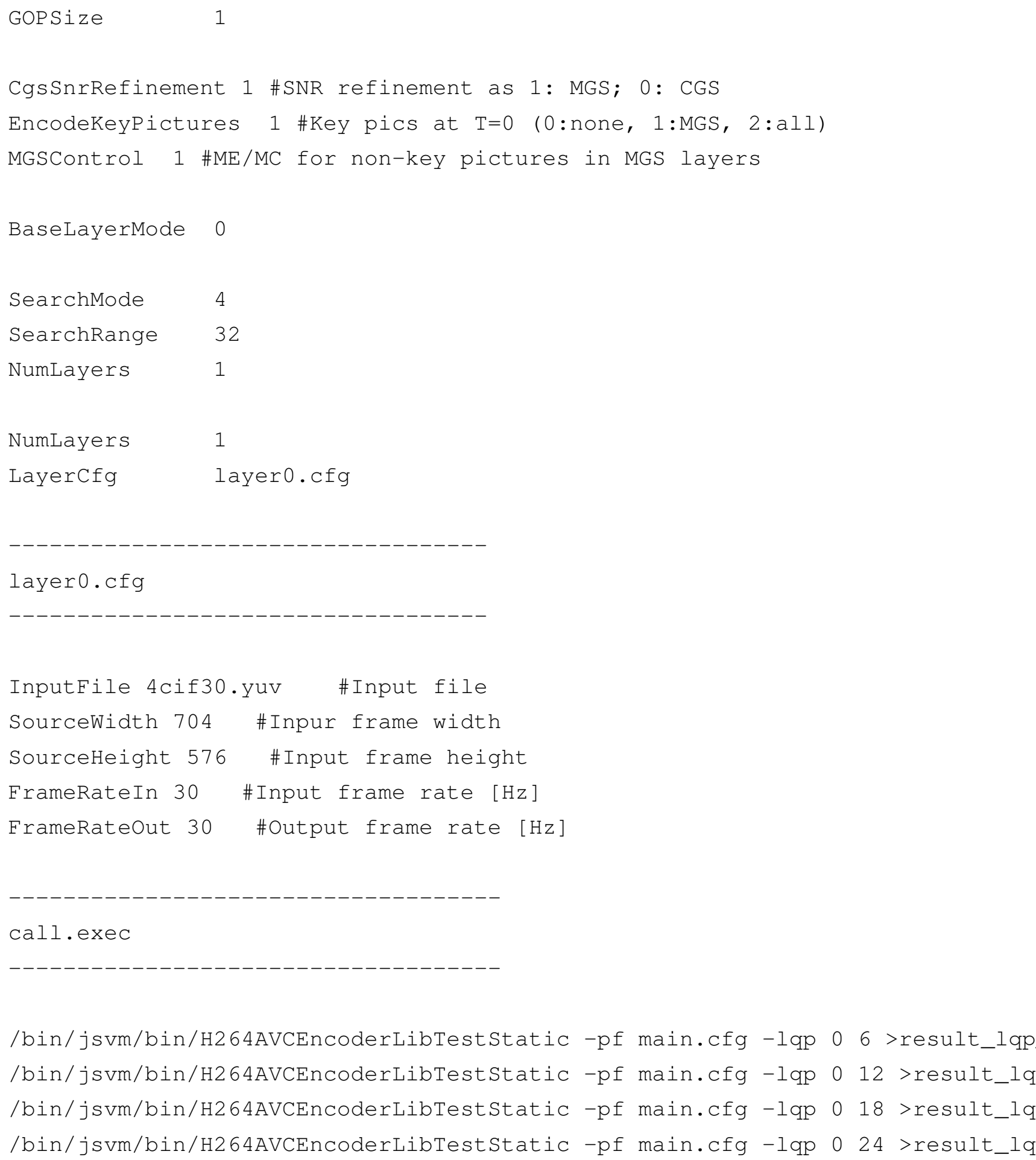


/bin/jsvm/bin/H264AVCEncoderLibTestStatic -pf main.cfg-lqp 030 >result_lq /bin/jsvm/bin/H264AVCEncoderLibTestStatic-pf main.cfg-lqp 036 >result_lq /bin/jsvm/bin/H264AVCEncoderLibTestStatic -pf main.cfg-lqp 036 >result_lq /bin/jsvm/bin/H264AVCEncoderLibTestStatic -pf main.cfg-lqp 036 >result_lq

\section{B. 1.2 Teste 2. GOPs.}

\section{GOP 2}

Main.cfg

\# JSVM Main Configuration File

OutputFile test.264

FrameRate $\quad 30.0$

FramesToBeEncoded 300

GOPSize 2

CgsSnrRefinement 1 \#SNR refinement as 1: MGS; 0: CGS

EncodekeyPictures 1 \#Key pics at $\mathrm{T}=0$ (0:none, 1:MGS, 2:all)

MGSControl 1 \#ME/MC for non-key pictures in MGS layers

BaseLayerMode 0

SearchMode $\quad 4$

SearchRange $\quad 32$

NumLayers $\quad 1$

Layercfg layero.cfg 
Layer0.cfg

InputFile 4cif30.yuv \#Input file

SourceWidth 704 \#Input frame width

SourceHeight 576 \#Input frame height

FrameRateIn 30 \#Input frame rate [Hz]

FrameRateout 15 \#Output frame rate [Hz]

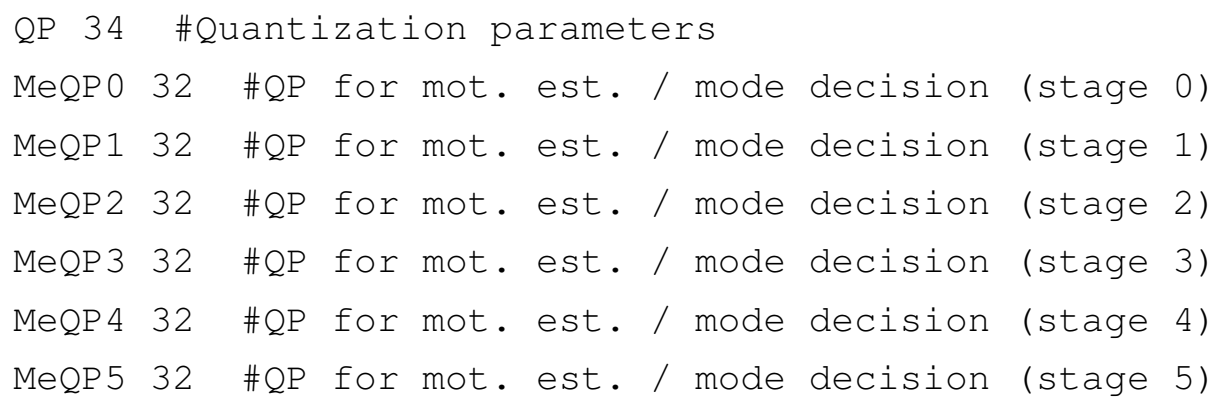

GOP 4

main.cfg
\# JSVM Main Configuration File
OutputFile $\quad$ test.264
FrameRate $\quad 30.0$
FramesToBeEncoded 300
GoPSize $\quad 4$


CgsSnrRefinement 1 \#SNR refinement as 1: MGS; 0: CGS

Encodekeypictures 1 \#Key pics at $\mathrm{T}=0$ (0:none, 1:MGS, 2:all)

MGSControl 1 \#ME/MC for non-key pictures in MGS layers

BaseLayerMode 0

SearchMode $\quad 4$

SearchRange $\quad 32$

NumLayers $\quad 1$

LayerCfg layero.cfg

layer0.cfg

InputFile 4cif30.yuv \#Input file

SourceWidth 704 \#Input frame width

SourceHeight 576 \#Input frame height

FrameRateIn 30 \#Input frame rate [Hz]

FrameRateout 15 \#Output frame rate [Hz]

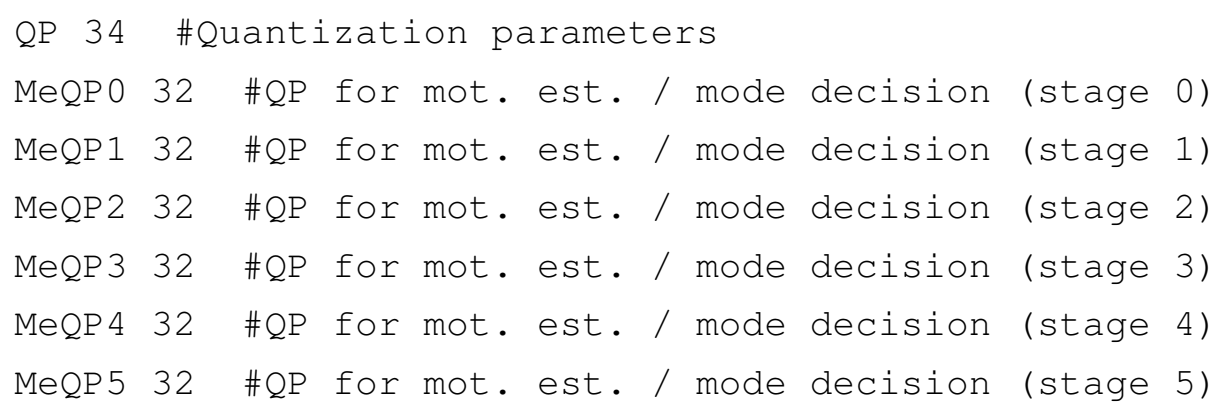




\section{GOP 8}

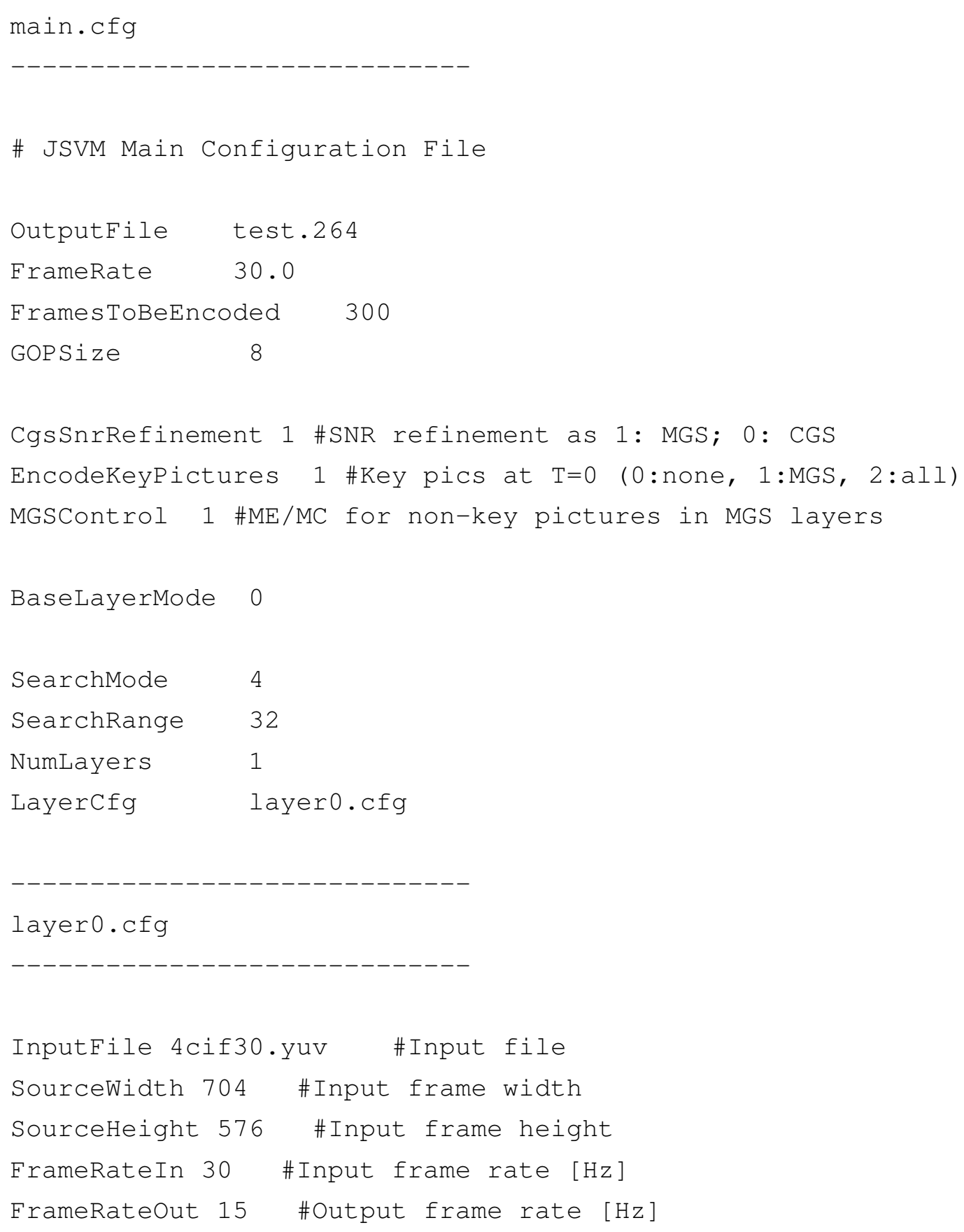




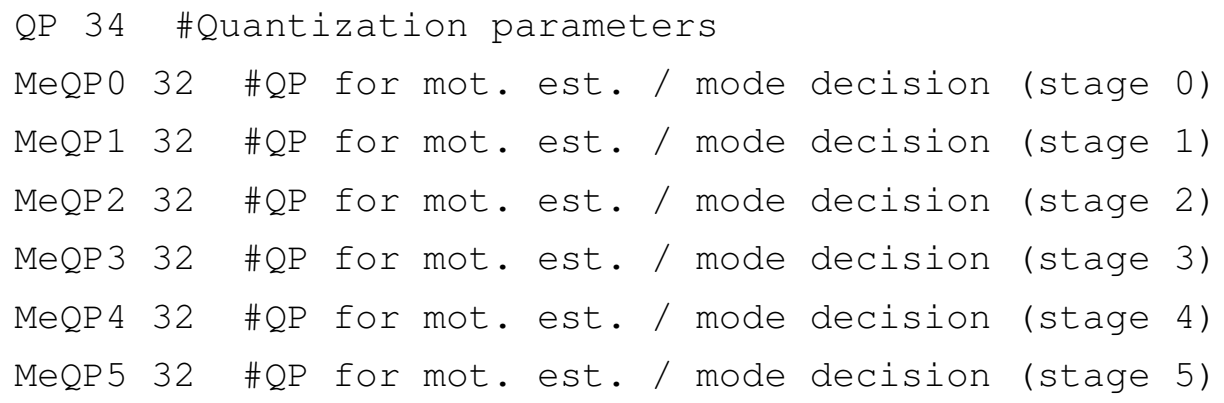

GOP 16

main.cfg

\# JSVM Main Configuration File

OutputFile test.264

FrameRate $\quad 30.0$

FramesToBeEncoded $\quad 300$

GOPSize $\quad 16$

CgsSnrRefinement 1 \#SNR refinement as 1: MGS; 0: CGS

EncodekeyPictures 1 \#Key pics at $\mathrm{T}=0$ (0:none, 1:MGS, 2:all)

MGSControl 1 \#ME/MC for non-key pictures in MGS layers

BaseLayerMode 0

SearchMode $\quad 4$

SearchRange $\quad 32$ 


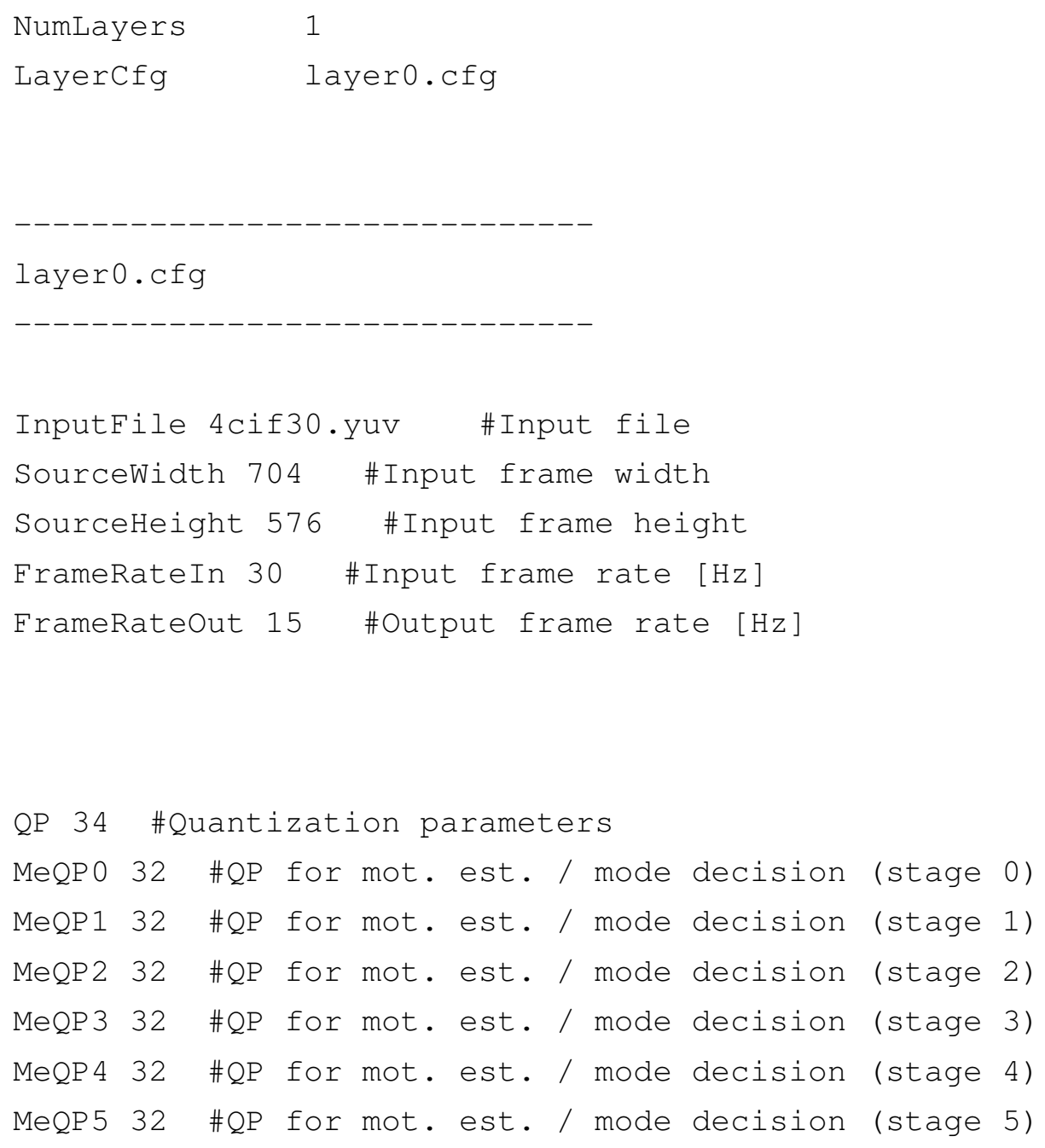

\section{B. 1.3 Teste 3. Predição Espacial.}

$4 C I F \times C I F$

main.cfg 
\# JSVM Main Configuration File

OutputFile test.264

FrameRate $\quad 30.0$

FramesToBeEncoded 300

GOPSize 1

CgsSnrRefinement 1 \#SNR refinement as 1: MGS; 0: CGS

EncodekeyPictures 1 \#Key pics at $\mathrm{T}=0$ (0:none, 1:MGS, 2:all)

MGSControl 1 \#ME/MC for non-key pictures in MGS layers

BaseLayerMode 0

SearchMode 4

SearchRange $\quad 32$

NumLayers 2

LayerCfg layero.cfg

Layercfg layerl.cfg

layer0.cfg

InputFile 4cif30.yuv \#Input file

SourceWidth 704 \#Input frame width

SourceHeight 576 \#Input frame height

FrameRateIn 30 \#Input frame rate [Hz]

FrameRateout 15 \#Output frame rate [Hz] 


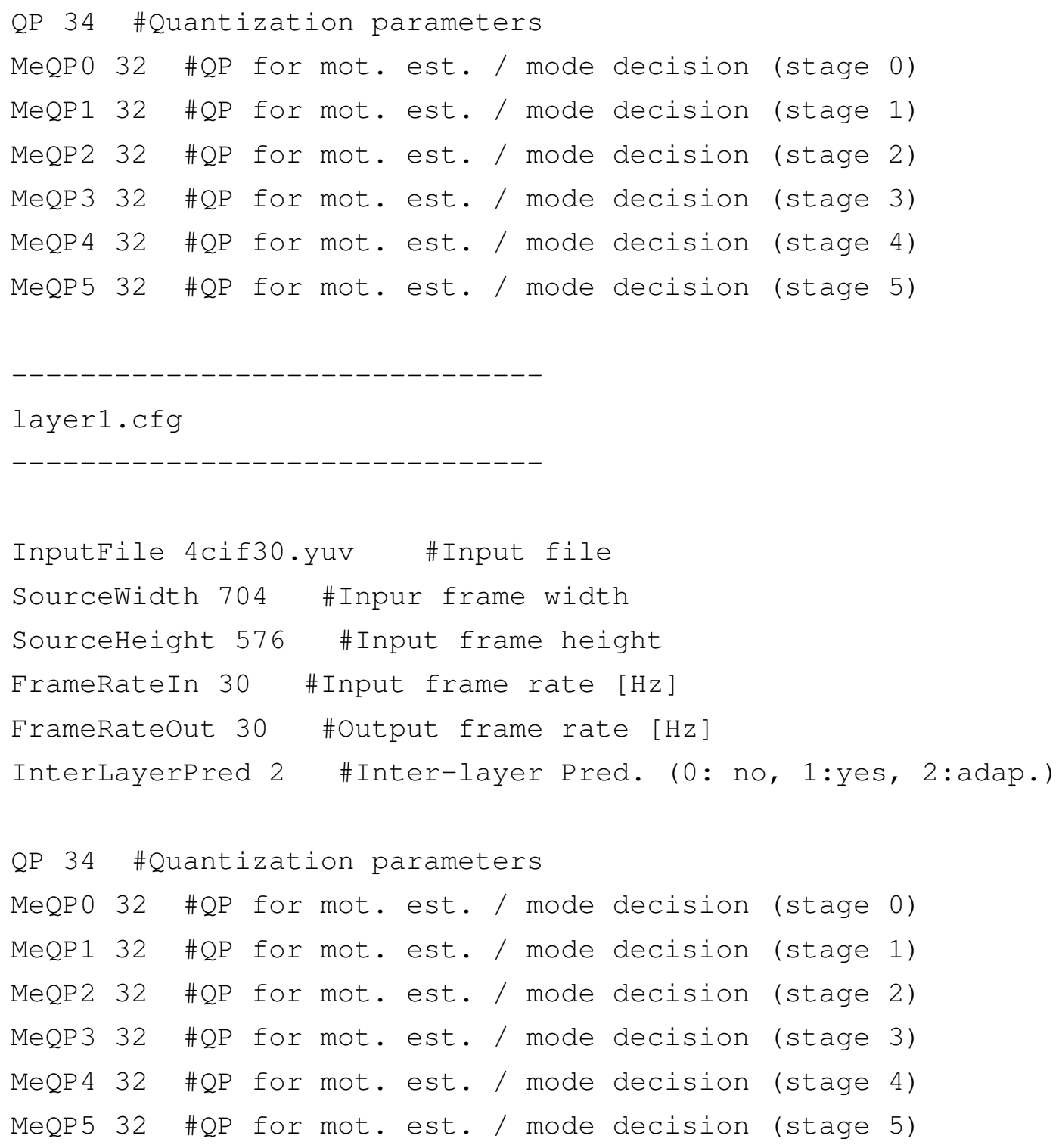

\section{$4 C I F \times Q C I F$}

main.cfg 


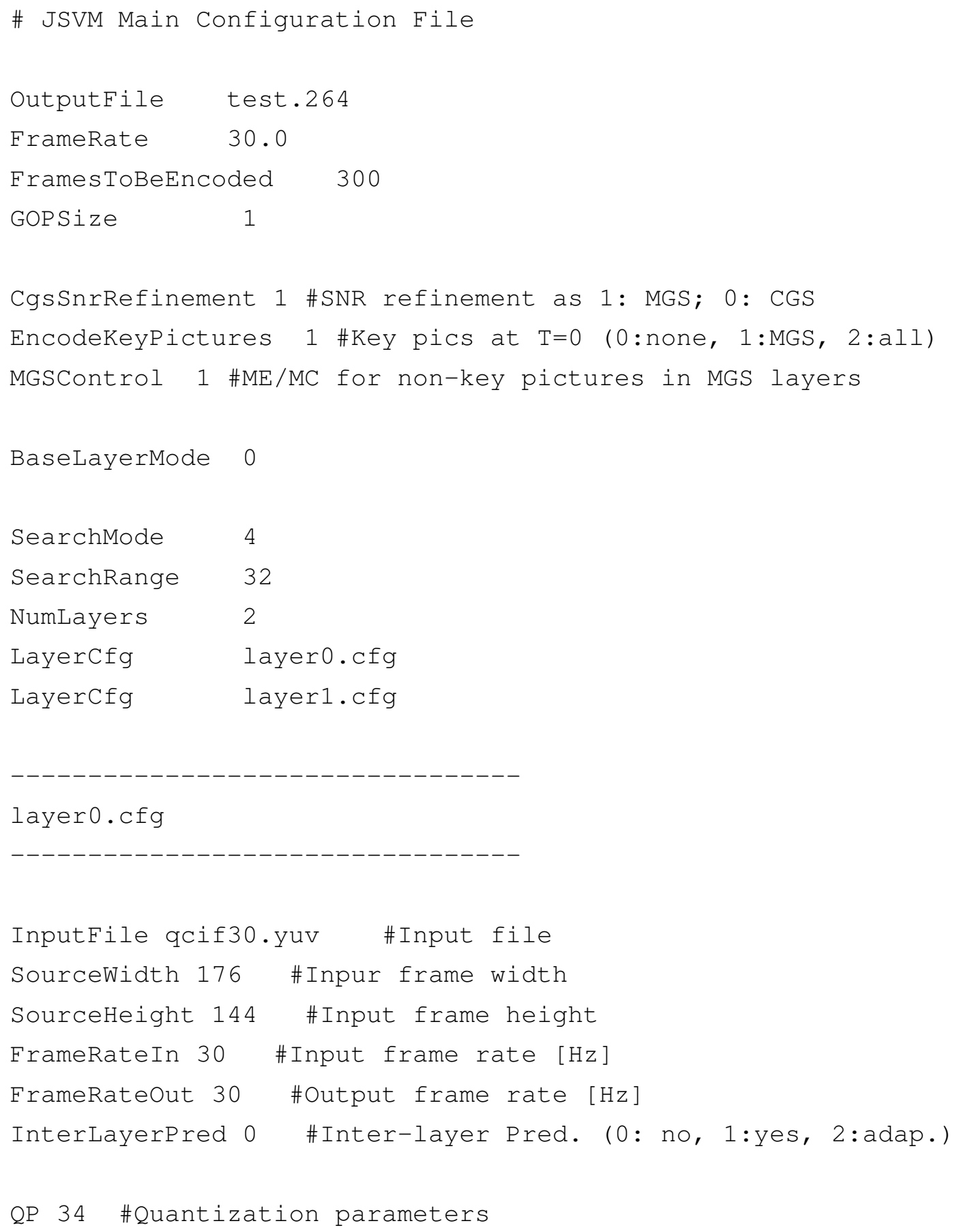




\section{CIF XQCIF}

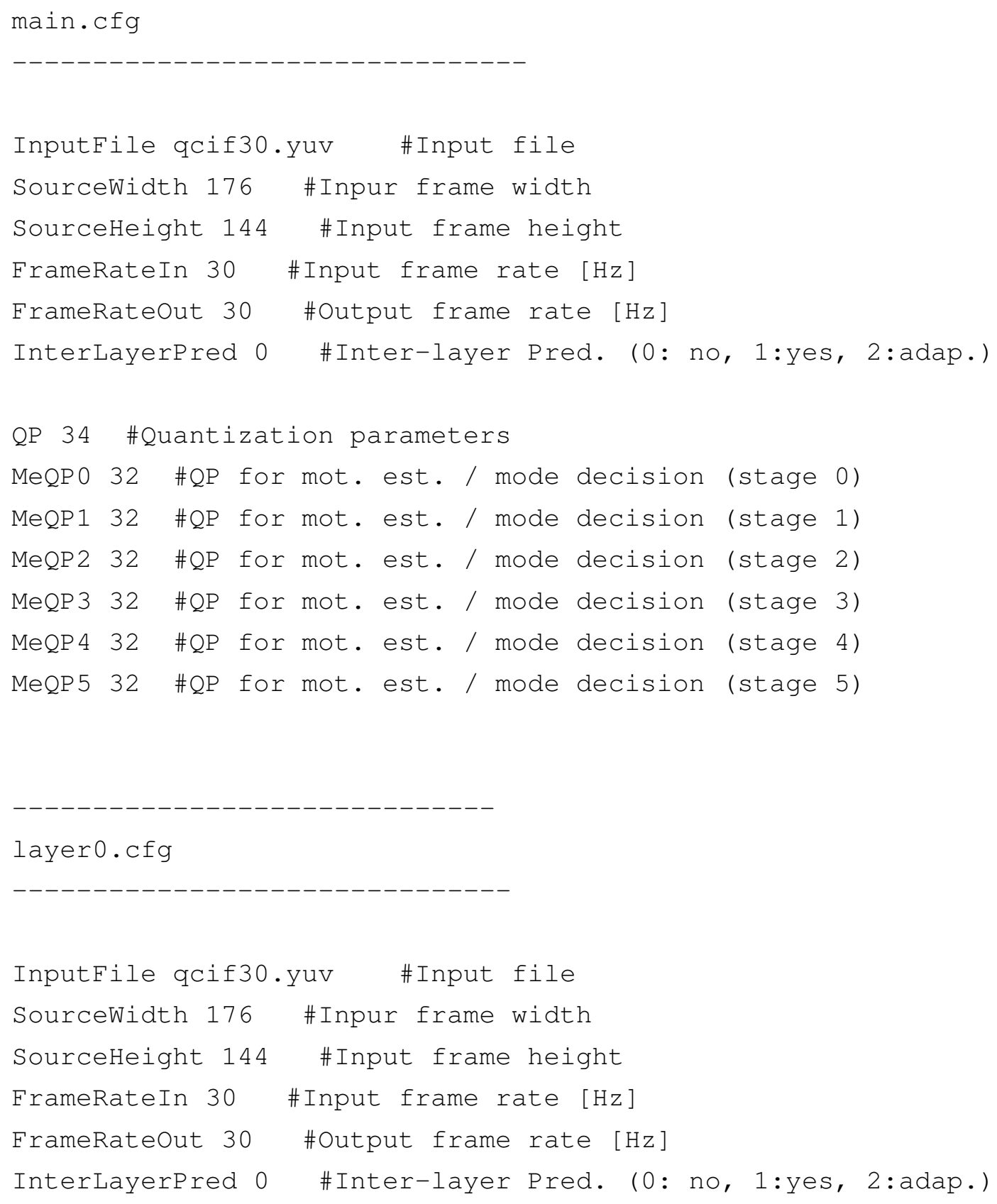




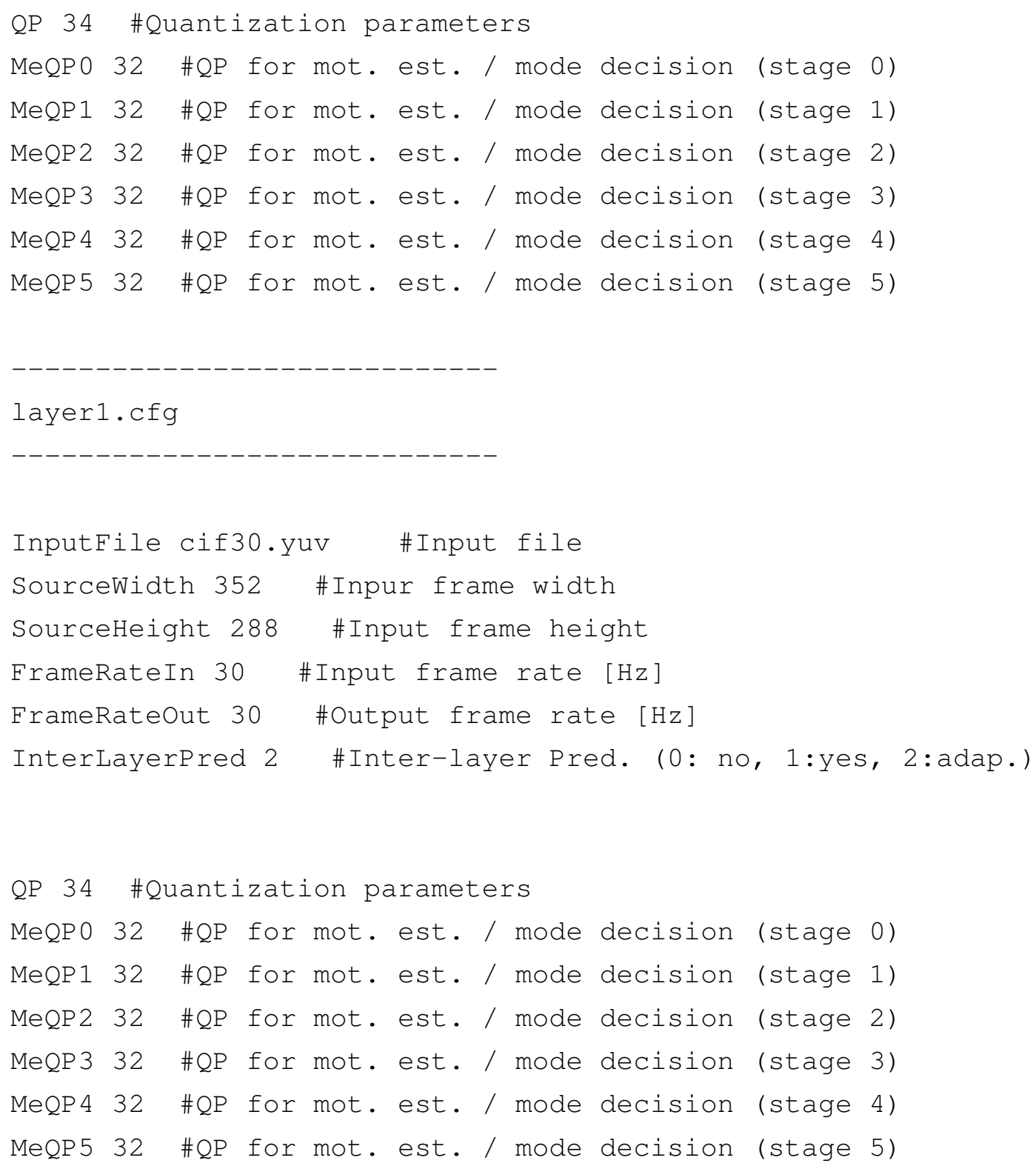




\section{CIF, CIF e QCIF}

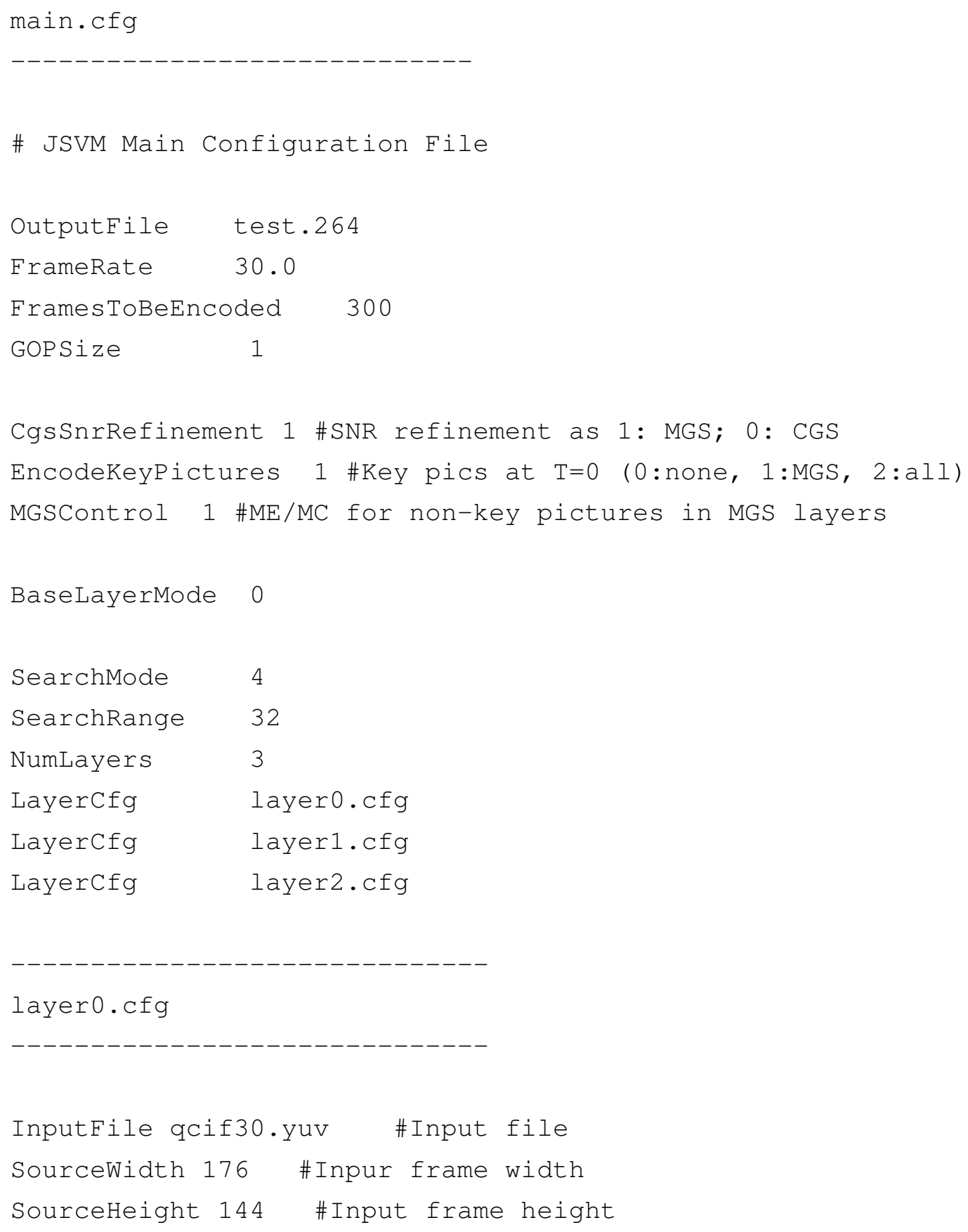




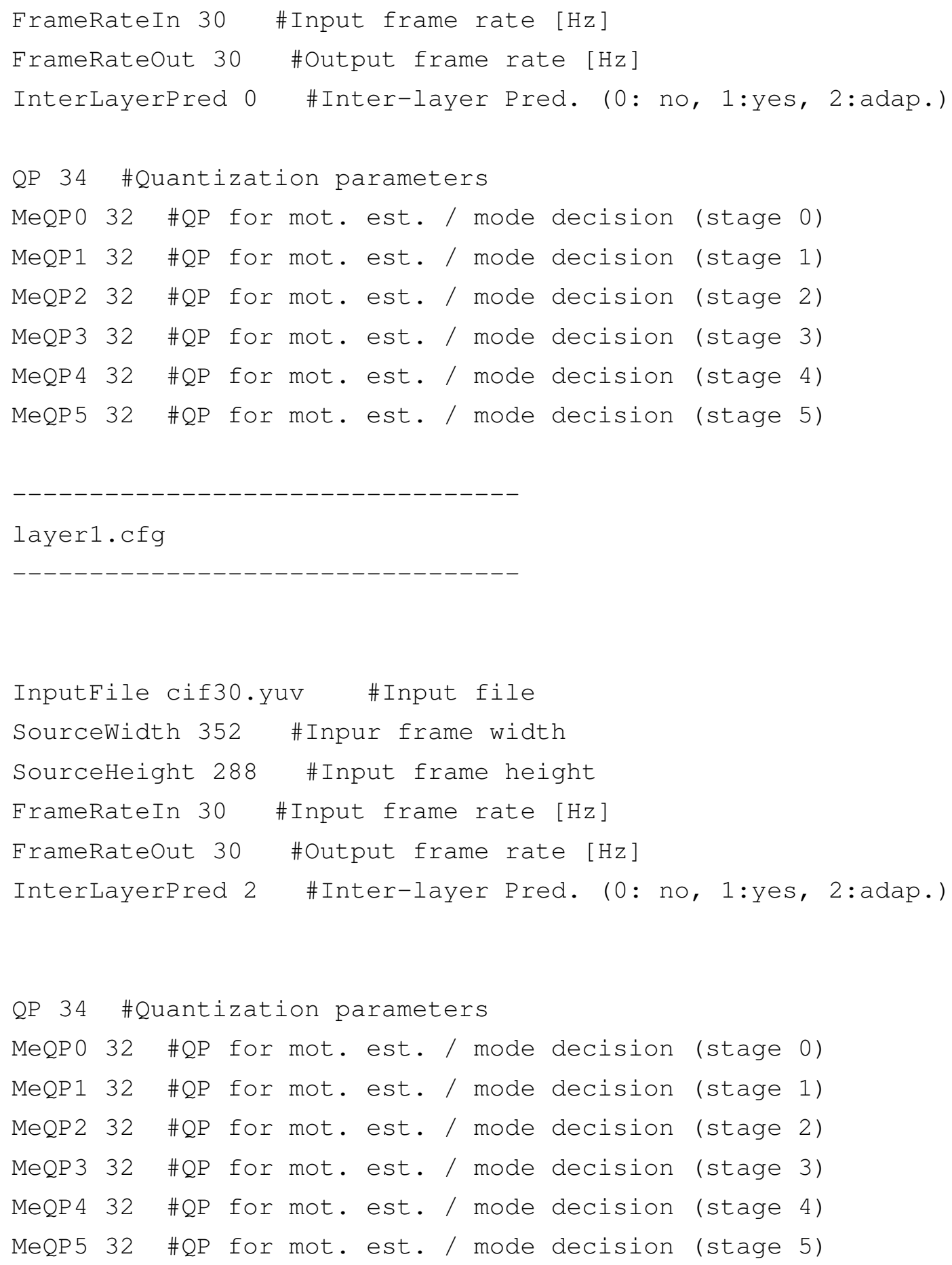


layer2.cfg

InputFile 4cif30.yuv \#Input file

SourceWidth 704 \#Input frame width

SourceHeight 576 \#Input frame height

FrameRateIn 30 \#Input frame rate [Hz]

FrameRateout 30 \#Output frame rate [Hz]

InterLayerPred 2 \#Inter-layer Pred. (0: no, 1:yes, 2:adap.)

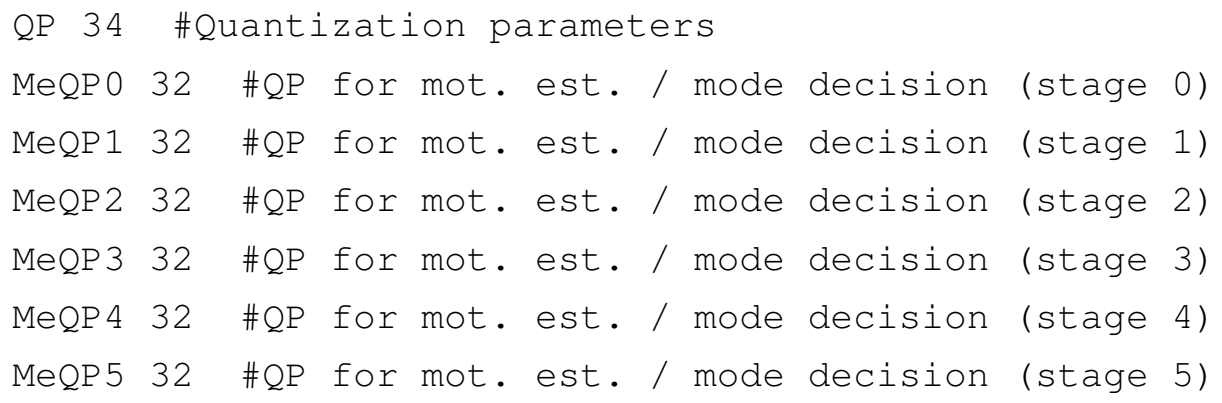

\section{B. 1.4 Teste 4. Escalabilidade Combinada.}

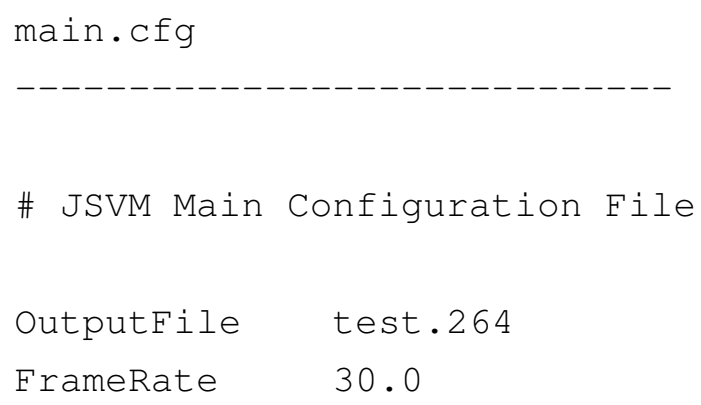




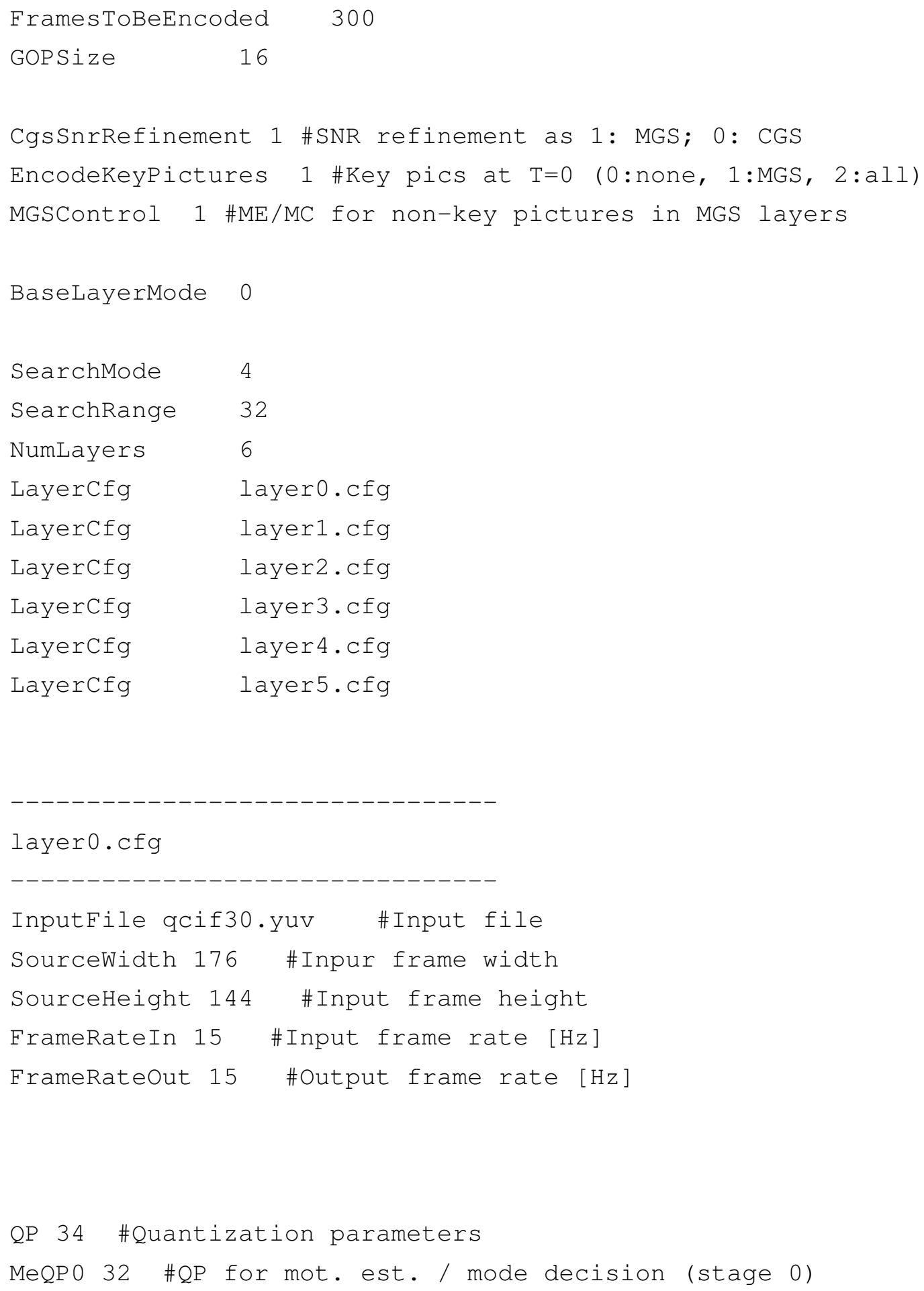




$\begin{array}{lllll}\text { MeQP } & 32 & \# Q P \text { for mot. est. / mode decision (stage 1) } \\ \text { MeQP } 2 & 32 & \# Q P \text { for mot. est. / mode decision (stage 2) } \\ \text { MeQP } 3 & 32 & \# Q P \text { for mot. est. / mode decision (stage 3) } \\ \text { MeQP } 4 & 32 & \# Q P \text { for mot. est. / mode decision (stage 4) } \\ \text { MeQP } 5 & 32 & \# Q P \text { for mot. est. / mode decision (stage 5) }\end{array}$

layer1.cfg

InputFile qcif30.yuv \#Input file

SourceWidth 176 \#Inpur frame width

SourceHeight 144 \#Input frame height

FrameRateIn 15 \#Input frame rate [Hz]

FrameRateout 15 \#Output frame rate [Hz]

InterLayerPred 2 \#Inter-layer Pred. (0: no, 1:yes, 2:adap.)

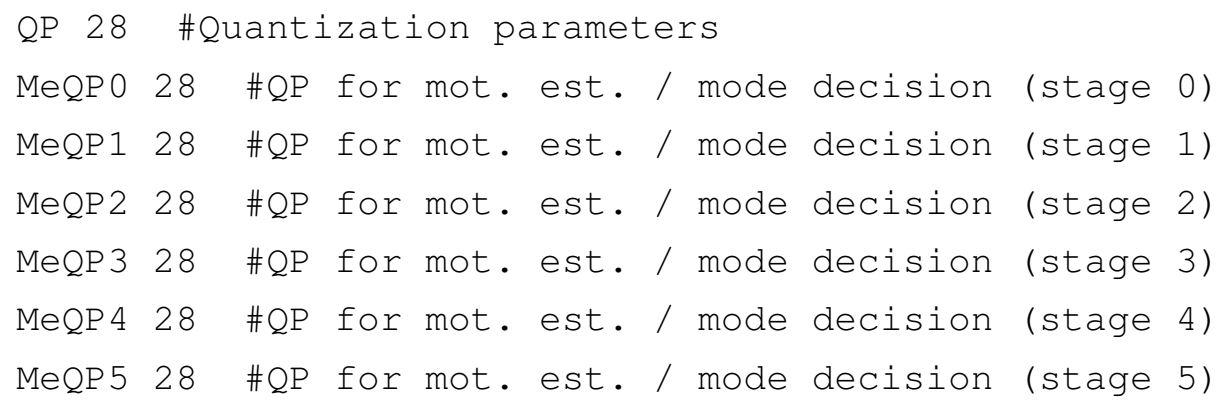

layer2.cfg

InputFile cif30.yuv \#Input file

SourceWidth 352 \#Inpur frame width 


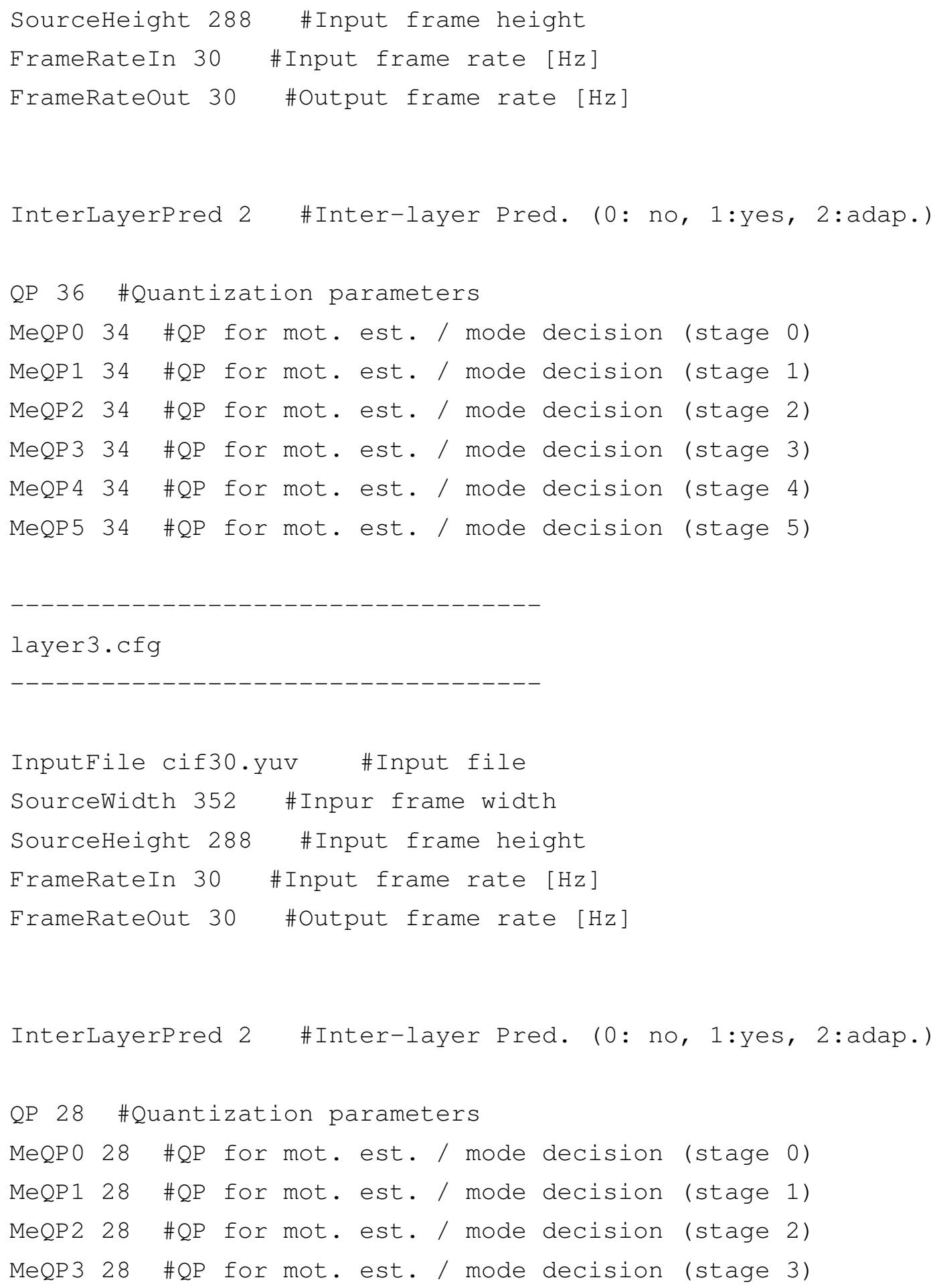




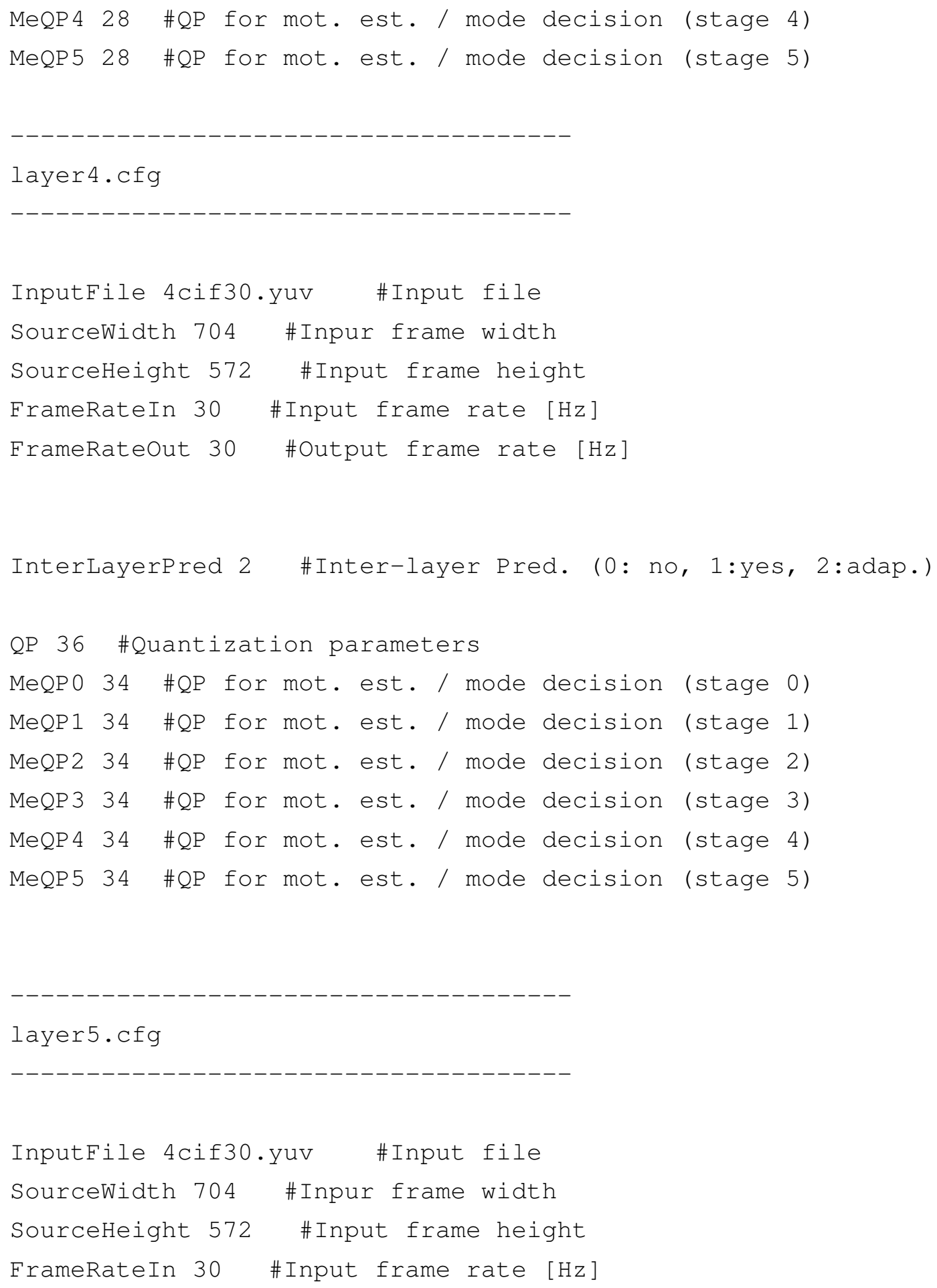




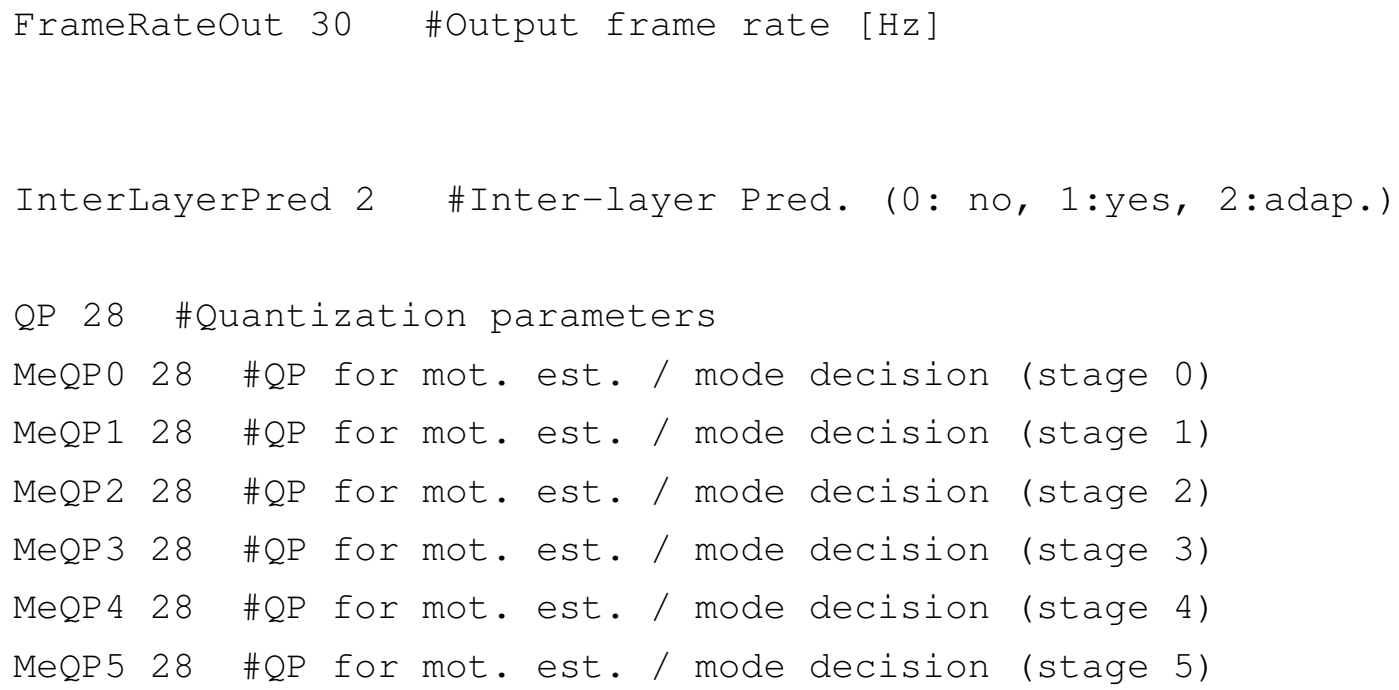

